\title{
“I HAVEN'T DONE ANYTHING TO BE POLARIZING”: JEREMY LIN'S STRATEGIC APPROPRIATION OF BLACK MASCULINITY
}

\author{
by \\ Nicholas H. C. Wong \\ Bachelor of Arts, University of Victoria, 2014 \\ A thesis presented to Ryerson University and York University \\ in partial fulfillment of the \\ requirements for the degree of \\ Master of Arts \\ in the joint program of \\ Communication and Culture
}

Toronto, Ontario, Canada, 2019

(C) Nicholas Heng Hua Churchill Wong, 2019 


\section{Author's Declaration for Electronic Submission of a Thesis}

I hereby declare that I am the sole author of this thesis. This is a true copy of the thesis, including any required final revisions, as accepted by my examiners.

I authorize Ryerson University to lend this thesis to other institutions or individuals for the purpose of scholarly research.

I further authorize Ryerson University to reproduce this thesis by photocopying or by other means, in total or in part, at the request of other institutions or individuals for the purpose of scholarly research.

I understand that my thesis may be made electronically available to the public. 


\title{
“I HAVEN'T DONE ANYTHING TO BE POLARIZING”: JEREMY LIN'S STRATEGIC APPROPRIATION OF BLACK MASCULINITY
}

\author{
Nicholas H. C. Wong \\ Master of Arts in the joint program of Communication and Culture \\ Ryerson University and York University, 2019
}

\begin{abstract}
This thesis investigates the appropriation of Black masculinity by Asian American basketball player Jeremy Lin. Subjecting media coverage to a combination of content analysis and critical discourse analysis uncovers the presence of four appropriative themes of Asianness: (a) the supraethnic viability of Asianness; (b) the necessary defeat of Blackness; (c) the disallowance of anti-Asian sentiment; and (d) the presence of a helpful Black cohort. These themes are themselves given meaning by five racially magnetized frames that position Asian Americans in opposition to Blackness across multiple dimensions: (a) Asian Americans as model minorities; (b) Asian American men as emasculated; (c) Asian Americans as invisible; (d) Asian Americans as forever foreign; and (e) Asian and Black Americans as enemies. The results of this study suggest that Asian American men benefit from the appropriation of Blackness, but that this benefit is contingent upon their ability to uphold heterosexist, white supremacist ideologies.
\end{abstract}

Keywords: Jeremy Lin, basketball, race 


\section{Acknowledgements}

I would like to thank my supervisor, Dr. Nicole Neverson, for her patience, wisdom, and guidance throughout this process. I would also like to thank my committee members, Dr. Lily Cho and Dr. Anne-Marie Lee-Loy, for generously taking the time to share their perspectives on this project. And lastly, a big thank you to my family, friends, and partner Lauren for their support and encouragement. 
Table of Contents

Author's Declaration for Electronic Submission of a Thesis ii

$\begin{array}{ll}\text { Abstract } & \text { iii }\end{array}$

Acknowledgements $\quad$ iv

List of Tables

$\begin{array}{ll}\text { Introduction } & 1\end{array}$

Theoretical Concepts $\quad 6$

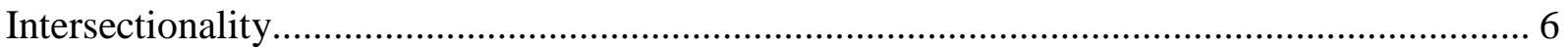

Race and Racialization: Racial Formation and Race as Sliding Signifier ............................. 7

Relative Racialization: Racial Triangulation and Racial Magnetism ................................. 8

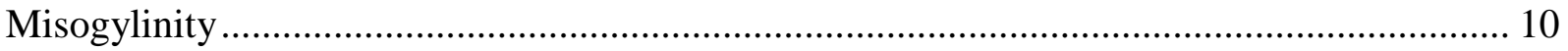

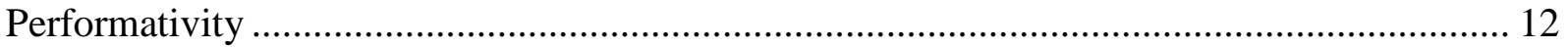

Cultural Appropriation and Minstrelsy ............................................................................ 13

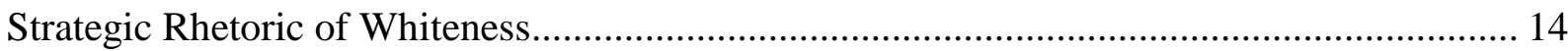

$\begin{array}{ll}\text { Literature Review } & 17\end{array}$

Revolutionary Roots: Afro-Asian Relations in the United States (1950s-1970s).................. 17

Racial Adversaries: Afro-Asian Relations in the United States (1980s-Present) .................. 25

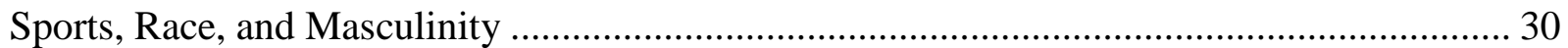

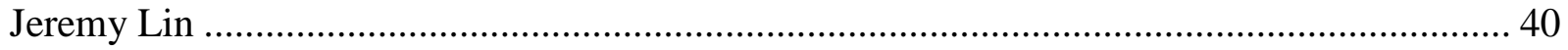

$\begin{array}{ll}\text { Research Questions } & 45\end{array}$ 


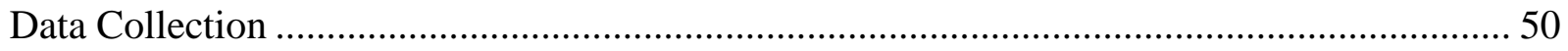

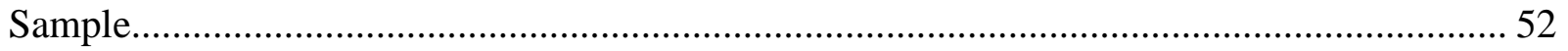

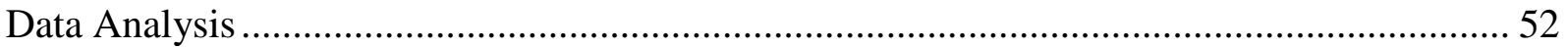

$\begin{array}{ll}\text { Findings } & 56\end{array}$

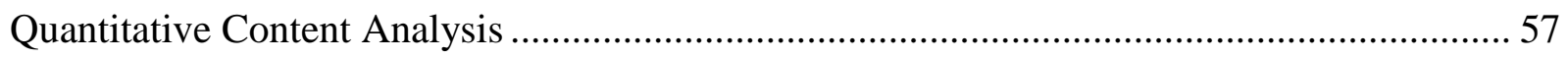

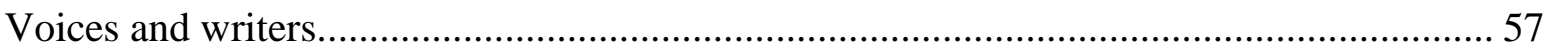

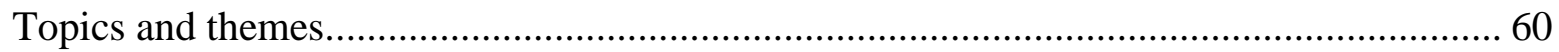

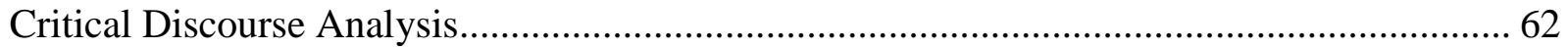

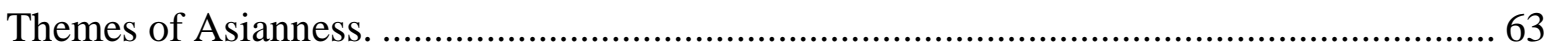

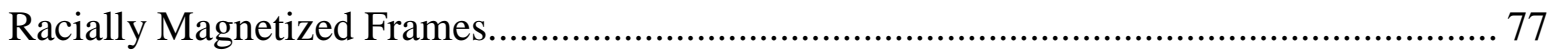

$\begin{array}{ll}\text { Conclusion } & 103\end{array}$

$\begin{array}{ll}\text { References } & 108\end{array}$ 


\section{List of Tables}

Table 1 Analytical Concepts Organized According to Campbell \& Wiggins (2015) Typology ... 57

Table 2 Race of Writers and Voices in Jeremy Lin Media Coverage ........................................ 58

Table 3 Topics and Themes Over Time in Jeremy Lin Media Coverage .................................. 60

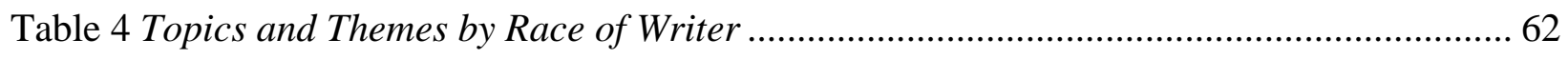


“I Haven't Done Anything to be Polarizing”: Jeremy Lin's Strategic Appropriation of Black

$$
\text { Masculinity }
$$

\section{Introduction}

When Jeremy Lin briefly became the marquee star of the National Basketball Association (NBA) in February 2012, the story generated an unprecedented amount of media attention for a number of reasons. There was his education and college basketball career at Harvard University-a school synonymous with high academic achievement but typically devoid of basketball standouts. There was his path to the NBA—passed over by every team in the entry draft and then twice cut by teams after receiving little playing time. There was also the setting-New York City, the centre of the media universe and so called "Mecca of basketball". There was, of course, the team - the long-suffering New York Knicks, desperate to give their fanbase a taste of success after years mired in disappointment and mediocrity. Then there was the level of play-Lin led the struggling team to seven straight victories, hitting game-winning shots and breaking scoring records after finally getting the opportunity to showcase his talents.

However, of all the factors just mentioned, none was more salient and scrutinized than race. Lin, who was born in Palo Alto, California to Taiwanese immigrant parents, was considered a racial anomaly. Only a handful of players of Asian descent—and even fewer Asian Americans ${ }^{1}$ — have ever played in the NBA, let alone found success. Basketball has long been considered a Black ${ }^{2}$ domain, a notion seemingly borne out by the fact that African American

\footnotetext{
${ }^{1}$ Following the Asian American Journalists Association (2014), I use the term "Asian American" rather than "Asian" when referring Lin and others of Asian descent who are U.S. citizens. Making this distinction clarifies the cultural differences between the two groups and disrupts stereotypes of Asians as "forever foreign". However, the category of "Asian"-American or not—is itself broad, ill-defined, and unstable (Korhonen, 1997). While my analysis tends to maintain a focus on East Asian (e.g., Chinese, Taiwanese, Japanese, Korean) diasporic people and communities, aspects of it may be relevant to those with roots in West, South, and Southeast Asia.

2 Traditionally, most style guides have recommended writing "black" and "white" in all lowercase letters when referring to race (Perlman, 2015; "White, white", 2016). However, more recently, many have argued strongly in
} 
athletes make up nearly 75 percent of NBA players (Lapchick, 2018). Asian American men by contrast have been viewed as too small and meek to possibly succeed against their supposedly physically superior, aggressive Black counterparts. Lin's streak of stellar play therefore left media commentators baffled, seemingly unable to process the incongruous visual spectacle of an Asian American man competing and excelling against Black athletes at the highest level of hypermasculine sport. This media frenzy came to be known as Linsanity, a derivation of NBA icon Vince Carter's nickname "Vinsanity". It is a phrase that therefore captures both the surreal quality of Lin's star turn, and binds him to a legacy of Black athletic excellence as embodied by Carter.

Characterizations of Lin's basketball success as beyond belief and "Linpossible" seem to support Sean Tierney's (2006) expectation that unquestioned movement across racial boundaries is a privilege only afforded to white ${ }^{3}$ people in popular culture. For him, the ability of white people to profit from the cultural practices of racialized communities, while simultaneously devaluing the mastery of white cultural practices by those same communities, is what constitutes cultural appropriation. Writing on themes of whiteness in Western martial arts films, Tierney (2006) illustrates this by asking us to alternatively "[i]magine a noncomedic film in which [Chinese actor] Tony Leung Chiu Wai becomes the greatest hockey player in America 6 months after first picking up a stick, winning not only the Stanley Cup but the MVP award" (p. 621). Tierney suspects that this narrative will register as ridiculous, a tongue-in-cheek demonstration

favour of capitalizing "Black" in order to grant it the same group status and typographic respect as other racial groups such as "Asian" or "Hispanic" (Colón, 2003; Tharps, 2014).

${ }^{3}$ The decision whether or not to capitalize "white" has been met with more ambivalence than has been the case for "Black" (Perlman, 2015). While some have chosen to capitalize both "white" and "Black" in the interest of consistency (Colón, 2003; Perlman, 2015; "White, white", 2016; Yin, 2017), I write "white" in lowercase throughout this thesis as a small intervention into the common white supremacist convention of only capitalizing "white" (Perlman, 2015). 
of how racial boundaries constrain imagined possibilities for people of colour while allowing white people free passage through them.

However, despite the eerie similarities between this fictional scenario and the real life story of Linsanity, there is at least one crucial distinction. Rather than demonstrating mastery over a white cultural domain like ice hockey, Lin carried out his run of excellence in the Black domain of basketball. Lin's story thus represents an opportunity to test the relevance of Tierney's theorizing to a novel dynamic, that of Asian appropriation of Blackness. This dynamic, in which neither the enactor nor the receiver of the appropriation is white, has the potential to complicate or even expand understandings of how the forces of appropriation play out across the uneven terrain of U.S. racial politics. Mapping out this terrain is all the more crucial when, as Vijay Prashad (2001) notes, "[t]here is little space in popular discourse for an examination of what goes on outside the realm of white America among people of color" (p. x). Doing so raises a number of vital questions for Afro-Asian relations: How does Asian appropriation of Blackness manifest itself, and why is it enacted? What are its effects, for Asian Americans, Black Americans, and white Americans? In what ways does it resemble or diverge from white-enacted appropriation? Can we meaningfully distinguish between different types of Asian appropriation of Blackness? What is Lin's role in all of this?

In beginning to answer these questions, I have already noted that Lin's race made his success seem incomprehensible, which would seem to support the idea that benefitting from cultural appropriation is reserved for white people. Yet Lin's story was also widely glorified in popular media, which despite its shock still celebrated him as an Asian American underdog who beat the odds to demonstrate mastery of a supposedly Black skill. Glorifying Lin's adoption of Black cultural practices suggests that people of Asian descent are not always only victims of 
cultural appropriation. Lin has indeed reaped significant benefits from his ability to subvert stereotypes based on his performance of Blackness. In fact, I argue that Lin was glorified in a startlingly similar fashion to the white protagonists that Tierney (2006) studies in his thematic analysis of the Hollywood martial arts films Bulletproof Monk, Kill Bill, and The Last Samurai. In these films, Tierney identifies the presence of four themes that work to universalize and centre whiteness: The supraethnic viability of whiteness, the necessary defeat of Asians, the disallowance of anti-white sentiment, and the presence of at least one helpful and/or generous Asian cohort. In Lin's case, I hypothesize that these themes of whiteness are re-inscribed as antiBlack "themes of Asianness" that nonetheless maintain white supremacy by upholding racist myths about both Black and Asian Americans. A major objective of the present study is therefore to identify the presence of these themes in popular media discourse on Jeremy Lin, as well as whether they have persisted in Lin's post-Linsanity career. I also uncover and historically situate the media frames that structure Afro-Asian relations along multiple "racially magnetized" axes, and thus shape how meaning is produced by themes of Asianness. In detailing these patterns in the production of Lin-related media discourse, my aim is to reveal how Lin's proximity to Blackness serves as a battleground upon which notions of Asian American masculinity, social position, and cultural belonging are contested. I pay particular attention to how Lin and other Asian Americans participate in shaping discourse around the significance of Lin's Asian American identity. In doing all of the above, the current study reveals how certain Asian American political projects rely on leveraging anti-Black racism and misogyny to gain a sense of national belonging.

In the service of making these discoveries, the present study uses a combination of quantitative content analysis and critical discourse analysis (CDA) on print and digital media 
coverage focused on Jeremy Lin and his Asian American identity. The content analysis determines the presence and prevalence of the topic of Blackness in this media coverage, as well as the presence and prevalence of the four themes of Asianness outlined above. The CDA then provides qualitative depth and interpretive power to the results of the content analysis, while also identifying five "racially magnetized" frames that position Lin in opposition to Blackness. It furthermore demonstrates not just what topics, themes, and frames exist, but how they are brought into existence and into relation with one another.

Prior to engaging in the thematic analysis proper, I introduce seven theoretical concepts essential to my analysis: (a) intersectionality, (b) racial formation and race as sliding signifier, (c) racial triangulation and racial magnetism, (d) misogylinity, (e) performativity, (f) cultural appropriation and minstrelsy, and (g) whiteness as a strategic rhetoric. I follow this theoretical overview with a review of the relevant literature, in which I first situate Lin in the context of Afro-Asian historical relations in the United States. The literature review then details research on the articulation of sport with race and masculinity, before concluding with a more specific overview of scholarly work on Jeremy Lin. After presenting my research questions, I then provide a detailed description of my methodological choices. This includes brief overviews of qualitative content analysis and CDA, and the rationale behind combining the two. This section will also introduce a typology for distinguishing between topics, themes, and frames, and detail my data collection and analysis procedures. The methodology section is followed by the two-part analysis, starting with the content analysis and then shifting into the CDA. The CDA is broken down into two subsections, the first of which addresses four themes of Asianness, and the second of which analyzes five media frames. Lastly, I will conclude with some further contextualization and implications of my findings. 


\section{Theoretical Concepts}

The theoretical concepts outlined here form some of the basic assumptions of my analysis. The theories I engage with in the present study are: (a) intersectionality, (b) racial formation and race as sliding signifier, (c) racial triangulation and racial magnetism, (d) misogylinity, (e)

performativity, (f) cultural appropriation and minstrelsy, and (g) whiteness as a strategic rhetoric.

\section{Intersectionality}

One key concept underpinning the present study is that social phenomena cannot be understood in isolation. My research approach will therefore be informed by "intersectionality", a term originally coined by legal scholar Kimberlé Crenshaw (1991) to describe "the various ways in which race and gender intersect in shaping structural, political, and representational aspects of violence against women of color” (p. 1244). While Crenshaw’s original analysis focuses specifically on women of colour, it was based on her more general observation that the field of identity politics has often failed to recognize difference that occurs within groups, instead opting to treat the experiences of different social categories such as race, gender, class, and sexuality as homogenous and mutually exclusive. In doing so, the specific issues affecting, for instance, women of color often remain unrecognized because they become subsumed into political movements that cater to white women and men of color. Using intersectionality as a guiding lens in the present research allows me to attend to the specificity of Lin's gendered and racialized identity as an Asian American man. It is a reminder that the issues Lin faces as an Asian American are not universal, but are instead modulated through his gender. Consequently, the solutions to Asian American problems he supposedly embodies, such as his hypermasculinity, may not work for Asian American women. However, Crenshaw (1991) insists that recognizing these distinctions should not be cause for splitting into smaller identity-based factions; "[r]ather, 
intersectionality provides a basis for reconceptualizing race as a coalition between men and women of color" (p. 1299). Attending to intersectionality should therefore lead to more inclusive social movements.

\section{Race and Racialization: Racial Formation and Race as Sliding Signifier}

Assessing how popular media commentary views Jeremy Lin's Asian American identity requires an understanding of the social significance and slipperiness of the concept of race itself. Michael Omi and Howard Winant (1986) recognize the need for racial discourse to move beyond biological essentialism while still retaining a firm grasp of the real effects of race. In order to avoid thinking of race as either an "imaginary" social construct, or a biological truth, they propose the concept of "racial formation", which describes "the sociohistorical process by which racial categories are created, inhabited, transformed, and destroyed" (p. 55). They view this process as consisting of "racial projects" that organize our social worlds and institutions around discursively constructed racial meanings.

Stuart Hall (2017) argues for a discursive conception of race, treating it as a "sliding signifier" that acts as a system of meaning for classifying human difference. He observes that both antiquated and "progressive" racial discourses alike continue to rely on essentialist assumptions that assign fixed social, political, and cultural characteristics to different races. Hall instead asks us instead to consider race from a linguistic perspective, treating it as a signifier rather than a biological fact in which "those things gain their meaning, not because of what they contain in their essence, but in the shifting relations of difference, which they establish with other concepts and ideas in a signifying field" (Hall, 1997, p. 8). While the idea that race signifies "real" genetic and biological differences is easily dismissed, Hall also rejects the idea that race is an empty signifier with no referent. Thus, like Omi and Winant (1986), Hall 
recognizes the need for racial discourse to move beyond biological essentialism while still retaining a firm grasp of the real effects of race. My analysis of Lin incorporates this view of his Asian American racial identity as a flexible signifier that is nonetheless negotiated through and tethered to complex sociohistorical processes.

\section{Relative Racialization: Racial Triangulation and Racial Magnetism}

Understanding Jeremy Lin's role in contemporary Asian American politics requires positioning Asian Americans within existing U.S. racial dynamics. This necessarily involves articulating Asian Americans in relation to the Black-white binary racial paradigm that tends to dominate U.S. racial discourse. Where Asian Americans fit in relation to this paradigm is contested. Some recognize the utility and continued relevance of the Black-white paradigm (J. Kim, 1999), while others have sought to develop entirely new paradigms that recognize the uniqueness of Asians as belonging to a third racial category, most of which position Asianness as somewhere "in between” Blackness and whiteness (see Kim \& Lee, 2001).

One of the most influential of these models is Claire Kim's (1999) theory of "racial triangulation". She argues that Asian, Black, and white Americans are racialized in relation to one another across two axes in a "field of racial positions" (p. 106). The first axis of “insider/foreigner" positions Asian Americans as unassimilable outsiders compared to their white and Black counterparts via the process of "civic ostracism". Along the second axis, "relative valorization" reinforces Asian racial and cultural superiority over Black Americans, but maintains their inferiority to white Americans. This triangulation has been accomplished through such discourses as the Asian "model minority" and "forever foreigner" myths, and tangible policies such as targeting Black people with anti-affirmative action initiatives and denying citizenship to Asian Americans. Through the concept of racial triangulation, Kim makes two 
critical contributions to the theorizing of Asian American racialization. The first recognizes that while they may result in distinct outcomes for different racial groups, "racialization processes ... are in fact mutually constitutive of one another" (C. Kim, 1999, p. 106). Secondly, Kim identifies how racial triangulation acknowledges the organization of race along two axes of privilege, rather than a single superior-inferior axis that places Asian Americans between Black and white poles. Racial triangulation therefore illuminates the privileges that Lin's Asianness grants him over his primarily Black colleagues, and explains how the power of Lin's proximity to Blackness lies in its ability to confer an insider status that has long eluded Asian Americans. However, racial triangulation is not without conceptual blind spots. Its two-dimensional model risks oversimplifying the racial hierarchy such that Asian American ostracism and Black American denigration are treated as equal and offsetting disadvantages. Indeed, Xiaofeng Stephanie Da (2007) argues that racial triangulation does not go far enough in accounting for the multiple dimensions along which Asian and Black Americans have historically been constructed as racial foils, often to the benefit of Asian Americans. This most notably occurs in the realms of education and labour, where Asian Americans are stereotyped as intelligent and hard-working, while Black Americans are disparaged as infantile and lazy. In this model, white Americans are left to occupy the coveted middle ground, away from the stereotyped extremes used to mark Asian and Black Americans. Chong Chon-Smith (2015) takes up this model of Black-Asian comparative racialization by coining the term "racial magnetism" to describe the opposing characteristics ascribed to Black and Asian masculinities in the United States. He identifies a fundamental binary construction of "[B]lack men as all bodies and no brains, and Asian men as all brains and no body" (Chon-Smith, 2015, p. 3) that generates a multitude of polarized axes. Given the power of racial magnetism to position Asian and Black American men as racial 
combatants, Chon-Smith provocatively asks "how could the tenets of antiblackness be a rite of passage and compliance for citizenship and capital reproduction from Asian alien outsider to Asian American insider?” (p. 12). This question precisely articulates a crucial aspect of what I aim to address in the present thesis regarding Jeremy Lin's performance of Black masculinity.

\section{Misogylinity}

As part of the "brains vs. brawn" dichotomy of racialized masculinity described above, the emasculation of Asian men in American popular culture is one of the most persistent and recognized stereotypes that Asian American men have been forced to endure and fight back against (Eng, 2001; Park, 2013; Zhang, 2010). With his displays of physical strength and athletic skill, Jeremy Lin appears well-poised to debunk the myth of Asian American men as weak and consequently sexually undesirable. It therefore makes sense to frame the glorification of Lin's athletic accomplishments as part of an ongoing project to reclaim Asian American masculinity.

However, while Asian emasculation undoubtedly bears harmful psychological and material effects for the Asian American men it targets, efforts to combat this pernicious discourse can themselves marginalize other groups. Yen Le Espiritu (1997) notes that "some Asian American men seek to reassert their masculinity by physically and emotionally abusing those who are even more powerless: the women and children in their families" (p. 114). Activist and blogger Jenn Fang (2014) uses "misogylinity" — a portmanteau of "misogyny" and "masculinity" - as a way of conceptualizing this pattern of Asian American men "defin[ing] masculinity by the objectified ownership of female sexuality" (Masculinity vs. Misogylinity, para. 1). Fang coined the term in the wake of the 2014 Santa Barbara, California attacks that took the lives of six people and wounded 14 others. The man who perpetrated the violence, 22 -year old Elliot Rodger, reportedly carried out the attacks in retaliation for his perceived humiliating 
emasculation at the hands of society—particularly women. Crucially, Rodger attributed his lack of sexual attention in part to his mixed race Asian heritage, a fact largely glossed over by popular media. Rodger appeared to deeply loathe the idea that the Asian part of his heritage may have turned off women from reciprocating his affections.

Fang (2014) draws parallels between Rodger's misogynistic logic and internalized racism and the popularity of the men's rights movement and seduction community among a sizable portion of Asian American men. The seduction community, which has experienced an explosion in global popularity since the publication of the infamous pickup-artist's handbook The Game in 2005, consists mainly of heterosexual men who seek the guidance of dating coaches in how to successfully flirt with, and ultimately attract, women (Wallace, 2017). These men "typically selfidentify as nerds and are employed in the white-collar service sector" (Wallace, 2017, p. 287), a demographic which sounds strikingly similar to stereotypical depictions of Asian American men. To Asian American followers of seduction training or men's rights activism, Asian American men like Lin who display physical—and by implication, sexual—prowess are heroes to be emulated. These men feel entitled to sexual attention from women and lash out at those who fail to provide them with it. Asian American women who choose partners of a different race are especially targeted by this vitriol for being "race traitors". In short, Rodger and many other Asian American men believe that their worth as men — and thus their place in the racial hierarchy—is contingent on their ability to sexually conquer women, a task which requires reinforcing the heterosexist, misogynistic behaviour characteristic of normative American masculine ideals.

Rodger's desire to possess and enact these normative masculine ideals manifested itself as a pathological coveting of whiteness. However, there also exist non-white models of masculinity that are perceived by Asian American men as effective paths to attaining masculine 
legitimacy. Mark Tseng-Putterman (2015) invokes misogylinity in a critique of TaiwaneseAmerican celebrity chef, author, and television personality Eddie Huang. Tseng-Putterman contends that "Huang grounds his project of Asian American manhood in the attempted subversion of stereotypes of Black male hyper-masculinity and the adoption of hip hop culture". For Huang, imitating Blackness serves as a conduit for asserting masculine dominance through misogylinity. Huang's Black-inflected misogylinity therefore offers a useful point of comparison to Lin's own appropriation of Black culture.

\section{Performativity}

The fact that acts of (hetero)sexual conquest can be used by some men to define their masculinity speaks to the idea of gender as performative. This idea originates with feminist scholar Judith Butler (1990), who suggests that "the gendered body . . has no ontological status apart from the various acts that constitute its reality" (p. 136). Gender is not some interior essence; rather, it is performed through our actions. In other words, we are what we do.

While the concept of performativity may be most strongly associated with gender, it can also be applied to other aspects of identity, including race. In her discussion of racial capitalism, Nancy Leong (2013) suggests that while race is partially ascribed based on physical markers, these visible indicators are modulated through the performance of racial identity. This gives individuals a certain level of agency when it comes to how they are racialized. They may choose to wear certain clothing to accentuate their racial identity, or go by a different name to mask it. These identity performances are also negotiated upon the terrain of racial stereotypes and the expectations that accompany them. It may require little to no performative effort to reinforce certain racial stereotypes, but breaking them may be an uphill battle. Moreover, successfully countering racial stereotypes may in turn influence how others perceive our racial identity 
(Leong, 2013). Ultimately, these "identity performances shape the racial commodity that we produce" (Leong, 2013, p. 2185). The concept of performativity is thus useful in articulating how Jeremy Lin concurrently negotiates his masculinity and racial identity through his actions.

\section{Cultural Appropriation and Minstrelsy}

Johnson (2003) argues that performance "facilitates the appropriation of blackness" (p. 6). For Johnson, racial signifiers like Blackness are slippery and "[do] not belong to any one individual or group", but are instead appropriated "in order to circumscribe [their] boundaries or to exclude other individuals or groups" (p. 2-3). It follows, then, that appropriation can occur not just within, but also between racial groups, as a means of contesting those boundaries delimiting cultural authenticity and ownership.

It is out of this dynamic that debates around "cultural appropriation" emerge. According to Minh-Ha T. Pham (2017), these debates are often framed as a disagreement over whether a given act of borrowing constitutes problematic cultural appropriation, or neutral-to-flattering cultural "appreciation". However, she suggests that both of these terms risk falsely locating the potential for harm in either the act of exchange itself, or the feelings and intentions of the "appreciator". Instead, Pham argues that the debate should centre on the racial power dynamics at play. These power dynamics allow the dominant—-typically understood to be white — racial group to seize control of cultural artifacts originating with people of colour, all without crediting, compensating, receiving permission, or suffering consequences. This process is often enacted through a fetishistic desire for racialized people and cultural practices, or what bell hooks (1992) calls "eating the other". For example, Johnson (2003) claims that white people stereotype Black linguistic practices "only to then reappropriate these stereotypes to affect a fetishistic 'escape' into the Other ... as well as to feed the capitalist gains of commodified blackness" (p. 5). 
Perhaps no form of cultural appropriation has been as influential in the United States as blackface minstrelsy. Eric Lott (2013) defines blackface minstrelsy as "an established nineteenth-century theatrical practice, principally of the urban North, in which white men caricatured blacks for sport and profit" (p. 3). He further explains that this practice was animated by white ambivalence toward Blackness: fascination and desire on the one hand, and fear and anxiety on the other, a tension that Lott sums up as "love and theft". Blackface minstrelsy thus originated as a means of exploring the "other" while keeping them at arm's length. David Roediger (2007) observes that this was a particularly useful strategy for borderline-white European ethnic groups, such as the Irish and Italian, to earn the "wages of whiteness". Their participation in minstrelsy allowed for "a liquidation of ethnic and regional culture into blackface and, ultimately, into a largely empty whiteness" (p. 118). Thus, blackface minstrelsy has played a defining role in both how Blackness is represented in popular culture, and also how whiteness is defined and achieved through opposition to those representations.

One issue with both cultural appropriation and minstrelsy is that they both tend to conceptualize a white perpetrator. Less often considered is how racialized people themselves might be capable of committing acts of cultural appropriation and minstrelsy. So, while studies on white-enacted appropriation abound (e.g., Johnson, 2003; Kleisath, 2014; Pham, 2017; Tate, 2003; Tierney, 2006), there exist relatively few studies on Asian-enacted appropriation (though see Maeda, 2005; Wang, 2006). My own investigation of Jeremy Lin's appropriation of Black culture should therefore not only draw upon, but expand the theoretical purview of these terms.

\section{Strategic Rhetoric of Whiteness}

While I have just now argued for increased attention on forms of appropriation that do not include white participation, whiteness remains a key player to be reckoned with in frameworks 
that theorize appropriation. To that end, my analysis utilizes a strategic rhetoric of whiteness framework that was first introduced by Thomas Nakayama and Robert Krizek (1995). Their research exposes the hidden ways in which whiteness strategically exerts its power. In fact, they contend that the invisibility of whiteness is in large part the driving force behind its power because it allows whiteness to go uninterrogated. This invisibility is in turn a consequence of normative rhetorics that strategically maintain the universalized position of whiteness. In other words, we cannot see that which we take for granted, and we cannot critique that which we cannot see.

Nakayama and Krizek (1995) are primarily concerned with the everyday, individual deployment of whiteness as a strategic rhetoric, but Tierney (2006) takes the concept and applies it to Hollywood films, specifically three martial arts films: Bulletproof Monk, Kill Bill, and The Last Samurai. Each of these films features white protagonists with Asian supporting characters, a relationship that centres whiteness. How this relationship is maintained and reproduced through dialogue, narrative, and characterizations is the central concern of Tierney's study. He does so by identifying four main themes of whiteness common to all three films: The supraethnic viability of whiteness, the necessary defeat of Asians, the disallowance of anti-white sentiment, and the presence of at least one helpful and/or generous Asian cohort. The supraethnic viability of whiteness describes how the whiteness of a protagonist never precludes them from quickly mastering martial arts, despite facing doubts. The necessary defeat of Asians occurs when the Asianness of a defeated martial artist legitimates the white protagonist's mastery. The disallowance of anti-white sentiment refers to the dissipation of anti-white hostility either through the use of force, or through the process of acceptance. The presence of a helpful Asian cohort is represented by the willingness of certain Asian characters to provide aid to the white 
protagonist, often in the form of special skills or tools. Together, Tierney (2006) argues that these themes form a "[s]trategic rhetoric of whiteness ... [that] helps to defend and perpetuate the conflation of White with human to rationalize and camouflage cultural appropriation as a normal, harmless, natural behavior" (p. 609). These themes also form the basis of the present study's thematic analysis, in which they are modified to become "themes of Asianness". 


\section{Literature Review}

The aim of this literature review is to help situate Jeremy Lin within the context of historical Afro-Asian relations in the United States. I break this history into two parts, a reflection of the substantial demographic and ideological shifts that occurred around the 1980s. I then narrow my focus to the role that sports have played in shaping gendered racial dynamics in the United States, particularly for Black and Asian American men. Finally, I conclude with an overview of scholarly work that explicitly deals with Lin.

\section{Revolutionary Roots: Afro-Asian Relations in the United States (1950s-1970s)}

The history of Afro-Asian contact can be traced back to antiquity, when spice routes created economic and cultural conduits between ancient China, India, Persia, Egypt, Somalia, Tanzania, and other empires (Raphael-Hernandez \& Steen, 2006). However, the contemporary conditions of Afro-Asian contact in the Americas largely originate with the global movement to abolish slavery throughout the nineteenth century. With the transatlantic slave trade no longer a viable option for powering colonial industries, Britain and other European empires turned to Asia to supply the newly created demand for cheap labour (Raphael-Hernandez \& Steen, 2006). Not coincidentally, the conditions necessary to promote such vast levels of "voluntary" migration were often a direct result of violent upheaval and poor living conditions caused by European colonialism in Asian homelands. Such is the case with the mass migration of labourers from southern China to the Americas in the mid-19th century, which coincided with the economic devastation wrought by the Opium Wars waged by Britain against China (Raphael-Hernandez \& Steen, 2006).

As European colonial empires began to recede, formerly colonized peoples sought to forge their own postcolonial ideologies and goals. The history of colonial exploitation shared by 
newly independent African and Asian nations created a basis for political solidarity against colonialism and imperialism. In 1955, several of these nations participated in the Bandung Conference, which endeavoured to forge Afro-Asian alliances across racial, cultural, and national boundaries in opposition to all forms of Western domination, whether capitalist or communist (Prashad, 2006).

The recognition of a common Afro-Asian struggle soon spread globally among formerly colonized peoples and their descendents (Prashad, 2006), leading to a spirit of mutual admiration and influence. In the United States, the racial landscape of the 1960s was already being transformed by Martin Luther King Jr. and the civil rights movement. Their efforts secured legal victories for not just Black Americans, but Asian Americans as well, including rights related to voting, immigration, and interracial marriage (Nakagawa, 2014). Furthermore, victories like these helped politically galvanize Asian Americans by demonstrating the power of participatory democracy (Umemoto, 2007). However, while the civil rights movement was predicated on integration and nonviolence, anti-imperialist efforts in the Third World preached a need to exercise self-determination and independence "by any means necessary" (Umemoto, 2007). These Third World anti-imperialist ideologies were taken up by Malcolm X and other Black revolutionaries frustrated by the limitations of civil rights ideologies, leading to the rise of the Nation of Islam, Black Panther Party, and other Black Power organizations. Many Black Americans thus began to support and take inspiration from militant Asian resistance to Western imperialism, particularly Japan with its military might (Maeda, 2005). Activist and boxing champion Muhammad Ali famously refused to participate in the Vietnam War on the grounds that "[m]y enemy is the white people, not Viet Cong or Chinese or Japanese" (Metz, 2013), and the communist writings of Chinese leader Mao Zedong were integral to the teachings of the 
Black Panthers (Maeda, 2005). Likewise, newly formed Asian American organizations like the Asian American Political Alliance incorporated the works of Black revolutionaries like Frantz Fanon and members of the Black Panthers into their own political philosophies (Umemoto, 2007). Indeed, Omatsu (2007) has argued that the true awakening of Asian American political consciousness owes more to the influence of Malcolm X and Black liberation than the integrationist politics of the civil rights movement. While this reading may underestimate the radicalness of Dr. King's politics, the point remains that Asian American rights and political movements owe a debt to the work of a diversity of Black revolutionaries (Maeda, 2005; Nakagawa, 2014; Tseng-Putterman, 2017a).

Beyond mutual admiration and influence, Third World liberation movements also encouraged direct alliances between Black people and Asian people in the United States. PostSecond World War demographic shifts increasingly placed Black and Asian Americans in direct contact with one another (Maeda, 2005). Prominent Asian American activists like Grace Lee Boggs, Richard Aoki ${ }^{4}$, Yuri Kochiyama, and Steve Louie were directly involved in various Black liberation organizations (Maeda, 2005). One of the most significant of these alliances was the Third World Liberation Front (TWLF), a multiracial coalition of students that advocated education for students of colour that was accessible, relevant to their lived experiences, and implemented and overseen by their own communities (Umemoto, 2007). In 1968, TWLF members at San Francisco State College attempted to get their demands met by carrying out a student strike, the longest in U.S. history (Omatsu, 2007). The strike eventually faltered under

\footnotetext{
${ }^{4}$ In recent years, Aoki's involvement with the Black Panther Party has come under scrutiny due to allegations that he was an FBI informant (Nopper, 2012).
} 
repressive state measures and internal discord among participants, but when the dust had settled, the first Ethnic Studies departments in the nation were born.

Along with this accomplishment, another lasting legacy of the strike was its influence on Asian American political consciousness. While Asian Americans from Filipino farmworkers to Japanese internment resistors had waged their own political struggles long before the strike, these battles were often waged primarily along lines of ethnicity and nationality (Maeda, 2005). To many, the strike marked the beginning of the Asian American movement, which constituted Asian Americans as a unified political bloc whose goals intersected with those of other people of colour at home and abroad (Omatsu, 2007).

Moving from the late 1960s into the 1970s, political and cultural ties between Black and Asian Americans became further entwined. Frequently, these ties were expressed via acts of cross-racial imitative performance. Black admiration of Asian militant anti-imperialism led to a fascination with Asian cultural traditions, with some Black revolutionaries even dressing in Chinese peasant garb as an homage to communist China (Maeda, 2005). However, perhaps no Asian cultural tradition was more widely emulated among Black Americans than martial arts like kung fu and karate. Bearing a close association with violent struggle against authoritarianism, "martial arts as a tactic of self-defense appeals to individuals historically denied the right to be freely expressive in public space as well as denied the power to defend themselves, including African Americans" (Hewitt, 2008, p. 266-267). Martial arts were thus seen as a viable means of resisting (white) Western domination, not only in Third World contexts by Asians, but domestically by Black Americans. Aspiring Black and other non-Asian martial artists initially experienced a great deal of resistance from Asian — specifically Chinese - teachers, who wished to carefully guard their cultural practices (Wheeler, 2008). However, thanks to the less 
conservative policies of legendary martial artist Bruce Lee and others, Black people eventually gained access to martial arts training and soon became a dominant presence (Wheeler, 2008).

Martial arts films, particularly those of the aforementioned Lee, were instrumental in spreading these combat techniques and philosophies to Black American audiences. These films often featured plots that depicted standing up to Western bullies, combined with tropes like maintaining traditions, mastering the mind and body, and defending the weak from powerful enemies using determination and guile rather than brute strength (Ho, 2006). Martial arts films also served as vehicles for promoting Afro-Asian alliances. Bruce Lee's iconic martial arts film Enter the Dragon, for example, features a Black revolutionary played by martial artist Jim Kelly, whose heroic death is avenged by Lee's character (Ho, 2006). Yet the surging popularity of martial arts in the West, while in many respects strengthening Afro-Asian ties, was at times a source of tension. Asian American youth were wary of wholeheartedly embracing the popularity of the martial arts warrior due to frustrations with stereotyping by others, including Black people (Ho, 2006). Nonetheless, by appropriating Asian martial arts, both on screen and off, Black revolutionaries were able to reassert their ability to defend themselves against a common AfroAsian enemy of white Western hegemony, reaffirming solidarities between the two groups.

Martial arts, along with other Asian motifs and aesthetics eventually made their way into areas of Black American cultural production ${ }^{5}$. Around the same time that martial arts were attaining prominence in U.S. popular culture, hip-hop was emerging as a new musical form in the urban Black communities of Brooklyn. The formative influence of martial arts is apparent in the name of hip-hop pioneer Grandmaster Flash, who borrowed the title "grandmaster" from

\footnotetext{
${ }^{5}$ Curiously, the Vietnam War was largely an exception to this, at least in the realm of literature, being conspicuously absent from Black American literature both during and after the war (Raphael-Hernandez, 2006).
} 
martial arts films (Phi, 2008). Fred Ho (2006) suggests that this influence is no coincidence, arguing that "hip-hop artists aspired to the commitment, dedication, righteous integrity, and level of competitive excellence and mastery of form and craft that they identified with the martial arts" (p. 306). However, the subsequent proliferation of Asian language scripts and geisha characters in hip-hop visual culture, while tied to the popularity of martial arts, cannot be entirely explained using this argument. Deborah Elizabeth Whaley (2006) argues that Asian signifiers are strategically deployed by Black hip-hop artists as a "yellow mask" that allows them to inhabit an exotic persona untethered to the restrictive racial boundaries prescribed to Blackness. The impulse to wear a different racialized mask comes from a historical denial of the existence of Black culture under white cultural hegemony (Whaley, 2006). Asians, by contrast, have historically been popularly depicted as possessing an excess of culture (Lee, 1999; Prashad, 2001; Whaley, 2006). Overall, then, Black appropriation of Asian signifiers in the 1960s and 1970s may be characterized as motivated by a desire to reclaim a cultural distinctiveness and bodily autonomy denied to them under white supremacy and the legacy of chattel slavery.

While Black Americans were absorbing Asian philosophies and aesthetics into their own cultural practices, Asian Americans were appropriating aspects of Blackness in attempting to shape their own recently realized identity. Daryl Maeda (2005) argues that this Black performativity was crucial in "producing a novel form of Asian American subjectivity by highlighting parallels between the common racialization affecting African Americans and Asian Americans of various ethnicities" (p. 1087-1088). By imitating militant Blackness, Asian American activists were able to see and present themselves as a racialized collective who, like their Black Power counterparts, rejected assimilation as a solution to racism. This ideology flew in the face of an emerging model minority mythology that was tempting Asian Americans with 
the promise of inclusion, a promise predicated on the necessary exclusion and denigration of Black people.

Maeda (2005) specifically singles out the Red Guard Party and trailblazing playwright Frank Chin as utilizing performative Blackness to articulate an anti-assimilationist Asian American identity. The Red Guards were composed mainly of young Chinatown radicals who were heavily influenced — and in some respects directly molded and guided—by the Black Panther Party. They adopted the "garb, confrontational manner, and emphasis on selfdetermination" (Maeda, 2005, p. 1079) of the Black Panthers as a strategy to advance their own platform of racial justice for "yellow people" under the guidance of Red China socialist policies. The Red Guards' politics were thus firmly grounded in Third World internationalism, which recognized a collective need among all people of colour to combat Western imperialism abroad, and assimilation at home. Yet at the same time, the confrontational political performances of the Red Guards were steeped in the problematic sexual politics of "male chauvinism", an issue inherited from the Black Panthers they sought to imitate (Maeda, 2005). This emphasis on a millitant, hypermasculine style of activism had the effect of marginalizing women and queer folks from these revolutionary movements by making it difficult for them to ascend to leadership positions and have their voices heard (Maeda, 2005).

Like the Red Guards, Frank Chin recognized Black masculinity as a valid model for resisting assimilation into whiteness. Chin, however, derided the Red Guards' political performances as an inauthentic "yellow minstrel show" (Maeda, 2005, p. 1093) that overromanticized the similarities between Black and Asian racialization. Chin instead promoted the organic emergence of Black masculine performativity as a solution to Asians having "no presence, no image in American culture as men, as people” (Maeda, 2005). Rather than coveting 
Black masculinity as a vehicle for promoting Third World radical politics, Chin instead turned to Black masculinity as a model of sexual potency by which Asian masculinity might be reclaimed (Maeda, 2005). Yet like the Red Guards that he tried to distance himself from, Chin has been criticized for grounding his politics of racial liberation in a masculinist framework that leaves no place for women or subordinated forms of masculinity (Maeda, 2005). Together, the Red Guards and Chin demonstrate that the history of Asian American activism is steeped in performative Black masculinity, if not always for the same purpose.

From Bandung to Bruce Lee, Afro-Asian solidarities in the United States during the 1950s-1970s were forged through mutual influence, multiethnic alliances, and cross-racial imitation. The anti-assimilationist politics of Third World anti-imperialism and Black liberation proved particularly fertile ground for cultivating these revolutionary relationships. Cross-racial performativity grounded in this anti-assimilationist stance created a conduit for politics to spill into culture, percolating through the films, music, and other forms of culture produced by Black communities and Asian communities in the United States. Black Americans emulated Asian martial arts to reclaim cultural and bodily autonomy under white Western hegemony, while Asian Americans sought a place in the cultural and political fabric of the United States by imitating their most prominent racialized analogues—Black Americans. In other words, Black Americans and Asian Americans turned to one another in search of models of nonwhite strength. While these relationships were not without tension, the recognition of a common enemy in white supremacy formed the grounds for a baseline of mutual respect between Black Americans and Asian Americans. 


\section{Racial Adversaries: Afro-Asian Relations in the United States (1980s-Present)}

While a shared commitment to resisting assimilation encouraged cross-racial solidarity among Asian Americans and Black Americans from the 1950s-1960s, changes in the racial landscape of the United States moving into the 1980s and beyond have tested its limitations. Glenn Omatsu (2007) observes that "[f]or African Americans and many other people of color, the period from the mid-1970s through the Reagan and Bush presidencies [was] ... a time of corporate assault on their livelihoods and an erosion of hard-won rights" but that for Asian Americans, the same period was "much more ambiguous" (p. 68). This is because while Black American communities were being devastated by governmental repression and austerity measures, certain aspects of Asian American life were actually improving.

According to Omatsu (2007), these improvements have at times been attributed to the supposed status of Asians as "model minorities" whose cultural values stress the importance of educational success and family. This loaded term problematically implies that there are "bad minorities" who would do well to mimic their studious, industrious Asian counterparts. Other proposed explanations for Asian American success have included the advent of immigration patterns that favoured the highly educated; the importation of political resources from Asian nations; rising power in the Asia Pacific region; and community-driven immigrant entrepreneur success (Omatsu, 2007). Omatsu himself, however, posits that Asian Americans owe much of their success to the relatively low profile of the Asian American movement's grassroots activism, which allowed its principles to survive and adapt to the priorities of an influential new generation of young professionals. These young professionals aligned the ethnic pride and socioeconomic mobility that they inherited from the Asian American movement with neoconservative values that relegated racism to the realm of personal attitudes and cultural representations rather than 
institutionalized systems of power. Coming to this conclusion was of course only possible due to their inherited class privilege, which shielded them from much of the structurally-generated struggles of their Black counterparts. Understanding race in this individualistic way has led Asian American neoconservatives to posit individual advancement as the only correct means of overcoming racial discrimination. This in turn has led Asian American neoconservatives to an emphasis on meritocratic success based on objective measures along with a concomitant disdain for affirmative action and other forms of social intervention. In this way, they have "propose[d] a strategy of alignment with existing centers of power and not the creation of new power bases among the disenfranchised sectors of society" (Omatsu, 2007, p. 74).

Although Omatsu's (2007) insights provides a useful intervention for conceptualizing the origins of Asian American (neo)conservatism, his dismissal of model minority discourse relies on a face-value analysis of its explanatory power. As Omatsu himself points out, many scholars have disputed the idea that Asians possess an ethic of hard work and obedience derived from culturally instilled "Asian values" (Glassman, 2016). However, the dubious truthfulness of the model minority concept does little to detract from its ideological function. Robert G. Lee (1999) asserts that the origins of model minority discourse lie in American Cold War strategizing that promoted successful Asian assimilation in order to gain the ideological upper hand over communism in Asia and discipline Black militancy at home. These pressures encouraged the relaxation of previously draconian immigration laws, culminating with the Hart-Cellar Act of 1965 that officially ended race-based immigration quotas in the United States. The lifting of these restrictions coincided with a growing urban workforce in Asia simultaneously created and spurred to emigrate by Asian economic development, not to mention an increased need for skilled labour in the postindustrial U.S. economy (Zhou \& Gatewood, 2007). It is this influx of 
affluent Asian immigrants that is responsible for the emergence of the Asian American professional class that Omatsu (2007) alludes to, and their willingness to buy into the model minority myth that is in turn responsible for producing their neoconservative values.

The proliferation of the model minority myth and the eagerness of certain Asian American groups to embrace its neoconservative implications has profoundly altered Afro-Asian relations. The rhetoric of Asian cultural superiority and Black cultural inferiority created tension between the two groups that sometimes spilled into acts of violence. While there were of course many more instances of neutral or positive interactions between the two groups, coverage of these events juxtaposed the supposed criminality of Blackness with the hard-working, entrepreneurial spirit of Asian immigrants. Black-Korean conflict was particularly sensationalized, with high profile instances including the fatal shooting of Black teenager Latasha Harlins by a Korean store owner, and the 1992 Los Angeles riots (Lee, 2007). Jennifer Lee (2007) notes, however, that Black resentment of Korean businesses and Korean distrust of their Black clientele both largely disappear in more middle-class neighbourhoods. This hints at the fact that the racial animosity so widely reported arises not from innate cultural or racial differences, but from conditions of poverty and class anxiety (Lee, 2007).

Popular culture of the 1980s and 1990s began to reflect the Afro-Asian tension being broadcast on the news. Some works of notable Black artists, such as Spike Lee's film Do the Right Thing and Ice Cube's song “Black Korea”, prominently featured themes of Afro-Asian conflict, and Korean American artist David Choe's work has been deeply influenced by his participation in the Los Angeles riots (Sung, 2016). However, conflict and tension have not always been at the centre of recent Afro-Asian cultural representations, with cross-racial coalitions and performances still prevalent as they were in the 1960s and 1970s. However, the 
conditions of these cross-cultural exchanges are not immune to the same shifting racial politics that have positioned Black and Asian people in opposition to one another. Fred Ho (2006) laments the commercialization of more contemporary martial arts films like Rush Hour, which has turned them from strongholds of revolutionary Afro-Asian solidarity to exercises in minstrelsy and police state violence. Mita Banerjee (2006) further elaborates that the racial caricatures performed by actors Chris Tucker and Jackie Chan in Rush Hour enact an ersatz Afro-Asian political alliance, which ultimately serves the invisible spectre of whiteness by keeping Blackness and Asianness contained within non-threatening stereotypes. Crucially, however, Chan's minstrel performance is afforded the dynamism to undertake Americanization through the imitation of his static Black counterpart in Tucker (Banerjee, 2006). Rush Hour thus stands in stark contrast to the martial arts films of Bruce Lee, which were created and set in the context of Black and Asian people collectively waging a revolutionary fight against whiteness, rather than performing their stereotypical differences for white edification.

Along with martial arts films, hip-hop has been the other dominant cultural form in which Black-Asian relations have historically been articulated, often through racial appropriation. Indeed, the same obsession with martial arts and Asian aesthetics that characterized early hiphop has continued to this day, permeating hip-hop's visual culture in the form of tropes like the sexualized but chaste geisha, and the kung fu warrior (Whaley, 2006). As well as being a site for Black experimentation with Orientalist tropes, hip-hop music and culture have been embraced by an increasing number of Asian Americans. Thien-bao Thuc Phi (2008) contends that in order to be taken seriously in hip-hop, Asian Americans must move beyond a search for mere representation, and instead "must revolutionize the way [they] conceive and practice hip hop so that Asian America is at the center of it” (p. 299). Such a move might create a uniquely Asian 
hip-hop practice that authentically represents Asian American culture rather than merely imitating Blackness. This authenticity is key for Phi, who sees it as a way to even a racial playing field in hip-hop dominated by Black artists and white corporate interests. However, Phi's call for centreing Asianness in hip-hop risks brushing aside the ways in which Asian Americans are already more "centred" by virtue of their model minority positioning. The exclusion and at times outright hostility directed at Asian Americans in hip-hop is thus not a particularly convincing reason for attempting to marginalize Black people within that space. The brief stardom of Asian American rapper Jin in the early 2000s became a focal point for discussions about the place of Asian Americans in hip-hop. Some have pointed out how Jin's race-based marginalization from hip-hop created a "Black versus Asian" narrative that portrayed Jin as a model minority within a Black cultural space (Kim, 2005; Wang, 2006). Others have noted that Jin's cross-racial performative Blackness should not be read as inherently radical; Asian displays of aggression and anger do not themselves constitute a liberatory racial politics, and in fact can be channeled into acts of anti-Blackness (Nopper, 2004). Indeed, Kenyon Farrow (2004) asks whether Asian hip-hop performance is in fact a form of minstrelsy rather than "cultural appreciation".

How do these new instances of cross-racial performativity compare to previous iterations from the 1960s and 1970s? Examples from that earlier era were characterized by a shared AfroAsian goal of resisting assimilation. However, the proliferation of the model minority myth has divided this alliance by granting Asian Americans a degree of socioeconomic mobility not afforded to their Black American counterparts. On the other hand, Black Americans continue to receive a significant degree of representation in American popular culture through the widespread appropriation and commodification of Black cultural practices like hip-hop (Cashmore, 1997). Yet these very processes that highlight Black culture — or perhaps more 
accurately, certain aspects or versions of it-paradoxically deny its very existence, instead subsuming it under the deracinated umbrella of American popular culture. Black American adoption of distinctly non-Western practices and motifs from Asian cultures can thus be read as a continuation of efforts to establish sovereignty over their own cultural expressions and products (Whaley, 2006).

Conversely, Asian Americans have suffered from a perceived lack of representation and continue to be saddled with the "perpetual foreigner" stereotype, which has led to a shift in preoccupation from anti-assimilation to striving for cultural citizenship in the United States. Lori Kido Lopez (2016) makes the case that contemporary Asian Americans are challenging the ways in which they are represented in media in order to demand cultural citizenship. For all Asian American media activists, cultural citizenship is the recognition of their own cultural practices as integral to the cultural fabric of the United States. However, different understandings of what constitutes cultural citizenship ${ }^{6}$ have produced disagreements and contradictory strategies for attaining it. Still, Lopez emphasizes that her project is not to "question how [Asian American media activism] functions as a social movement" (p. 5), leaving open the question of what role if any media activism has in the pursuit of social justice goals beyond the rhetoric of representation.

\section{Sports, Race, and Masculinity}

The critical study of sport is one area of cultural production that is ideally suited to revealing the shifting social and political dimensions of race relations in the United States. As Hylton (2009) notes, "[s]port and its representation through media messages have proved a central site for the reproduction of dominant ideas concerning the racialisation of different groups" (p. 81). The

\footnotetext{
${ }^{6}$ For a more thorough overview of the diverse meanings of cultural citizenship, see Klaus and Lünenborg (2012).
} 
ideal of sport competition as meritocratic and its highlighting of physical characteristics make racial patterns of performance an obvious point of focus (Hylton, 2009). Blackness in particular has been bound to athletic prowess in the public imagination. In the first half of the 20th century, the undeniable success of Black athletes like boxer Jack Johnson and track star Jessie Owens over their white opponents forced a dramatic reconsideration of the assumed physical supremacy of the white race (Hughey and Goss, 2015).

It is telling that Johnson's victories were framed by writers of the era as evidence that "his race ha[d] acquired full stature as men" (Messner, 1992, p. 12). It speaks to how the conflation of Blackness and athleticism is intimately tied to discourses of masculinity in sport. The world of sport has been constructed as an unequivocally masculine domain, and is in fact a crucial social institution for the formation and maintenance of masculine discourses (Messner, 1992). Chon-Smith (2014) traces the tradition of popular sport in the United States to a late nineteenth century "remasculinization" project in the wake of industrial capitalism. A "lost sense of independence, ownership and freedom" among white working-class men paved the way for “[p]opular sport [to] offer[] ... a means by which they could emphasize the male body as a locus for remasculinization" (p. 295). It is into this sporting context that Black athletes like Johnson were able to insert and assert themselves as men, reclaiming their own masculinity not from industrial capitalism, but from racist ideologies and policies that positioned them as inferior. Athletic success thus allowed Black men to claim cultural citizenship through the performance of masculine ideals that can be read as hegemonic, such as physical strength and aggression that demonstrated their superiority over women and subordinated masculinities. However, it is crucial to bear in mind that Black men have historically been denied the same opportunities as white men to fully embody hegemonic masculinity, such as being the breadwinner for a nuclear 
family (Majors \& Billson, 1992). This calls into question the extent to which Black men can truly completely attain hegemonic masculine ideals, and thus cultural belonging, in the eyes of white America. Instead, under the continued limitations imposed by structural racism, sport has become one of the few "domain[s] where black people, so often the underdog, are often depicted as successful, heroic, winners" (Hylton, 2009). Taking this idea a step further, Chon-Smith (2014) argues that under the contemporary logics of transnational capitalist consumerism, "black men have completely displaced the white male body, once the icon of physical and mental superiority, as the exclusive ideological signifier of athletic superiority" (p. 298). Of course, this does not mean that whiteness has completely disappeared; on the contrary, Andrews (1996) contends that "African Americans are tolerated, even valued, if they abdicate their race and are seen to successfully assimilate into the practices, value system, and identity, of white America" (p. 140). Therefore, the ability of Black men to be celebrated for their athletic accomplishments is highly contingent on their persistent rejection of Blackness.

However, even within the limited realm of sport, celebration of Black success is far from universal. Despite - or perhaps due to - seemingly conforming to normative masculine expectations, Black athletic success has been treated with widespread ambivalence. Black athletes are both celebrated and feared for their perceived physical advantages; consequently, they frequently encounter attempts to undermine their success. Often the desirability of athletic ability itself is downplayed. The initial acknowledgement of Black physical abilities led to a "Black brawn vs. white brains" racial model that conceded physical superiority to Black athletes while emphasizing white intellectual superiority (Hughey \& Goss, 2015). Pseudoscientific speculation then promulgated the claim that Black physical prowess is a legacy of genetic selection introduced by the harsh demands of slavery (Hughey \& Goss, 2015). Under this logic, 
Black athletic success is dismissed as the inevitable result of genetically inherited physical characteristics rather than skill and hard work. These discourses produced the contemporary stereotype of the "Black jock", a genetically hypermasculine figure whose dominant physical attributes are matched by deficiencies in intellect and character.

The Black jock stereotype has permeated contemporary sport media commentary, which frequently depicts successful Black athletes as physically skilled but morally flawed. Delia Douglas (2012), for example, interrogates the intense media scrutiny surrounding the personal lives and performances of Black tennis stars Venus and Serena Williams, finding that it frames their off-court interests and unapologetic self-love as selfish. Nikolas Dickerson (2015) analyzes the racialized masculine ideologies produced by Internet memes comparing ice hockey and basketball. Dickerson argues that the memes glorify the toughness of white hockey players while depicting Black basketball players as "individualistic, selfish, and unwilling to sacrifice their bodies for the greater good of the team" (p. 304), which "suggest the failure of the Black male body to live up to traditional sporting norms" (p. 311). This subordination of Black masculinity contradicts understandings of Black masculinity as embodying hegemonic masculinity.

The supposed failure of Black athletes to fully live up to hegemonic masculine ideals is often couched in the language of criminal deviance. This is no accident, as "contemporary constructions of the pathologically criminal and naturally sporting black body are founded upon a common assumption of the innate physicality of the black body" (Andrews, 1996, p. 135). In contemporary sports media, the preoccupation with the criminality of Black men has been conflated with the proliferation of "hip-hop culture", leading to the policing of Black athletes through white-imposed dress codes and behavioural standards (Cunningham, 2009; Lorenz \& Murray, 2014). However, Black masculinity is not uniformly constructed as criminal in mediated 
sport discourse. Instead, the construction of a "good Black/bad Black" dichotomy serves to discipline deviant Black behaviour by glorifying the accomplishments of a select few who play by the rules of whiteness (Abdel-Shehid, 2005; Neverson \& Knight, 2011; Wilson, 1997). The dichotomy of "good Black/bad Black" can even occur in media representations of the same athlete, as Andrews (1996) demonstrates in his analysis of representations of Michael Jordan's Blackness. He observes that Nike's early "Air Jordan" advertising campaigns "were evidently dominated by the signification of Jordan's naturally athletic black body" (p. 137), but that they subsequently attempted to market Jordan as a racially transcendent hero. While Jordan's phenotypical Blackness was still evident, Nike sought to distance him from it by endowing him with an artificially constructed wholesome, non-threatening personality. This "All-American" character was contrasted with Black caricatures played by the likes of Spike Lee and Charles Barkley in order to make Jordan more appealing to white American consumers. Yet for Jordan and other widely celebrated Black cultural figures, "[a]ny fall from grace ... recasts the hitherto American person as a criminally deviant, sexually promiscuous, or simply threatening racial Other" (Andrews, 1996, p. 140). This is precisely what happened when Jordan encountered controversy, with his frequent gambling serving as the primary vice marking his deviance and thus Blackness. The relationship between Black masculinity and hegemonic masculinity is thus highly tenuous. Masculine Black athletes, even those at the pinnacle of their sport, must forfeit parts of their Black identity in order to be seen as law-abiding citizens worthy of admiration, a privilege which is always under threat of being revoked.

The relationship between Blackness and sport may be readily observed, but the role of sport in constituting Asian racial identity is less widely acknowledged. As with Blackness, Asianness in the context of sport is inextricably tied to masculine discourses. However, while 
Black masculinity is at least contingently associated with hegemonic masculinity, Asian masculinity has been historically subordinated as an asexual or feminized masculinity (Eng, 2001; Park, 2013). Asian athletic success is typically imagined as limited to individual sports like tennis and figure skating, which lack physical contact and thus tend to reinforce more subordinated masculinities (Park, 2015). Asian success in sports coded as "masculine", like boxing, hockey, baseball, football, and basketball, is therefore generally viewed as aberrant and noteworthy. An exception to this rule is athletes who are both Black and Asian, such as former football star Hines Ward and current NBA point guard Jordan Clarkson. However, these athletes are rarely read as Asian, and are instead largely seen as typical examples of Black athleticism. That caveat aside, for non-Black Asian American men, popular sport acts as a space in which they "presuppose and indeed attempt to produce Asian masculinity by inverting the bodily emasculation of Asian American men" (Chon-Smith, 2014, p. 292).

Martial arts tend to dominate discussions related to Asian physicality and aggression. Many of the most prominent Asian men in U.S. popular culture, such as Bruce Lee, Jackie Chan, and Jet Li, have earned fame on the basis of their martial arts skills. However, while these martial artists are undoubtedly athletes, "the physicality of martial arts, though considered masculine for its violence, does not carry the weight of popular sports' mass appeal" (ChonSmith, 2014, p. 303). Asian martial arts also carry an air of exoticism (Chon-Smith, 2014) that limits their capacity for producing an acceptable U.S. national masculinity. The popular image of the Asian martial artist instead risks evoking "Yellow Peril" anxiety that elicits more fear than admiration by stereotyping Asian men as "mindless martial arts maniacs” (Ho, 2006, p. 310).

In the post-World War II period, Yellow Peril has frequently been articulated as Asians representing an economic threat, a trope which Asian athletes have not been exempt from. David 
Mayeda (1999) reveals that media coverage framed Japanese baseball pitcher Hideki Irabu as a risky investment when the New York Yankees signed him to a lucrative Major League Baseball (MLB) contract. His failure to become a productive baseball player confirmed suspicions that he was not worth the risk, and was instead taking away opportunities from more deserving — and, presumably, white American-men. However, Mayeda contrasts Irabu's representation as an economic threat with that of another pitcher who made the move from Japan to the United States, Hideo Nomo. Nomo was praised as a model minority, whose hard work, sacrifice, and humble attitude had allowed him to achieve fame and fortune in the United States. Despite refuting stereotypes of Asians as unathletic, media discourse surrounding these two athletes therefore reinforced other stereotypes.

Nomo is far from the only Asian athlete to be framed as a model minority. Constancio Arnaldo (2016) reveals that mainstream media representations of boxer Manny Pacquiao promote his "assimilable masculinity" through narratives that focus on his humbleness, respect for his opponents, and devotion to religion and family. These narratives are deliberately contrasted with those of his Black and Latino opponents, who are often framed as selfish and mean-spirited (Arnaldo, 2016). Pacquiao is thus positioned as a model minority who, like Michael Jordan and other globally marketable racialized stars, symbolizes the realization of a “post-racial" world of equal opportunity. Like Jordan, then, Pacquiao's global media image is used to discipline Blackness and other forms of deviant masculinity. However, Pacquiao also serves an important symbolic function for members of the Filipinx diaspora, and Asians around the world more generally. His undeniably physical masculinity carries on the boxing tradition of reinstituting masculinity to working class men and disrupts the previously noted discourse of Asian emasculation (Arnaldo, 2016). Moreover, the ways in which Pacquiao's masculine body 
have been celebrated by Filipinx folks are often steeped in the politicized aesthetics of hip-hop. Arnaldo cautions that this appropriation of hip-hop carries its own set of liberatory limitations stemming from issues of appropriation and gender/sexuality hierarchies. Pacquiao therefore embodies a number of contradictions: He is celebrated for his violence but also mercy, and he appropriates, while at the same time disciplining, Blackness.

Chon-Smith (2014) elaborates on the relationship between Blackness and Asianness in the context of global sport. He argues that "the ways in which Asian male bodies inhabit black cultural spaces illustrate the complex process of Asian ethnic assimilation into national culture, a process that depends on mechanisms of black racialization already in motion" (p. 293). In particular, Chon-Smith singles out how the success of baseball star Ichiro Suzuki and nowretired basketball phenomenon Yao Ming contested the rigid racial hierarchies that recognize Black men only for their physical bodies, while discursively constructing Asian men as bodiless. At the same time, media representations of these Asian athletes also indicate how " $[\mathrm{g}] \mathrm{lobal}$ multiculturalism binds Asians and blacks into a coherent narrative of the US racial state's progress" (p. 305). He observes how Ichiro's breakthrough as the first true Asian baseball star was frequently equated with Jackie Robinson's breaking of baseball's colour barrier, a move that sanitizes the politically radical nature of Robinson's actions. Pioneering Black athletes like Robinson thus opened up sport as a space for other men of colour to pursue cultural citizenship through masculine performance, while having their own political legacies subsumed under narratives of multicultural diversity.

Yao Ming's ascendence to global superstardom in basketball is another striking example of Blackness mediating popular understandings of Asian athletes. According to Chon-Smith (2014), Yao's "promise as a cultural ambassador for global multiculturalism in the service of 
NBA sport internationalism hinged on his representational force vis-à-vis black masculinity in the NBA" (p. 308). For Chih-ming Wang (2004), these oppositional representations illuminate how the commodification of Black and Asian sporting bodies constitute distinct forms of capital. Black athletes like Michael Jordan represent a uniquely American "labour of conquest” (p. 270), that involves selling an All-American hero to aggressively penetrate global markets. By contrast, Yao comes to represent the "attraction of the market" (p. 270), in which Yao's immense 2.29 metre-tall body and foreignness stand in for the excessive desires of Chinese nationalism and global capitalism. Chon-Smith (2014) also emphasizes how Yao's physically imposing size has pitted him in direct opposition to not only emasculating Asian stereotypes, but also Black NBA centres, a position traditionally occupied by the largest, most marquee players. Yao is conveniently positioned as a foreign threat to be subdued by these gatekeepers of American masculinity (Chon-Smith, 2014). This dynamic became evident in widely publicized comments made by Shaquille O’Neal in which he disparages Yao via racial taunts, which prompted angry reactions from many Asian Americans. However, Chon-Smith astutely points out that "the framing of O'Neal's blackness, in particular as a "brute," racializes him by representations that rely on Asian America's racial and sexual anxieties about African-American masculinity, vocality, and politics" (p. 310). Asian Americans therefore reinforced rather than challenged the same racial essentialism that O'Neal's comments were rightly criticized for promoting.

Yao's success in basketball carries particular weight because of the way that basketball has become racially coded as Black, perhaps more so than any other sport. The impression that basketball is a "Black game" is reinforced by the fact that nearly 75 percent of NBA players identify as Black or African American (Lapchick, 2018). In addition, basketball is uniquely suited to racial representation because its uniforms lack extensive covering of the face and skin 
(Chon-Smith, 2014). This ease of racial identification makes racially unexpected participants stand out even more.

Despite its supposed Blackness, basketball also carries a great deal of significance to Asian American communities. Basketball has long operated as a space in which the place of Asian Americans in the U.S. racial hierarchy has been negotiated. For example, Kathleen Yep (2012) contends that barnstorming basketball teams of the 1930s were "racially triangulated" in relation to one another as heroes (white teams), threats (Black teams), or novelties (Asian and Native American teams) in order to promote the appearance of liberal multiculturalism while in practice still privileging whiteness. The early participation of Asian Americans in basketball speaks to its importance not only as a visual consumer spectacle, but as an everyday social practice. Joel Franks (2016) notes that "community basketball was and remains very meaningful to participants and supporters desirous of connecting with people they have deemed ethnically similar while not surrendering their right to cultural citizenship" (p. 226). Basketball thus has a long tradition of negotiating inter- and intracultural relationships for Asian Americans. It can also act as a site for Asian American identity formation, as Stanley Thangaraj’s (2013) ethnographic study of South Asian American basketball players demonstrates. He highlights the role of basketball as an avenue for South Asian American men to enact normative masculine ideals through comparative racialization. Asserting their masculine credentials enables them to resist emasculating stereotypes, but these notions of queerness are then projected onto other racialized masculinities, including Black masculinities. Thus the search for national belonging and identity for South Asian American basketball players involves practices that create and police racial boundaries to exclude other groups. 


\section{Jeremy Lin}

While Asian global sporting superstars like Ichiro Suzuki and Yao Ming transformed the racial topography of U.S. culture for Asian Americans, their position as foreign imports invites a necessary distinction between Asian and Asian American experiences. The phenomenon of Jeremy Lin's rise to fame offers an opportunity to analyze the social, cultural, and political reception of an Asian American sports star.

Much of the research that frames Lin in explicitly political terms focuses on his status as a transnational symbol. His U.S. citizenship, Taiwanese parentage, and Chinese ethnicity have resulted in multiple claims to, and distinct constructions of, his identity (Combs \& Wasserstrom, 2013). For example, Lin's Taiwanese roots have made him a powerful symbolic figure in Taiwan's construction of national identity. Emphasizing Lin's Taiwanese-ness while downplaying his American-ness has been consistently recognized as characteristic of Taiwanese media (Chiang \& Chen, 2015; Combs \& Wasserstrom, 2013; Su, 2014). Chiaoning Su (2014) contends that Taiwanese media have unambiguously construed Lin as a national hero, whose success and fame created positive visibility for the nation. However, despite claiming that Lin was consistently defended as a national hero, $\mathrm{Su}$ (2014) hints that over time, "unanimous celebration of Lin as a national hero was challenged by narratives that expressed resentment and embarrassment at seeing a foreigner claimed as Taiwanese" (p. 487). Therefore, while Taiwanese media may have consistently defended Lin as both Taiwanese and a hero, his ambiguous identity reflects Taiwan's own crisis of identity.

Ying Chiang and Tzu-hsuan Chen (2015) contend that Taiwan's multiple colonial legacies are responsible for creating this ambiguous and unstable national identity. The insecurity of the Taiwanese national identity is marked by a tendency to define itself in relation 
to others, particularly the West. This manifests itself as a desire for having their best and brightest "Glories of Taiwan" receive validation and acclaim from the West. Thus Lin's adoption as a national hero stems less from his ability to defeat foreign enemies, and more from his ability to compete alongside them. Furthermore, Lin's distinct Americanness as a California-born, Harvard-educated, devout Christian basketball star has confounded attempts by Taiwan to fully embrace him as one of their own. In other words, glorifying the Western visibility of an American-born basketball player has only amplified pre-existing insecurities about what constitutes Taiwanese identity. A significant factor in Taiwan's insecure national identity may be its contentious relationship with China. Taiwan's fervent desire to claim Lin for themselves indicates its hunger for global visibility, which has eluded it for so long under China's long shadow (Chiang \& Chen, 2015; Combs \& Wasserstrom, 2013; Su, 2014).

Research on Lin's reception in the United States generally highlights how popular media coverage focuses on Lin's Asian racial identity as opposed to ethnic and national allegiances. As might be expected, there is plenty of evidence to indicate that Lin is portrayed in ways that rely on Asian stereotypes. Stereotypes such as "model minority", "Yellow Peril", and "forever foreigner" emerged as common themes in online conversations about Lin (Kurylo, 2014), and Orientalizing tropes like fortune cookies featured heavily in marketing efforts (Magat, 2015; Park, 2015).

Lin's reinforcement of the model minority stereotype is particularly noteworthy because it is paradoxically contingent on his ability to subvert certain other stereotypes about Asian men. Lin's unexpected success in basketball flaunts conventional representations of Asian men as small and weak, but his unexpected success despite numerous obstacles supports the mythical notion of Asians and Asian Americans as inherently hard-working high-achievers (Kim, 2014; 
Leung, 2013). This re-inscription of the model minority myth positions Lin as a "post-racial" hero demonstrating the meritocracy of sport, and by extension, the United States. Such colourblind racial discourse not only obscures the broader systemic effects of racism, it ignores the fact that Lin's Asian heritage played a significant role in securing him a lucrative post-Linsanity contract (Chang, 2014). Therefore, while it may be true that Lin succeeded in basketball despite his race, his fame and financial fortune were in large part achieved because of it.

Michael Park's (2015) critical discourse analysis of Linsanity media coverage elaborates on how Lin's refutation of emasculating stereotypes commanded such intense media attention. His findings indicate that while most media coverage was careful not to overtly racialize Lin's story, the several instances that did do so reinforced dominant discourses that subordinate Asian masculinities through emasculating stereotypes. Furthermore, the sheer intensity of the coverage itself implicitly indicated the low expectations placed on the physical prowess of Asian men (Park, 2015). Thus, while Lin's athletic performances contradicted expectations of Asian men, he has remained haunted by discourses that seek to marginalize his masculinity and make his confounding body more racially legible. Rather than embodying the promise of a new model of Asian masculinity, Lin may instead represent the exception that proves the rule of Asian men's emasculation.

While Park’s (2015) study makes some crucial connections between Lin and hegemonic masculinity, he fails to adequately probe the significance of Lin succeeding in a sport that features a model of masculinity racially signified as Black. Kathleen McElroy (2014) addresses this blind spot by analyzing opinion columns that explicitly position Lin in relation to Blackness. She found that Lin was framed as an oddity and underdog, a reminder of racism, a pioneer and agent of change, and an antidote to Blackness. His status as an oddity and underdog have been 
well documented by other research (Kurylo, 2014; Park, 2015), but the other frames reveal some aspects of "Linsanity" that have garnered less attention. For example, while the racism directed at Lin has also been well-documented, McElroy observes that the lack of concern over this antiAsian racism was frequently contrasted with the visibility of, and sensitivity to, anti-Black racism. This comparison reinforces the idea of Asians as quietly suffering while their Black counterparts loudly complain. Lin's status as a pioneer is also noteworthy because it is a position most frequently taken by Asian American commentators (McElroy, 2014). They view Lin’s dismantling of certain racial stereotypes not merely as a novelty, but as the promise of increased visibility, inclusion, and respect for Asian Americans. Conversely, the framing of Lin as an antidote to Blackness tends to emphasize Lin's adherence to stereotypical Asian American values like humbleness and politeness, a position vehemently opposed by Asian American commentators (McElroy, 2014). McElroy concludes that "Asian American commentators hoped 'Linsanity' would improve their group's 'insider' positioning within racial triangulation, but the frames emphasized Lin and his success as otherworldly — thus no closer to Whiteness, still linked to Black America in a battle over minority status" (p. 446-447). The discrepancy that McElroy reveals between Lin's promise as a masculine racial saviour for Asian America and his use as an anti-Black pawn to legitimize white supremacy deserves further scholarly attention, particularly in light of more recent, post-Linsanity events.

In his analysis of media representations of Lin and Samoan American football player Manti Te'o, David Leonard (2016) ties together some of the themes from Park's (2015) analysis of Lin's masculinity and McElroy's (2014) analysis of Lin's proximity to Blackness. He suggests that for Asian American and Pacific Islander athletes like Lin and Te'o, as well as predecessors like Dat Nguyen and Junior Seu, their "athletic success derives from a closeness with and a 
mimicking of black athletic bodies" (p. 227). The historically subordinated masculinity of Asian American men like Lin complicates their ability to convincingly enact that association, making their athletic successes largely illegible. As a result, dominant discourses have attempted to shoehorn Lin into narratives of hard work and intelligence usually reserved for white athletes (Leonard, 2016). Yet, Lin's aggressive "baller" style of play belies these narratives, instead suggesting an attempt to perform Blackness. Thus, "[f]or Lin, his entry into the realm of professional basketball does not follow the dominant discourse of assimilation into whiteness but reflects how blackness affords possibilities for expressing and claiming American masculinity" (Leonard, 2016, p. 233).

Lin's ability to be interpreted as more "white" while displaying clear signifiers of Blackness perhaps points to a discrepancy in the narrative goals of popular media as opposed to those of Lin himself. Yet even when this discrepancy is acknowledged (e.g., Leonard, 2016), scholarly literature on Lin has to this point largely shied away from including analysis of Lin's own takes on his racial identity. While Lin has admitted a reluctance to talking about race early in his career, he also claims that going through Linsanity emboldened him to become a more outspoken advocate for Asian American issues in recent years (Yam, 2019). The failure of scholars to continue tracking Lin's media presence in the years after Linsanity has resulted in this critical dimension being overlooked. By limiting the purview of their analyses to Linsanityera media discourse produced by outside observers, researchers studying Lin have missed an opportunity to interrogate his agency and complicity in shaping popular discourse about himself post-Linsanity. If Lin is serious about becoming a voice for Asian Americans, it is only fair that his messaging be critically evaluated as a barometer for the contemporary climate of Asian American politics. 


\section{Research Questions}

Engaging with the above overviews of relevant theory and literature led to the formulation of nine primary research questions. Note that the terminology used in these questions is operationally defined in the "Methodology" section.

Regarding the content analysis, I developed the following six research questions: In popular media coverage of Jeremy Lin's Asian American identity,

RQ1. What is the ratio of Black writers to Asian American writers to "other" writers?

RQ2. What is the ratio of Black voices to Asian American voices to "other" voices?

RQ3. How frequently does the topic of Blackness occur?

RQ4. How frequently do the themes of (a) the supraethnic viability of Asianness; (b) the necessary defeat of Blackness; (c) the disallowance of anti-Asian sentiment; and (d) the presence of a helpful Black cohort occur?

RQ5. To what extent do RQ3 and RQ4 vary by race of writer?

RQ6. To what extent do RQ1-RQ4 vary by time period? (i.e., Linsanity vs. postLinsanity)

Regarding the critical discourse analysis, I posed a further three questions:

RQ7. How were the four themes of Asianness manifested in popular media?

RQ8. What media frames were used to situate Lin's Asian American identity in relation to Blackness?

RQ9. How did these media frames manifest themselves and what was their effect upon interpretations of the four themes of Asianness? 


\section{Methodology}

Broadly speaking, my thesis aims to examine the role of Blackness in shaping contemporary Asian American identity and politics. For this purpose, I chose to analyze mass media representations of Asian American athlete Jeremy Lin in popular culture. Mass media are a primary site of ideological production, through which hegemony is produced and maintained (Gramsci, 1971). Analyzing mass media messages can thus help identify where and how the dominant culture's power structures operate along lines of race, class, gender, and sexuality.

Stuart Hall (2003) proposes that by examining the symmetry between the encoding of a media message by its producer and its decoding by a receiver, one can reveal the ideological values embedded within that message. In particular, he makes the following observation:

[S]igns appear to acquire their full ideological value $\ldots$ at the level of their "associative" meanings (that is, at the connotative level)—for here "meanings" are not apparently fixed in natural perception ..., and their fluidity of meaning and association can be more fully exploited and transformed. (p. 122, emphasis in original)

Yet far from being completely fluid, the range of connotative meanings is delimited - though not prescribed — by a set of dominant or preferred meanings that "both have the institutional/political/ideological order imprinted in them and have themselves become institutionalized" (p. 124). It is these preferred meanings that systematically structure discourse, and which can be read in order to uncover how the dominant culture operates.

Though once overlooked as a site of serious study, the everyday salience of mass mediated sporting culture makes it a rich area for investigating dominant discourses of nationhood, race, and gender (Wenner, 2002). Issues of race and racial difference are especially foregrounded in sport thanks to its fixation on human physicality and the ideal of sporting 
competition as meritocratic (Hylton, 2009). For similar reasons, organized sport has also been a crucial domain for the assertion of men's physical dominance over women, thus playing a key role in shaping contemporary expressions of masculinity (Messner, 1992). Therefore, analyzing how Lin's Asian American racial identity is mediated through sporting culture should offer informative and indeed indispensable insight into Asian American gendered (inter)racial politics.

In order to study mass mediated representations of Jeremy Lin's Asian American identity, I have chosen to employ a mixed-methods approach. The first technique used in the present study is quantitative content analysis. Content analysis "seeks to quantify content in terms of predetermined categories and in a systematic and replicable manner" (Bryman, 2001, p. 177). This allows the researcher to "ascertain the trends and patterns of words used, their frequency, their relationships and the structures, contexts, and discourses of communication" (Grbich, 2012, p. 190). Content analysis can be used on a wide range of audio, visual, or written documents, making it a flexible and efficient strategy for analyzing and distilling large amounts of textual information (Grbich, 2012). However, content analysis has also been accused of being atheoretical (Bryman, 2001; Grbich, 2012) and of having difficulty interpreting how meaning is created within a given text (Grbich, 2012; Hardin, Kuehn, Jones, Genovese, \& Balaji, 2009; Park, 2015).

It may therefore be desirable to augment content analysis with other research strategies. Indeed, Stokes (2003) maintains that content analysis is well suited to being used in tandem with interpretive textual analysis techniques. One popular form of textual analysis is discourse analysis. Discourse analysis encompasses a wide variety of approaches that can be broadly characterized by four themes: "a concern with discourse itself; a view of language as constructive and constructed; an emphasis upon discourse as a form of action; and a conviction 
in the rhetorical organization of discourse" (Gill, 2000, p. 4). Discourse itself has been defined as "linguistic action, be it written, visual or oral communication, verbal or nonverbal, undertaken by social actors in a specific setting determined by social rules, norms and conventions" (Wodak \& Krzyznowski, 2008, p. 5). However, because of the extraordinary variation within discourse analysis (Bryman, 2001; Gill, 2000; Stokes, 2013), it may be helpful for researchers to specify precisely which school of discourse analysis their work draws upon (Wodak \& Krzyznowski, 2008). One influential form of discourse analysis is critical discourse analysis (CDA). Norman Fairclough (2003), the originator of CDA, defines it as "analysis of the dialectical relationships between discourse (including language but also other forms of semiosis, e.g. body language or visual images) and other elements of social practices" (p. 205). This allows practitioners of CDA to "uncover ... social inequalities, hierarchies of power and non-democratic practice" (Grbich, 2012). However, CDA is not without its own deficiencies. It has been accused of lacking systematic rigour and allowing the researcher's political interests to overdetermine the results (Grbich, 2012).

The strengths and weaknesses of content analysis and CDA thus compliment one another. The critical distance and structure offered by quantitative content analysis helps balance out the strong perspectives and potential biases informing my CDA, which in turn adds qualitative and theoretical depth to the content analysis. In keeping with their distinct strengths, the content analysis and CDA elements of my research serve different purposes. The content analysis is concerned mainly with a descriptive, quantitative overview of author demographics, temporal context, topics, and themes, while the CDA is devoted to the detailed qualitative analysis of the themes as well as media frames. 
The demographic section of the content analysis focuses on identifying the race of those who have played a role in producing and shaping discourse around Lin's Asian American identity. The temporal context identifies the time period during which a text was created. This information can help us better grasp the social conditions and hegemonic interests under and through which media messages about Jeremy Lin are produced and disseminated. Interrogating the subject positions and contexts of those responsible for producing discourse is a key tool of CDA, making this demographic and temporal information pertinent to the rest of my analysis. The differentiation between textual topics, themes, and frames in my analysis follows Kenneth Campbell and Ernest Wiggins (2015), who developed a typology to hierarchically organize these three related concepts. Under this typology, topics are the least powerful and merely identify the subject at hand; themes are more complex and delineate what a reader should think about; and frames are the most powerful, suggesting to readers how they should think about the ideas conveyed by themes and topics. Campbell and Wiggins (2015) also helpfully clarify that "answering what, which identifies the theme, refers to knowledge and understanding of a topic; answering how refers to the perspective and context that generates meaning. Direction of thinking is key in determining the frame" (p. 187). On framing, Entman (1993) offers the following definition:

To frame is to select some aspects of a perceived reality and make them more salient in a communicating text, in such a way as to promote a particular problem definition, causal interpretation, moral evaluation, and/or treatment recommendation. (p. 52, emphasis in original)

In many cases, simple differences in phrasing through the inclusion/omission of certain aspects of the same issue are enough to produce large differences in perceived meaning (Chong \& 
Druckman, 2007). Linguistically focused methodological approaches like CDA are thus wellsuited to revealing the mechanisms of framing used to construct dominant or preferred meanings.

\section{Data Collection}

The present study used a non-random, cyclical sampling procedure to collect data from both print and digital media sources. This approach has been deemed more appropriate for qualitative research than random sampling in instances when the population is unknown and there is a desire to not pre-determine categories (Mautner, 2008). While this type of sampling does raise issues of validity for quantitative studies, I consider this study primarily qualitative, with the quantitative data serving a more descriptive function.

An initial corpus was built using print media. Print sources were obtained by conducting LexisNexis Database searches of newspaper articles that contained the search terms Jeremy Lin and Asian American. These search terms were chosen to help obtain a sample that focuses on Jeremy Lin's Asian American identity. However, unlike McElroy (2014), I did not further narrow my list of potential sources by pairing these search terms with Black or African American because I wanted to capture items that contain latent rather than only explicit references to Blackness. Sampling at this stage was conducted within two separate time frames: (a) Linsanity and (b) post-Linsanity. This was done in order to ensure robust representation from each time period for comparative purposes, as post-Linsanity content was at risk of being drowned out by the high volume of media coverage concentrated in the relatively short Linsanity era. The Linsanity period is defined here as lasting from February 4, 2012 — the day of Lin's breakout game - to May 31, 2012 - approximately when search activity for Lin's name subsided to near pre-Linsanity levels, according to Google Trends. The post-Linsanity period begins June 1, 2012, and ends June 14, 2019 - the date after Lin's NBA championship victory at the conclusion of the 
2018-2019 NBA season. Searching within the Linsanity period returned 365 results, which decreased to 337 after applying a LexisNexis filter that removed duplicates. A search conducted within the post-Linsanity time parameters yielded 315 results, dropping to 268 once filtered for duplicates. In order to maintain a practical scope for my project, I sorted through only the first 100 results of each search as sorted by relevance. At this point, pieces were discarded if they were (a) letters to the editor; (b) book or film reviews; (c) duplicates not captured by the filter; (d) lacking substantive commentary on Jeremy Lin and Asian American identity; or (e) not from U.S.-based publications.

Once the initial corpus of print media was subject to analysis, the findings were used to help select a limited number of non-print texts from the web. Including digital media provides an opportunity to excavate more diverse representations of Lin's racial identity that may be less salient in the mainstream print coverage (Park, 2015). Some web-based Lin commentary was collected via Google Internet search using the same search terms as the print corpus. As with the print corpus, the search procedure for online Lin content was divided into Linsanity and postLinsanity searches. In this case, only the first 10 pages of results for each search were considered. Google search results reflect the popularity of a link as determined by a proprietary algorithm; therefore, the linked articles selected for analysis are ostensibly among the most salient and relevant online media pieces available on the subject of Jeremy Lin and Asian American identity. Another round of sampling was performed using a Google search of the terms Jeremy Lin, Asian American and interview from the start of Linsanity to the end of postLinsanity. This search was performed in order to yield more commentary from Lin himself, whose voice has been left largely unexamined in the academic literature. The first five pages of results were perused for links to interviews with Lin; only transcribed interviews were 
considered for this study. In addition to adhering to the same criteria as the print corpus, all eligible web content — Lin commentary and Lin interviews - needed to come from news, culture, or sports media websites rather than other sources such as personal blogs.

\section{Sample}

The final sample contained a total of 95 texts. 70 of these were newspaper articles, with 49 coming from the "Linsanity" period and 21 coming from the "post-Linsanity" era. 25 pieces of web content were also selected, 10 pieces of commentary from the "Linsanity" era, 11 from the "post-Linsanity" era, and 4 interviews with Lin from across those combined time periods.

\section{Data Analysis}

A quantitative content analysis was used to determine answers to RQ1-RQ6 (see "Research Questions" section). Texts were coded by hand to identify the presence of predetermined categories.

The race of each writer and voice was coded as either Asian American, Black, or Other (i.e., neither Asian American nor Black). A writer is defined here as the author credited in the byline of a given piece, while a voice refers to someone delivering first-person commentary, either the writer themself or someone whose opinion they are directly quoting. These categories are therefore not mutually exclusive; for example, an Asian American writer writing in the firstperson would be counted as an Asian American writer as well as an Asian American voice. All efforts were made to categorize writers and voices based on self-identification, but in many cases identifications were inferred based on biographical and contextual information, (e.g., surname) and sometimes photographs. I readily acknowledge that relying on visual cues for racial identification defers to potentially harmful biological essentialist notions of race. This risks misattributing and erasing the contributions of mixed-race or racially ambiguous people. 
However, I believe this approach can still yield informative results based on the fact that race is constructed not only internally through self-identification, but also socially through ascription (Vargas \& Stainback, 2016). Ambiguous or unknown cases were placed in the Other category. Explicit examples of Blackness within sampled documents were found through keyword searches of the terms Black and African American. Texts that contained either of these terms in reference to race or ethnicity (there are obviously many alternative contexts for the word black) were coded as explicitly mentioning Blackness. However, as stated previously, one of the goals of this study is to also reveal Blackness when it is more implicit. For the purposes of the content analysis, this was operationalized as instances in which Lin was compared to or commented on by Black/African American people.

Four themes of Asianness were also coded for, derived from Tierney's (2006) themes of whiteness. They are: (a) the supraethnic viability of Asianness; (b) the necessary defeat of Blackness; (c) the disallowance of anti-Asian sentiment; and (d) the presence of a helpful Black cohort. For the purposes of the present study, the supraethnic viability of Asianness was activated whenever Lin's ability to successfully perform Blackness was affirmed, such as his ability to play basketball or wear dreadlocks. However, this theme was only coded for when the possibility that Lin's abilities were representative of all Asian Americans remained open. Instances in which Lin was singled out as anomalous among Asian Americans were thus disqualified. The necessary defeat of Blackness occurred when Lin was described as having defeated a Black opponent, often in terms of scoring more points or winning a game. The disallowance of anti-Asian sentiment was marked by the meting out of punishment or strong criticism against those who displayed hostility to Lin based on his race. Lastly, the presence of a helpful Black cohort was characterized by featuring Black people who offered their support to 
Lin, often in defending him against race-based hostility. Correlations between the race of writers/voices, temporal context, topics, and themes were noted when present, but no attempt was made to perform inferential statistical analyses due to the non-random sampling method, which would make this step inappropriate.

The second analytical step taken in the present research was CDA, which was used to address RQ7-RQ9 (see "Research Questions" section). An open, iterative coding technique was used to generate frames via repeated readings of the texts and note-taking. I paid particular attention to the identities of voices, differences in phrasing, and contextual information. Unfortunately, since I was the sole researcher undertaking this study, it was not possible to establish intercoder reliability, a desirable step when manually coding (Chong \& Druckman, 2007). This poses a problem, given that how we engage in research is profoundly shaped by our lived experiences, multiple identities, and proximities to power (Sultana, 2007). I therefore want to reflexively acknowledge that my approach to the topic of Jeremy Lin's mediated Asian American identity is enriched and limited by my own perspectives as a mixed-race, whitepassing Chinese Canadian cishet man. Still, it must be said that "naming subject positionings does not address the question of how these subject positionings affect knowledge construction" (Doucet \& Mauthner, 2006, p. 42). While I want to avoid falling into the trap of shifting the focus of my research to myself (Doucet \& Mauthner, 2006), I will admit my interest in the subject at hand is largely derived from a combination of my basketball fandom and my affinity for fellow members of the Asian diaspora. While this has in the past biased me in favour of Lin, I believe the criticisms that I level against Lin in my analysis are evidence of the limits of kinship. That being said, my position as an insider is complicated by my mixed-race heritage and whitepassing privilege. These factors shield me from a great deal of anti-Asian racism, which perhaps 
makes it more difficult for me to fully empathize with Lin and what he means to other Asian men. 


\section{Findings}

My findings are broken down into two parts: quantitative content analysis and critical discourse analysis (CDA). The content analysis revealed that Asian Americans were the most frequently heard voices in the sample_-particularly post-Linsanity_-but that Other writers were responsible for producing a majority of the content. Conversely, Black voices and writers were underrepresented. Yet despite the exclusion of Black people from generating discourse, Blackness was a ubiquitous topic in media coverage of Jeremy Lin. In addition, the content analysis demonstrated that the supraethnic viability of Asianness was a common theme in Linsanity media coverage, while the disallowance of anti-Asian sentiment was more favoured post-Linsanity, at least among Asian American writers. The CDA found that the topics of Asianness and Blackness were placed in relation to one another through a series of racially magnetized stereotypes. These stereotypes formed the frames within which discourse on Lin took place, highlighting his proximity to Blackness as a means of subverting stereotypes, or his Asianness as evidence of his inability to escape them. Furthermore, these frames informed how the audience is intended to decode themes of Asianness that are common markers of cultural appropriation. As a point of reference, Table 1 displays the various topics, themes, and frames explored in my study. 
Table 1

Analytical Concepts Organized According to Campbell \& Wiggins (2015) Typology

\begin{tabular}{lcc}
\hline Topic & Themes & Frames \\
\hline Blackness & Supraethnic viability of Asianness & Asian Americans as model minorities \\
& Necessary defeat of Blackness & Asian American men as emasculated \\
& Disallowance of anti-Asian Sentiment & Asian Americans as invisible \\
& Presence of helpful Black cohort & Asian Americans as forever foreign \\
& Asian and Black Americans as \\
& & enemies \\
\hline
\end{tabular}

Note: See "Methodology" section for a more detailed explanation of these concepts.

\section{Quantitative Content Analysis}

The quantitative content analysis provides an overview of the statistical profile of the sample. I first compare the relative prevalence of writers and voices across race and time period.

Following this, I present the frequencies with which selected topics and themes (see Table 1) appear in relation to time period and race of the writer deploying them.

\section{Voices and writers.}

Table 2 displays a breakdown by race and time period of the voices and writers featured in the sampled texts. Asian American voices were featured most frequently overall (85.2\%), followed by Other voices $(42.1 \%)$, and Black voices $(31.6 \%)$. These differences are especially stark in the post-Linsanity sample, with nearly all (94.4\%) articles featuring at least one Asian American voice, while less than a quarter $(22.2 \%)$ featured Black commentary. While the prevalence of Asian American voices is to be expected in light of the emphasis placed on Lin's race, the relative dearth of Black viewpoints is more surprising given the racial makeup of the NBA. Table 2 also shows that the majority of sampled texts (64.2\%) were authored by Other writers. Very few Black writers appeared in the sample overall (5.3\%), and they were conspicuously 
absent from post-Linsanity coverage altogether. In contrast to their overwhelming presence as voices, Asian Americans were likewise only modestly represented as writers (30.5\%). However, as with Asian American voices, the proportion of Asian American writers in the sample also increases post-Linsanity, from $25.4 \%$ to $38.9 \%$.

Table 2

Race of Writers and Voices in Jeremy Lin Media Coverage

\begin{tabular}{lcccc}
\hline Race & Linsanity & Post-Linsanity & \% Difference & Total \\
\hline Asian American & & & & \\
$\quad$ Voices & $47(79.7 \%)$ & $34(94.4 \%)$ & +14.7 & $81(85.2 \%)$ \\
Writers & $15(25.4 \%)$ & $14(38.9 \%)$ & +13.5 & $29(30.5 \%)$ \\
$\quad \%$ Difference & -54.3 & -55.5 & & -54.7 \\
Black & & & & \\
$\quad$ Voices & $21(35.6 \%)$ & $8(22.2 \%)$ & -13.4 & $29(30.5 \%)$ \\
Writers & $5(8.5 \%)$ & $0(0.0 \%)$ & -8.5 & $5(5.3 \%)$ \\
$\%$ Difference & -27.1 & -22.2 & & -25.2 \\
Other & & & & \\
$\quad$ Voices & $26(44.1 \%)$ & $14(38.9 \%)$ & -5.2 & $40(42.1 \%)$ \\
$\quad$ Writers & $39(66.1 \%)$ & $22(61.1 \%)$ & -5.0 & $61(64.2 \%)$ \\
$\quad \%$ Difference & +22.0 & +22.2 & & +22.1 \\
\hline
\end{tabular}

Note: One text included in the sample did not provide an author name; for the purposes of analysis, their race was coded as Other.

While I want to caution against drawing any definitive conclusions from the results of this limited sample, they do open up some intriguing lines of inquiry which deserve to be highlighted. For one, how might we interpret the fact that non-Asian, non-Black writers are responsible for generating most of the media coverage regarding Jeremy Lin? The easy answer is purely demographic: Most people in the United States are not Asian nor Black; therefore, we would expect the demographics of content creators to reflect this. However, as has already been indicated, this racial pattern is not reflected in the quoted voices, where Asian Americans hold a 
strong advantage. In fact, of the three racial categories, the "other" category is the only one in which writers actually outnumber voices $(+22.1 \%)$. Since most of the "other" writers are white, this perhaps speaks to ability of whiteness to maintain control over the shaping of discourse - as content creators - while remaining hidden by adopting an ostensibly neutral position. Asian American and Black voices may be solicited and included, but it is ultimately the writer who is afforded the privilege of sculpting a narrative out of that raw material. At the same time, white writers can be absolved of responsibility for how their message is decoded by claiming to be merely the (unbiased) messenger. This dynamic recalls Nakayama and Krizek's (1995) strategic rhetoric framework, which contends that the invisibility of whiteness is in large part the driving force behind its power because it allows whiteness to go uninterrogated. This invisibility is in turn a consequence of normative rhetorics that strategically maintain the universalized position of whiteness. Thus, while it may be true that Asian Americans have received ample opportunities to voice their opinion on Jeremy Lin's significance, more often than not their opinions are being covertly filtered through white sensibilities.

Another noteworthy observation is that the proportion of voices and writers from both the Black and Other racial categories decreases in the post-Linsanity era, while Asian American representation in these two categories experiences a marked upward trend (voices $+14.7 \%$, writers $+13.5 \%$ ). It seems that in the post-Linsanity era, publications relied on Asian American voices to reflect on his past glory, or argue for his continued relevance. This may speak to the lasting impact that Lin has had on Asian Americans, even after the intense scrutiny of Linsanity had passed and other racial groups shifted their attention elsewhere. 


\section{Topics and themes.}

As seen in Table 3, the content analysis revealed that a large majority of the sampled items (89.5\%) contain references to Blackness, either through explicit use of the terms Black or African American, or by making reference to specific Black people, such as through direct quotes or comparisons. Table 4 shows that the prevalence of Blackness was consistently high for every racial and time category (>78\%), although it is slightly less widespread post-Linsanity compared to during Linsanity $(-14.4 \%)$. The ubiquity of Blackness as a topic in media coverage about Lin is evidence of the close association between Blackness and basketball. However, it also brings into even starker relief the previously noted lack of Black voices, and especially Black writers, being asked to produce discourse on Lin in popular media. Clearly, then, discourse on Lin frequently invokes Blackness, but rarely in a way that allows actual Black people to shape it in a meaningful way. How Blackness is deployed in media coverage of Jeremy Lin will be explored more in-depth in the CDA.

Table 3

Topics and Themes Over Time in Jeremy Lin Media Coverage

\begin{tabular}{lcccc}
\hline Factor & Linsanity & Post-Linsanity & $\%$ Difference & Total \\
\hline $\begin{array}{l}\text { Topic } \\
\quad \text { Blackness }\end{array}$ & $56(94.9 \%)$ & $29(80.6 \%)$ & $-14.4 \%$ & $85(89.5 \%)$ \\
$\begin{array}{l}\text { Themes } \\
\quad \begin{array}{l}\text { Supraethnic viability } \\
\text { of Asianness }\end{array}\end{array}$ & $50(84.7 \%)$ & $16(44.4 \%)$ & $-40.3 \%$ & $66(69.5 \%)$ \\
$\quad \begin{array}{l}\text { Necessary defeat of } \\
\text { Blackness }\end{array}$ & $26(44.1 \%)$ & $10(27.8 \%)$ & $-16.3 \%$ & $36(37.9 \%)$ \\
$\begin{array}{l}\text { Disallowance of anti- } \\
\text { Asian sentiment }\end{array}$ & $25(42.4 \%)$ & $20(55.6 \%)$ & $13.2 \%$ & $45(47.4 \%)$ \\
$\quad \begin{array}{l}\text { Presence of helpful } \\
\text { Black cohort }\end{array}$ & $22(37.3 \%)$ & $6(16.7 \%)$ & $-20.6 \%$ & $28(29.5 \%)$ \\
\hline
\end{tabular}


Turning now to the themes of Asianness, Table 3 shows that the presence of a helpful Black cohort was consistently the most infrequently featured theme (29.5\%), while the supraethnic viability of Asianness was the most popular theme overall (69.5\%) and the only one present in more than half the sample. However, this theme experiences a sharp decline in popularity post-Linsanity $(-40.3 \%)$. This decline is steep enough to allow the disallowance of anti-Asian sentiment to overtake it as the most common post-Linsanity theme (55.6\%). Sorting the themes by race helps clarify what is producing these inconsistencies. Table 4 reveals that the supraethnic viability of Asianness remains the most common theme expressed by writers regardless of race, and falls out of favour post-Linsanity for both Asian American and Other writers (see Table 4 note for Black writers). However, Asian American writers also deployed the disallowance of anti-Asian sentiment at nearly the same rate overall (62.1\%) as the supraethnic viability of Asianness (65.5\%). Moreover, Table 4 shows that among Asian American writers, the disallowance of anti-Asian sentiment jumps from $46.7 \%$ during Linsanity to $78.6 \%$ postLinsanity. This substantial increase helps drive the overall popularity of this theme among Asian American writers, and also explains its prominence as the most common post-Linsanity theme in the sample overall.

Regarding the theme of the necessary defeat of Blackness, it is notable for doubling in popularity among Asian American writers from Linsanity (20.0\%) to post-Linsanity (42.9\%). This result is all the more striking given that the opposite pattern is seen among writers in the Other racial category, who feature this theme substantially less in post-Linsanity $(18.2 \%)$ compared to Linsanity (48.7\%) coverage. Revealing this complex pattern is only made possible by analyzing the themes across the dimensions of both time and race. Possible factors underlying 
this and the other variances described above are probed further in the CDA, which comprises the next section.

Table 4

Topics and Themes by Race of Writer

\begin{tabular}{|c|c|c|c|c|c|c|}
\hline \multirow[b]{2}{*}{ Factor } & \multicolumn{3}{|c|}{ Asian American } & \multicolumn{3}{|c|}{ Other } \\
\hline & Linsanity & Post-Linsanity & Total & Linsanity & Post-Linsanity & Total \\
\hline \multicolumn{7}{|l|}{ Topic } \\
\hline Blackness & $\begin{array}{c}13 \\
(86.7 \%)\end{array}$ & $\begin{array}{c}11 \\
(78.6 \%)\end{array}$ & $\begin{array}{c}24 \\
(82.8 \%)\end{array}$ & $\begin{array}{c}38 \\
(97.4 \%)\end{array}$ & $\begin{array}{c}18 \\
(81.8 \%)\end{array}$ & $\begin{array}{c}56 \\
(91.8 \%)\end{array}$ \\
\hline \multicolumn{7}{|l|}{ Themes } \\
\hline $\begin{array}{l}\text { Supraethnic } \\
\text { viability of } \\
\text { Asianness }\end{array}$ & $\begin{array}{c}14 \\
(93.3 \%)\end{array}$ & $\begin{array}{c}5 \\
(35.7 \%)\end{array}$ & $\begin{array}{c}19 \\
(65.5 \%)\end{array}$ & $\begin{array}{c}32 \\
(82.1 \%)\end{array}$ & $\begin{array}{c}11 \\
(50.0 \%)\end{array}$ & $\begin{array}{c}43 \\
(70.5 \%)\end{array}$ \\
\hline $\begin{array}{l}\text { Necessary } \\
\text { defeat of } \\
\text { Blackness }\end{array}$ & $\begin{array}{c}3 \\
(20.0 \%)\end{array}$ & $\begin{array}{c}6 \\
(42.9 \%)\end{array}$ & $\begin{array}{c}9 \\
(31.0 \%)\end{array}$ & $\begin{array}{c}19 \\
(48.7 \%)\end{array}$ & $\begin{array}{c}4 \\
(18.2 \%)\end{array}$ & $\begin{array}{c}23 \\
(37.7 \%)\end{array}$ \\
\hline $\begin{array}{l}\text { Disallowance } \\
\text { of anti-Asian } \\
\text { sentiment }\end{array}$ & $\begin{array}{c}7 \\
(46.7 \%)\end{array}$ & $\begin{array}{c}11 \\
(78.6 \%)\end{array}$ & $\begin{array}{c}18 \\
(62.1 \%)\end{array}$ & $\begin{array}{c}14 \\
(35.9 \%)\end{array}$ & $\begin{array}{c}9 \\
(40.9 \%)\end{array}$ & $\begin{array}{c}23 \\
(37.7 \%)\end{array}$ \\
\hline $\begin{array}{l}\text { Presence of } \\
\text { helpful Black } \\
\text { cohort }\end{array}$ & $\begin{array}{c}5 \\
(33.3 \%)\end{array}$ & $\begin{array}{c}1 \\
(7.1 \%)\end{array}$ & $\begin{array}{c}6 \\
(20.7 \%)\end{array}$ & $\begin{array}{c}13 \\
(33.3 \%)\end{array}$ & $\begin{array}{c}5 \\
(22.7 \%)\end{array}$ & $\begin{array}{c}18 \\
(29.5 \%)\end{array}$ \\
\hline
\end{tabular}

Note: Black writers were not included in the main table because their poor representation in the sample (5 writers total, 0 post-Linsanity) did not justify their inclusion for comparative purposes. The topic of blackness was featured in all 5 Black-authored pieces $(100.0 \%)$ while each of the themes were included by 4 of the 5 writers (80.0\%).

\section{Critical Discourse Analysis}

The following critical discourse analysis (CDA) examines how themes of Asianness are manifested in media coverage of Jeremy Lin, while also identifying and unpacking the frames that shape interpretations of these themes. I maintain a focus throughout on how Blackness is deployed in the service of reinforcing these themes and frames. My analysis begins with a close 
reading of four anti-Black themes of Asianness manifested in the sampled media coverage (see Table 1). The second part of the CDA focuses on the frames used by popular media to situate Lin in relation to his Asian American identity, Blackness, and the themes described above. I find that these frames emerge from a central frame of racial magnetism, which posits Asian and Black racialization as co-constitutive across multiple, polarized dimensions (see "Relative Racialization" in "Theoretical Concepts" section).

\section{Themes of Asianness.}

For this analysis, I adopted Tierney's (2006) strategic rhetoric of whiteness framework (see Strategic Rhetoric of Whiteness section of Theoretical Concepts for more detail) to generate four themes of Asianness that centre Asian American interests in media coverage of Jeremy Lin. These themes are: (a) the supraethnic viability of Asianness; (b) the necessary defeat of Blackness; (c) the disallowance of anti-Asian sentiment; and (d) the presence of a helpful Black cohort. In the following sections, I define each theme more precisely and how it manifests in the sampled texts, particularly in relation to Blackness.

\section{Supraethnic viability of Asianness.}

In Tierney's (2006) original model, the supraethnic viability of whiteness describes how white film characters are often portrayed as "face[ing] ethnically based doubt, dismissal, or rejection ... and yet ... achieve[ing] exemplary skill” (p. 610). Media coverage of Lin reflected a similar sentiment, but reinscribed onto Asianness rather than whiteness. In other words, many writers positioned Lin's success as proof that "an Asian-American can play alongside -- and beat -- the best in the NBA" (Yu, 2012), a league "whose players are predominantly African American" (Reid, 2012). Key to this theme is how Lin is interpreted as standing in for all Asian Americans; his success is something all Asian Americans can aspire and relate to, not merely a singular 
occurrence achieved by an anomalous athlete. One Asian American voice touted Lin for "show[ing] ... [that] [a] lot of Chinese-Americans, Chinese period, can play basketball very well" (Lee, 2017). Another piece reminds the reader that Asian American athletic success should not come as a shock "considering the popularity of basketball in Asia and the deep tradition of Asian basketball leagues across this country" (Robbins, 2016, p. A18). In both pieces there is an effort to tie Lin's recent rise to deeper basketball traditions that demonstrate a widespread and long-standing affinity for basketball among Asian Americans.

Lin's ability to stand in for Asian Americans is frequently contrasted with the impact of Yao Ming, who became the first basketball player of Asian descent to achieve NBA superstardom before injuries prematurely ended his career. While Yao was widely celebrated among Chinese nationals and the Asian diaspora alike, his gargantuan size at 2.29 metres tall made him an aberrant and thus unsuitable representative of Asian athletic ability. Many Asian American voices thus expressed their admiration for, but lack of personal affinity to, Yao for this reason. His alien proportions made him seem not "like a normal human being" (Brown \& Pavlovic, 2012). Lin, by contrast, "looks more like an everyman" (Serby, 2012b) who shows that, as one Asian American voice put it, "an average guy can do it, too" (Brown \& Pavlovic, 2012).

For some, Lin's ability to represent the "everyman" allows him to blend in on the court. In this sense, it is his ability to be an unexceptional, team-oriented player that truly marks his full integration into the NBA. At the height of Linsanity, sports journalist Howard Beck (2012a) asserted that "Lin has cemented himself as a credible N.B.A. player, not a novelty act" (p. A1). Tim Kawakami (2012) likewise maintained that "[ $\mathrm{t}]$ he beauty of Jeremy Lin isn't his race; it's that he looks as if he belongs" and "the greatness of this is the incidentalness of his race". After 
Lin's move to the Houston Rockets, Lin was praised in a piece titled "From phenom to player" for "assimilat[ing] into the league's youngest team" and "establish[ing] a pick-and-roll and driveand-kick rhythm with James Harden" (Longman, 2013, p. D1), the team's star. Here, Lin's ability to establish himself as a legitimate NBA player is tied to his capacity to harmoniously coexist with Black teammates. Collectively, these statements reflect a belief that Lin has transcended his race to go from standing out as a novelty to fitting in as just another NBA athlete.

However, despite some writers and voices downplaying the significance of Lin's race, a much more common response was a singular fixation on it. Lin's rise was labelled as "surprising", "unexpected", and "improbable". While this was true for a number of reasons, such as his Harvard pedigree and sparse playing time prior to his remarkable run, Pablo Torre emphasized that "[t]he beating heart of the story, no matter what anybody says, is the fact that [Lin] is Asian-American" (Carr, 21012, p. B1). Former NBA star and current TV analyst Walt Frazier made the connection between Lin's race and the surprise it entailed when he declared that "[t]his league is dominated by African Americans. What are the odds of an Asian guy coming on and having this impact? It's amazing. It's inexplicable" (Zillgitt, p. 1A). Indeed, the sheer intensity of media scrutiny of Lin's story suggests that there was something particularly unsettling about the idea of an Asian American basketball star (Park, 2015).

This points to a key area in which Lin's story departs from Tierney's (2006) theme of the supraethnic viability of whiteness, namely that "there is nothing ethnically salient or even incongruous about a White person learning and mastering" an ethnically atypical skill (Tierney, 2006, p. 610). In other words, while white people are expected to cross racial and ethnic boundaries with ease, Lin's cross-racial success is considered incomprehensible. This speaks to 
the centreing of whiteness and freedom of movement granted to the white imagination in dominant discourse. As revealed by the content analysis portion of the present study, white writers appear to be shaping much of the discourse around Lin. It makes sense then that they might struggle to make Lin's star turn legible to a white audience, which is used to having a white protagonist through which to live vicariously. Lin's racial otherness disrupts this impulse. Moreover, this disruption is further intensified by racial magnetism's positioning of Asianness and Blackness as opposites, such that the "racial distance" Lin needs to travel to reach Blackness is considered impossible. On the other hand, Lin's positioning opposite to Blackness implicitly raises the possibility of white supraethnic movement. Thus, while his proximity to Blackness seems improbable, it is also alluring because it makes Blackness feel even more attainable for the white centre of the racial magnet.

Clearly, then, media coverage of Lin has been ambivalent about the supraethnic viability of his Asianness. As discussed in the content analysis, the degree to which writers upheld this theme was often drawn along racial and temporal lines. More specifically, the supraethnic viability of Asianness was most frequently adopted by Asian Americans writing during the Linsanity period. This supports McElroy’s (2014) finding that “Asian American male commentators took pride in [Lin]'s assertive, in-your-face play, turning the tide of the image of the meek Asian male” (p. 2014). In other words, Asian American men celebrated Lin's ability to subvert racial stereotypes by successfully performing Black masculinity. Post-Linsanity coverage, on the other hand, was often wary, or even pessimistic, about Lin's ability to signal the supraethnic viability of Asianness. The results of the content analysis reflected this doubt thorugh a sharp decline of this theme, especially among Asian Americans. As his career has progressed, Lin has faced questions about his ability to be a team player and fit into a system. 
This stands in stark contrast to earlier characterizations of Lin as the ultimate teammate. Raising doubts about Lin's ability to play with now-retired superstar Kobe Bryant, one writer called attention to the fact that "Lin's style did not mesh well in Houston alongside another shooting star, the Rockets' James Harden" (Frazier, 2014). This of course completely contradicts the earlier narratives that praised Lin and Harden's on-court chemistry. Another writer spoke of "sensationalized drama between Lin and Kobe" that "was just like Lin and Carmelo Anthony on the Knicks. Another superstar, another conflict" (Gu, 2017). Far from fitting in, it seemed that Lin was beginning to stick out for all the wrong reasons, mainly that perhaps he was not good enough to play NBA basketball at a high level after all.

However, Lin's post-Linsanity cross-racial activities appeared to be more readily accepted as evidence of his supraethnic viability when they took place outside of basketball. When Lin decided to get dreadlocks in 2017 , his right to wear them was rarely questioned on the basis of his ethnicity, despite an acknowledgement that it could be construed as cultural appropriation. When it was questioned by Black former NBA player Kenyon Martin, he was dismissed and disparaged for suggesting that Lin was trying to be Black.

Disagreement with Martin's accusations of cultural appropriation was expressed in multiple, sometimes contradictory ways. At times, Martin was refuted by denying the political significance of hair altogether, while in other instances, it was precisely Lin's respectful understanding of the political significance of Black hair that supposedly made Lin a cultural "appreciator" rather than "appropriator". One piece marveled at how "something as simple as what sits atop [Lin's] head became something else entirely" (Bonesteel, 2017). Dismissing Lin's hair choice as a "simple" matter of personal style signaled that discussions about hair should not be taken seriously, a move that devalues the deep cultural and political significance of Black 
hairstyles. At other times, it was Lin's ability to "appreciate" dreadlocks and their ties to Black culture that permitted him access to their aesthetic appeal. The process of getting them was emphasized as "no whim" (Bonesteel, 2017), positioning Lin as an expert on dreadlocks whose thoughtfulness and dedication to the subject earned him the right to wear them.

It is curious, then, that Lin fails to even once expound upon his understanding of the historical origins and continued significance of "natural" Black hairstyles, particularly dreadlocks. While dreadlocks have historical roots in many cultures across the globe, their current entrenchment in the popular imagination of the West is due largely to the Rastafari movement (Dash, 2006), an Afrocentric religion founded in Jamaica. Dreadlocks form a "sacred and inalienable part of [a Rastafari's] identity" (Chevannes, 1994, p. 145) as a visual profession of faith. The name may be derived from observations made by white people about the hair of newly landed Black slaves, whose hair was described as "dreadful" after months of cramped sea travel (Dash, 2006). For Rastafari, dreadlocks are therefore a symbolic refusal of dominant (i.e., Western) social norms. This symbolism has turned them into a political tool for resisting white oppression and "celebrati[ng] ... a renaissance in black pride, black physiologies and culture" (Dash, 2006, p. 31). Lin carries the weight of all this symbolism on his head, yet does not take responsibility for it, failing to even acknowledge the cultural history from which he is borrowing.

\section{Necessary defeat of Blackness.}

In the necessary defeat of Blackness theme, the Blackness of Lin's adversaries both on and off the court serves to establish and authenticate his mastery of basketball and Black culture. Vanquishing non-Black opponents, while impressive, does not carry the same symbolic weight due to the close association of basketball with Blackness. As presumed native practitioners of and experts in basketball, Black people act as gatekeepers, setting the standards that Lin is 
required to meet if he is to establish dominance. Therefore, Lin beating Black people at their own game, so to speak, symbolically indicates his cross-racial superiority.

The clearest example of this theme is when Lin directly defeats his Black opponents in athletic competition. The most frequently invoked opponent in this iteration of the theme was Kobe Bryant. In arguably his most signature Linsanity performance, Lin scored a career high 38 points and led his team to victory over Bryant and his Los Angeles Lakers squad. This performance is frequently mentioned in descriptions of Lin's exploits as a shorthand reference to his greatness, with some Asian American fans expressing glee that "[h]e outscored Kobe!" (Dolnick, 2012, p. D1). Several factors made Lin's defeated opponent particularly noteworthy. As one of the biggest names in the NBA, Bryant continued the tradition of Black dominance in basketball, often drawing comparisons to his predecessor and idol, Michael Jordan. Bryant himself is considered by many to be one of the greatest players in the history of the game, known particularly for his scoring prowess and competitive nature. Less than two seasons removed from winning his fifth NBA championship, Bryant would end the year as the league's second most prolific scorer, with his team posting a strong record. Bryant is also known for having a massive following in China, meaning his face and exploits would have been very familiar to many Asians and Asian Americans. For Lin to outduel Bryant, both from an individual perspective in terms of points scored, and a team perspective in terms of winning the game, was therefore the ultimate marker of excellence.

Another Black player Lin is frequently portrayed as defeating is John Wall. Wall and Lin both play the point guard position, entered the league in the same year, are similar in height and weight, and posted similarly excellent agility test times at the NBA Draft Combine. Yet Wall was the only one touted for his once-in-a-generation speed and athleticism, which made him the 
number one overall pick in the same year that Lin went undrafted. NBA teams began to take Lin seriously when he held his own against Wall in a pre-season summer league game in front of numerous scouts and team executives. Their careers have thus been inextricably linked and compared to one another from their earliest days as professionals. One of Lin's Linsanity games happened to come against Wall and the Washington Wizards, and Lin once again led his team to victory while outperforming Wall and even "victimiz[ing]" him on one play with a "crossover leading to a soaring dunk" (Washington, 2012). Lin's triumph over Wall served as poetic justice for the unfair double standard that left him always in Wall's shadow, and proved that Lin could beat the most highly acclaimed Black athletes in their own domain.

One piece is particularly noteworthy for its unique rhetorical use of the necessary defeat of Blackness. Journalist Jesse Washington (2012), asking Asian American cultural critic Phil Yu to relay his favourite Linsanity moment, mused whether it might be the Bryant or Wall games. He then proceeds to tell the reader that "instead, Yu cherishes seeing a picture of two white fans wearing Lin's No. 17 Knicks jersey” (Washington, 2012). Though Lin's defeat of Bryant and Wall are ostensibly dismissed, their inclusion rhetorically serves to remind the reader of Black defeat. Juxtaposed against the image of white celebration, this has the effect of directly tying the defeat of Blackness as a path to the reception of white validation. As in the supraethnic viability of whiteness, this is yet another example of how these themes, while privileging Asianness over Blackness, still centre whiteness.

In other cases, the theme of the necessary defeat of Blackness was deployed more implicitly. In these cases, Lin was compared favourably to a number of prominent Black players, demonstrating that he had supplanted them as the new gold standard in basketball. One Asian American writer relayed that his "son used to be Kobe Bryant. But lately when we play hoops, 
he's Jeremy Lin" (Youn, 2012, p. 13A). Another Asian American youth asserted that "[o]nce Jeremy becomes better and proves himself more, he'll probably surpass Chris Paul pretty easily as my favorite" (Ding, 2012). In this case, the fan takes a more measured approach to his Lin fandom, indicating that he still has work to do in order to truly establish his dominance. Yet the result is still treated as inevitable: It is only a matter of when, not if Lin will surpass the esteem granted to a premier player like Paul. Lin even garnered some comparisons to Michael Jordan, arguably the most influential basketball player, and perhaps athlete, of all time. Asian American journalist Théoden Janes (2016) speculated that "Lin is revered with a passion that even Michael Jordan may not have been able to relate to in his prime". While this comparison does not directly compare Lin's and Jordan's athletic abilities, it does entertain the notion that Lin might be able to outcompete Jordan as an object of fandom. Given the unmatched branding power that Jordan has to this day, this comparison implies Lin's mastery over the total basketball ecosystem.

Moving away from basketball, Lin has been pitted against Black opponents in other aspects of Black culture. In Lin's dreadlock controversy with Kenyon Martin, their debate turned into a competition over who is better able to appropriate the other's culture. In response to Martin's criticism of his dreadlocks, Lin pointed out that Martin has Chinese characters tattooed on his body, which was constructed as a "gotcha" moment for Lin that exposed Martin's hypocrisy. Adding to this effect were previous comments made by Martin, who once implied that Yao Ming did not understand Chinese when Yao offered a different interpretation of what Martin's tattooed characters actually mean (Lewis, 2017). The dedication to learning about and respecting Black culture that Lin displayed were thus contrasted with Martin's ignorance and disrespect of Chinese people and culture. Yet, as Jessica Prois and Lilly Workneh (2017) point out, the comparison between Lin's hair and Martin's tattoos is a false equivalency. Martin's 
tattoos are certainly problematic for promoting exoticizing, Orientalist tropes, but contemporary Asian Americans do not face the same kind of structural and material harm for using their languages as Black Americans do for simply wearing their hair in a way that offends Eurocentric sensibilities. Moreover, Tseng-Putterman (2017b) observes that "Lin's dreads won't make him [a] target of the aggressive black man trope being used to bash Martin's critique", illustrating the privileges that Lin's racial identity affords him.

Nevertheless, Lin's victory over Martin in this “appropriation battle” was framed as Lin having conquered the divisive and exclusionary rhetoric of Blackness, and thus earning him the right to wear dreadlocks. Moreover, the conversations that emerged around Lin and Martin's dialogue were taken by media coverage as evidence that Lin's dreadlocks really did accomplish what Lin had hoped for: intercultural dialogue and mutual understanding. When Martin eventually offered a half-hearted apology for questioning Lin's hairstyle (Bonesteel, 2017), the narrative was brought full-circle. Lin's dreadlocks had successfully initiated a conversation with a Black man that supposedly ended with the Black man humbled and apologetic, an outcome which was construed as a heartwarming tale of intercultural diplomacy. Put another way, Martin's Blackness in defeat served Lin's Asian self-actualization.

\section{Disallowance of anti-Asian sentiment.}

In the sampled media coverage of Jeremy Lin, perceived anti-Asian sentiment is almost always strongly rebuked. ESPN was responsible for arguably the most infamous incident involving antiAsian sentiment against Lin when one of its editors used an anti-Chinese racial slur in a headline entitled " $\mathrm{C}^{* *}$ nk in the armor". Other targets for criticism included Ben \& Jerry's-who were accused of essentializing Asian culture by releasing a fortune cookie flavoured frozen yogurt to 
“honour” Lin (Cepeda, 2012) — and Lin's former college opponents and spectators—who Lin claimed regularly hurled racist verbal abuse his way (Cepeda, 2017).

Disallowing the instances of anti-Asian hostility outlined above certainly seems to serve a positive, antiracist purpose. However, when it comes to criticism coming from Black people, the moral high ground becomes a little murkier. The politics of appropriation come into play, in which Lin's ability to move through Black spaces is uncritically defended. Race-based hostility toward Lin serves as a last defense mechanism of exclusion, questioning Lin's right to reap the privileges of basketball and other modes of culture coded as Black. However, the myth of the meritocracy of sport, and American society more broadly, makes opposing Lin's participation in Black activities seem like an affront to everyone's—including white people's — entitlement to "sample difference" (Tierney, 2006, p. 616). Punishing Black hostility toward Asian Americans may therefore overlook legitimate concerns of anti-Blackness.

While I have already discussed Lin's game against Kobe Bryant in regards to how it invoked the necessary defeat of Blackness, that game also served to illustrate the disallowance of hostility against Asians. In this case, Bryant's defeat at the hands of Lin served as punishment for dismissively claiming that he did not know who Lin was in a pregame interview. In response, one Asian American fan boasted that "38 amazing points later Kobe'll never forget Jeremy Lin" (Hamill, 2012, p. 32). Bryant was thus disciplined through public ridicule for daring to slight Lin.

In one of the more high-profile examples of Black hostility directed at Lin's Asianness, African American sports writer and media personality Jason Whitlock received widespread disapproval for a "crass", "derogatory", and "insulting" tweet he posted that invoked a stereotype about Asian penis size. While it is tempting to disregard this tweet as an intentionally 
inflammatory, racist joke, the context surrounding it reveals that it can also be read as an attempt by Whitlock to deny Lin access to aspects of hegemonic masculinity imparted through basketball. Whitlock's crude joke came on the heels of Lin's scoring outburst against Kobe Bryant and the Lakers, which had the effect of devaluing and deflecting attention from Lin's stellar performance to focus on an imagined physical inadequacy. As a result of the backlash he received, Whitlock “apologized within days, later writing a column noting some Asians may feel basketball culture is hostile to them" (Deggans, 2012, p. 2B). Notable in this phrasing is the way hostility toward Asians is specifically addressed, suggesting Whitlock is being made to apologize for contributing to a hostile, exclusionary environment. This reflects Tierney's (2006) observation that "the Other is assigned an attractive difference but is not entitled to (or allowed) an exclusive difference" (p. 616). Therefore, while Whitlock's choice of words was justifiably criticized, these criticisms failed to interrogate how anxiety about an Asian American's dominance in a Black field may have been the root cause.

Now-retired boxer Floyd Mayweather Jr. made some of these anxieties more explicit when he tweeted "Jeremy Lin is a good player but all the hype is because he's Asian. Black players do what he does every night and don't get the same praise" (Mayweather, 2012). As with Whitlock's tweet, Mayweather's functions to minimize Lin's accomplishments. Mayweather warns of a double standard that unfairly penalizes Black athletes for their success while overexaggerating the accomplishments of non-Black players. Nearly every piece that referred to Mayweather's tweet appeared to denounce it. Some were critical of its logic, emphasizing that it was obvious that Black NBA players were getting plenty of attention as it was, and that Lin's story was just as much about the other factors that made him an underdog (e.g., Harvard graduate, bench warmer) as his race (Reid, 2012). Others pointed out that ironically, Lin's race 
likely played a significant role in being overlooked his entire career prior to Linsanity (Donnellon, 2012). While some did acknowledge that race played a significant role in Lin's success, the tone aimed at Mayweather was altogether dismissive.

In another example of Black hostility being disallowed, Kenyon Martin was eventually forced to apologize for “attacking” Lin's dreadlocks. His apology emphasized that his comments were not "about race" and that Lin could "rock whatever hairstyle he wanna [sic] rock" (Bonesteel, 2017). These sentiments indicate that Martin's criticism of Lin's dreadlocks may have been construed by some as anti-Asian racism. This line of reasoning conflates the undoubtedly racial nature of calling out cultural appropriation with racist behaviour. Evidently, Martin was apologizing to "colour blind" supporters of Lin who think that the mere mention of race equals racism.

While anti-Asian sentiment was discouraged in coverage of the dreadlock controversy, the same cannot be said of anti-Black sentiment. Martin was reported to have received racial slurs from Lin's supporters, but the only admonishment of this behaviour came from Lin himself, who stated "[t]hat's not what I stand for at all", and that what he really wanted was for "both sides ... to come together" (Bonesteel, 2017). In focusing the attention on Lin's benevolence, Lin's complicity in precipitating the events that led to Martin's reception of racial harassment is erased.

\section{Presence of helpful Black cohort.}

In contrast to the Black people who displayed race-based hostility toward Lin, other Black people supported and defended him. While hostile Black people were consistently vilified, helpful Black people were treated more favourably, and were in fact a highly sought-after commodity when it came to contextualizing Lin in the U.S. racial landscape (McElroy, 2014). 
Film director and die hard Knicks fan Spike Lee was arguably Lin's most high profile and vocal Black supporter. He drew praise for his passionate Twitter campaign to generate a non-racist nickname for Lin, which saw him approve of names like "Stop Asian Profi-Lin" while rejecting more racist offerings (Lee, 2012). He also defended Lin against the previously mentioned double standard accusations leveled by Floyd Mayweather Jr. (Wise, 2012). Lee's position as a Black man gave him a sense of authority because his lack of racial identification with Lin presumably made him more "objective" in his support. His willingness to defend Lin against a fellow Black man similarly validated the criticisms of Mayweather made by members of other racial groups.

Perhaps this sense of objectivity played a role in why media coverage often relied on Black writers to defend Lin against racism. Four of the five Black writers in the sample wrote disapprovingly of Whitlock's and/or Mayweather's anti-Asian tweets. Put another way, $80.0 \%$ of the Black voices presented as unchallenged sources in the sampled texts were tasked with refuting the anti-Asian statements of other Black people. This pattern reveals a clear hierarchy of privilege among the Black voices vying to be heard: Only those loyal to Lin were permitted to speak authoritatively.

In the "supraethnic viability of Asian-ness" section, I mentioned that Lin's inability to mesh with his New York Knicks teammate Carmelo Anthony was sometimes used to question Lin's ability to fit in. Ironically, though, one piece reports that "it was Anthony who pleaded with Knicks coach Mike D'Antoni to insert Lin" into the game that triggered Linsanity (Rohde, 2012, p. 4B). This demonstrates that Black people can serve multiple narrative functions in media coverage of Lin. Yet it also reveals that even seemingly contradictory functions are often still tied to the same project of centreing Asianness through anti-Black themes. 
Perhaps the most illustrative example of a helpful Black cohort comes from Lin's dreadlock controversy. Media coverage pointed out that Lin "consulted with his African American teammates and team staff members" (Bonesteel, 2017) before deciding to get dreadlocks. In his Players' Tribune essay, Lin thanked these Black consultants for "being willing to help [him] talk through such a difficult subject" (Lin, 2017). The complicity of Lin's Black friends served two functions. One, they gave him practical information and even physical objects that help him "master" the art of Black hair. Lin (2017) singled out former teammate Kemba Walker as having once lent him a do-rag to take care of his—at that time — braided hair. He cited conversations with teammates D'Angelo Russell and DeMarre Carroll about “what the process of getting dreads is like — how painful the beginning process is, whether you could still rock a hat, how to maintain them, things like that" (Lin, 2017). However, the second function that Lin's Black friends served might be even more important. Their Blackness positioned them as insiders, and as such, their support of Lin was an especially powerful endorsement. They were presumed to be authorities of their own culture, and to have no ulterior motives in supporting Lin. When teammate Rondae-Hollis Jefferson agreed to get his hair done with Lin, it served as the ultimate seal of approval. By offering their insider knowledge, advice, and — most importantly—approval, Lin's Black teammates and friends legitimated Lin's appropriation of Black culture.

\section{Racially Magnetized Frames.}

The CDA found that the frames used to situate Jeremy Lin in relation to his Asian American identity operate through a series of binaries structured by racial magnetism. I distilled these into five main media frames: (a) Asian Americans as model minorities (and Black Americans as pathologically deviant); (b) Asian American men as emasculated (and Black men as hypermasculine); (c) Asian Americans as invisible (and Black Americans as hypervisible); (d) 
Asian Americans as forever foreign (and Black Americans as cultural insiders); and (e) Asian and Black Americans as enemies. These frames restrict possible readings of Jeremy Lin in relation to his Asian American identity by always interpolating him as either subverting or confirming the race-based expectations associated with these frames. The following section defines each frame and identifies its presence in media coverage of Jeremy Lin, as well as how each one comes to bear on the themes of Asianness discussed in the previous section.

\section{Asian Americans as model minorities.}

The idea that Asian Americans are model minorities is pervasive throughout media coverage of Lin. This stereotype holds that Asian Americans have overcome racial prejudice and found success through their inherently humble, studious, and industrious nature. Many of the voices featured in the sampled texts characterized Lin as "humble" and "smart", and his story as one of quiet perseverance to beat the odds. His Harvard education was frequently mentioned as a biographical detail, a clear symbol of his intelligence and high achievement while also denoting his modest basketball pedigree. It is not insignificant that Lin's alma mater has been at the centre of attention for debates around affirmative action, particularly within the Asian American community (Kang, 2019). While studies have demonstrated that Asian Americans on the whole overwhelmingly support affirmative action, it is true that a large number of conservative Chinese Americans who oppose affirmative action have skewed statistics and commanded the attention of media narratives (Ramakrishnan \& Wong, 2018). It is deeply ironic, then, that Lin was likely accepted into Harvard not solely on academic merit, but rather at least partly as a result of his non-academic basketball skills.

Lin's unusual path to NBA stardom was taken by one Asian American writer as evidence that "[i]f you work hard, you'll achieve great things" (Salaff, 2012, p. A). Many Asian 
Americans found this sentiment inspiring. Comparing the plight of Chicago's Chinatown to Lin's story, one Chinese American believed that "[w]ith time, patience and perseverance ... this community will get the recognition and respect it deserves" (Holland, 2012). The idea that Linand, by analogy, the Asian American community - has faced many obstacles but worked hard to overcome them promotes the notion that defeating racism is a matter of personal work ethic, and thus achievable by anyone who sets their mind to it. This is a key pillar of model minority discourse that supports the supraethnic viability of not only Asianness, but all races_at least in theory. Under the model minority doctrine, Asian Americans' ability to transcend the imagined confines of their race raises the implicit question of why Black people cannot do the same. If everyone theoretically has equal opportunity to transcend race, discrepancies in observable outcomes then become matters of personal or cultural moral failings.

The moral failings of Black athletes were often prominently displayed in media coverage of Lin, acting as a foil that brought his model minority characteristics into sharper relief. Lin himself has been complicit in espousing this rhetoric. Questioning why his career has elicited such varied opinions, Lin complained that unlike "Michael Vick with the dogs, or Tom Brady with the cheating scandals, or other NBA players with criminal records," he "[has]n't done anything to be a polarizing figure" (Janes, 2016). Intentionally or not, Lin's statement links sport to deviance and invites a reading of this link through the lens of race. The juxtaposition between the Black Vick and white Brady is particularly striking given the disparate effects of their transgressions on their respective careers and reputations. Since serving a four-game suspension for his involvement in a ball-tampering scandal, Brady has won multiple Super Bowl championships and garnered consideration as the greatest football player of all time. In contrast, Vick served 18 months in prison for operating a dog-fighting ring and has continued to receive 
calls for even harsher punishment, particularly from white people (Piquero et al., 2011). Thus, while Lin's mention of Brady merely conjures up a half-forgotten footnote to a hero's story, his invocation of Vick and NBA players - who are predominantly Black-evokes stereotypical associations between Blackness and criminality.

Often it was Lin's own Black teammates whose moral character was called into question, cementing his status as the model minority in the dynamic. Lin's hot streak was galvanized by receiving an opportunity to play due to a multitude of teammates suffering from injuries.

Notably, the team's two ostensible stars, Carmelo Anthony and Amar'e Stoudemire, were absent for most of Linsanity. The team's poor record prior to their injuries suggested that "they weren't getting enough from Anthony and Stoudemire" (Reid, 2012), and called into question their leadership qualifications. Much was made about the large sums of money these players were being paid to sit on the bench, conjuring up tropes of Black people as economic drains dependent on undeserved handouts. One writer mockingly referred to Stoudemire as a "\$100 million player" and Anthony as "the other rich, fancy player" (Lupica, 2012a, p. 49). In a similar vein, Lin's supporters decried the Knicks' willingness to let Lin walk after failing to match a lucrative contract offer from another team, while having a history of "chasing fading stars and overhyped talent with huge salaries, like Stephon Marbury, Jalen Rose and Steve Francis” (Beck, 2012b, p. B9)_all Black players.

By contrast, media coverage often portrayed Lin as what McElroy (2014) calls "an antidote to the NBA's Blackness" (p. 440). His modest character meant that he "appeared to have none of the 'Superman type of mentality' ... often [seen] in other athletes of [his] caliber" and "never does this chest-pumping" (Stelloh \& Rosenberg, 2012, p. D2). Where Anthony and Stoudemire played the role of overpaid losers, Lin was instead vaunted as the Knicks' saviour 
who "own[ed] all the monied players around him" (Carr, 2012). Of course, it did not hurt that Lin was costing the team "practically nothing, at least compared to what they [were] paying Carmelo Anthony and Amar'e Stoudemire" (Lupica, 2012b, p. 63). Lin was even more of a bargain given the fact that he was "an instant marketing boost" (Robbins, 2016, p. A18) to any team he was on. Several pieces commented on the popularity of Lin's jersey, with one showing an image of "Jeremy Lin's No. 17 jersey ... high above the jerseys of teammates Iman Shumpert, Amar'e Stoudemire and Carmelo Anthony on the sales racks" (Serby, 2012a, p. 66). This image symbolically places Lin in a position of superiority over his Black teammates, marking an example of the necessary defeat of Blackness.

Not only was Lin his team's saviour - he was also labelled "the league's biggest hope" (Maese, 2012, p. D01) in the wake of a lockout that temporarily marred the NBA's image. In this context, the celebration of Lin's ability to outproduce his Black colleagues both on and off the court while receiving a fraction of their pay eerily echoes the early racial politics of Chinese labour in the United States. Throughout the 19th century, Chinese "coolie" labour was used to undermine the ability of newly freed Black labourers to demand fair wages (Prashad, 2001). Similarly, Lin's success and affordable contract made the striking players look greedy. Yet even once he was offered a much larger contract, anxieties about his impact on the NBA labour market only intensified. His former teammate Anthony called the contract "ridiculous", while another claimed it "could stir jealousy in the locker room" (Beck, 2012b, p. B9). This points to the easy slippage between the model minority and "yellow peril" stereotypes, in which the same industriousness and intelligence that make Asian Americans desirable also threatens domestic labour (Okihiro, 2014). 
Despite how often Lin is depicted in model minority terms, his NBA success is also confusingly glorified as a corrective to the limits imposed on Asian Americans by model minority discourse. Far from a humble and reluctant star, Jay Kaspian Kang (2012) instead saw "a 23-year-old kid who dunks, keeps the ball for himself in pressure situations, preens, chest bumps, and gets caught up in Kim Kardashian rumors". Another Asian American commentator praised Lin for his "perseverance, humility and great faith" in one breath before going on to argue that Lin is "shattering stereotypes and proving to the world that we ... are more than 'Asian Whiz Kids,' computer geeks or aspiring brain surgeons" (Salaff, 2012, p. A). An Asian American youth quoted in another piece echoes the latter sentiment, saying that Lin "proves that Asians aren't all just nerdy and smart" (Ding, 2012, p. C). Thus, the positioning of Lin within the model minority frame as both confirming and denying its existence creates a perplexing paradox: To put it glibly, Lin, a Harvard Economics graduate, is proclaimed as proof that not all Asian Americans are math nerds.

This duality is not lost on some of the voices included in coverage of Lin. One quoted expert, Thad Williamson, observes that "Lin is changing perceptions of Asian Americans, in ways that both reinforce and deeply challenge existing stereotypes" because "[o]n the one hand, he is the prototypical high-academic-achieving Asian American. But on the other hand he is a baller who has shown he can not only compete but excel against the world's best players" (Zillgitt, 2012, p. A1). One Asian American writer similarly juxtaposes model minority imagery with stereotypically Black phrasing to describe Lin, asserting that "[h]e can fit into your perfect compartments of virtuous respect, but he's also swagaliciously addictive" (Gu, 2017). For many voices in the sampled texts, these contradictions in Lin's character, or at least his characterization in the media, led to mixed feelings. Some expressed reservations about even the seemingly 
positive aspects of the model minority myth. Lin himself felt that as supposed model minorities, "Asians are very easy to make fun of" due to the belief that [t]hey're nice people, respectful people; they won't do anything" (Torre, 2015). Many expressed frustration that Lin's stereotypebreaking capabilities were being assimilated into a classic model minority success story. Sports columnist Mike Wise observed that “[w]hen Lin's ability is dissected, he is often referred to as 'smart' and 'persevering' with a 'high basketball IQ,"' but that it is obvious that "Jeremy Lin did not cross-over John Wall and dunk on the Wizards because of his superior intellect" (Wise, 2012, p. D03). Chuck Leung (2012) framed Lin as conforming to model minority stereotypes by claiming that "he [had]n't exhibited that top-shelf swagger you see from players at the peak of their games". Yet rather than celebrating Lin's perceived modesty, Leung worried the reinforcement of these stereotypes meant that for Asian American men, "an opportunity to stifle the attacks on our masculinity was passing us by”.

Leung's invocation of masculinity is a crucial detail, as it offers a clue as to how Lin could be viewed and portrayed in such contradictory ways. One possible explanation is that it arises from a conflation of "being smart" with "being unathletic". A lack of physical strength and skill is characteristic of the next frame in my analysis.

\section{Asian American men as emasculated.}

The Asian American emasculation frame positions Asian American men as physically weak, passive, effeminate, and impotent. In a sense, the model minority and emasculation frames are merely opposite sides of the same mind/body duality coin: Asian American men, with their superior minds, must have proportionately inferior bodies; Black men, with their inferior minds, must possess proportionately superior bodies. The inferior aspect of each racial group is used to domesticate the potential threat posed to whiteness by their respective superior aspects. That is to 
say, the threat of Asian American intelligence and work ethic is neutralized through their emasculation, and the threat of Black men's sexual potency and physical strength is nullified through their pathologization as simple-minded, impulsive deviants. This duality contributes to the paradox observed in the previous section, that Lin's story both supports and contradicts the model minority myth. When voices in the media claimed that Lin shattered stereotypes about Asian Americans being smart and studious, what they really meant was that Lin contradicted the idea that Asian American men were physically inferior. In fact, he contradicted the mind/body duality itself by demonstrating both a strong academic bent and also a penchant for athletic pursuits.

Many of the voices featured in the sampled media coverage agreed that Asian American emasculation was a significant issue. Lin himself acknowledged that he did not agree with the perceptions most people seem to hold about "Asian-American masculinity or whatever you want to talk about" (Reed, 2016). It was considered a serious enough problem by the Asian American Journalists Association (AAJA) that they released a statement "urge[ing] caution "when discussing Lin's physical characteristics, particularly those that feminize/emasculate the Asian male"" (Tanner, 2012). One Asian American writer contended that "the Asian American male has always lagged behind in cultural visibility and acceptance" (Chi, 2012), while another further explained that for Asian American men, their "best chance for seeing someone who looked like them in popular entertainment was ... the archetypal small-dick-baby-man character" (Concepcion, 2015). Eddie Huang - a well-known celebrity chef and outspoken defender of Asian American masculinity - elaborates on this archetype, claiming that the dominant view of Asian American men is that they are "technologically proficient, [and] naturally subordinate," have "male anatomy ... the size of a thumb drive and ... could never in a thousand millenniums 
be a threat to steal your girl" (Cepeda, 2017, p. E4). Huang's quote vividly captures the frequent fusion of model minority tropes (e.g., technological proficiency) with emasculation discourse (e.g., small penis, lack of sex appeal).

Given the amount of bitterness directed at the emasculation stereotype by Asian American men, many were pleased to see that there was finally a sports hero who promised to dispel some of those notions. Most of the media that placed Lin within the emasculation frame seemed to position him as contradicting it. One Asian American writer enthusiastically claimed that "now, with Lin on our radar, my Asian American brothers can tell American pop culture, which has historically portrayed Asian males as awkward, unathletic and never the leading man, where to stuff it" (Salaff, 2012, p. A). Lin himself seems to say as much in an awkwardly translated interview in which he tells a reporter in Mandarin that "if we can have more Asian basketball players it will help our masculinity a lot" (Mano, 2017). Indeed, one writer called basketball "the defining test of American masculinity" (Samuel, 2017), marking Lin's accomplishments in that field as the ultimate masculine triumph. Timothy $\mathrm{Yu}$ (2012) is likewise adamant that "[e]very time [Lin] drives to the basket, he upends stereotypes of Asians as short, weak and nerdy" (Yu, 2012).

One feat of masculine athleticism particularly fixated upon by Asian American voices is dunking. In basketball, a dunk shot occurs when a player jumps high enough to forcibly drive the ball through the hoop with one or two hands, often with great violence and embellishment. The high degree of athleticism and strength required to do so make the dunk the pinnacle of masculine expression in the game of basketball. Lin's ability and willingness to dunk are therefore a key to his breaking of emasculation stereotypes. The shock that Lin's dunking elicits speaks to their power as tools of remasculinization. One piece details how a pre-NBA Lin nearly 
cleared out a gym with a dunk because, as one witness put it, he "[did]n't think they'd ever seen an Asian kid do anything like that" (Armstrong, 2012, p. 50). One Asian American fan watching Lin play against the Lakers expressed awe that "an Asian American dunked" (Dolnick, 2012, p. D1). Crucially, some pieces also mentioned that Lin, in a game against the Washington Wizards, dunked on his rival John Wall. According to Davis W. Houck (2000), “To dunk with violence apparently isn't enough; that violence isn't directed solely at an inanimate metal sphere but at an opposing player. To dunk at the highest levels is thus to do violence to another player" (p. 155). Lin's dunk on Wall thus symbolized a violent act of conquest over Wall's Black masculinity, thereby allowing Lin to reclaim his own Asian American masculinity through the necessary defeat of Blackness.

Lin's athletic success and its attendant masculine domination is also linked to sexual access. His attractiveness to women is a recurring motif, with one fan joking that "[i]f your name is Lin, it'll be easier to get a girlfriend" (Lopresti, 2012, p. 8C). The evidence supporting this notion is widespread; one writer recounts an exchange between two Chinese American women who "fanned themselves" and professed that "Jeremy's so cute" (Hamill, 2012, p. 32). Another writer was told a story about "Asian-American girls at a game ... gushing all night about how cute the new Knicks point guard is" (Lopresti, 2012, p. 8C). One Asian American fan summed up Lin's sexual potency by quipping that "[a]11 the Asian-American guys want to be Jeremy Lin ... [a]nd all the Asian-American girls want to marry him" (Dolnick, 2012, p. D1). However, Lin's perceived attractiveness was seemingly not limited to Asian American women. Jesse Washington (2012) reported that "[w]omen were in the stands ... with 'Be My Va-LIN-tine' signs. Websites were matchmaking Lin with women of all ethnicities. A YouTube video shows an Asian girl dumping her white boyfriend for an Asian man after watching Lin on the court". In 
these few lines, Lin is bestowed with the ultimate markers of sexual power for Asian American men: The ability to retain "their own" women from white men, and the ability to attract white women, the pinnacle of sexual prizes. Even more improbably, Lin was "rumored to be dating Kim Kardashian" (Lee, 2017). Not only is Kardashian considered by many to embody the gold standard of normative Western beauty standards, she and her sisters are also infamous for their pursuit of Black men. Whether or not the rumours about Lin and Kardashian had any basis, the remote possibility that Kardashian might be interested in him could be construed as a milestone victory for Asian American masculinity. The most sexually potent woman in the world, who makes a habit of seeking out Black hypermasculinity, had Lin, an Asian American, on her sexual radar. Lin, it seemed, had embodied Black masculinity well enough to claim the supraethnic viability of Asianness in the bedroom as well as on the court.

However, the unabashed celebration of Lin's ability to attract women evokes the troubling practice of misogylinity, or defining masculinity through the sexual conquest of women (see Misogylinity section of Theoretical Concepts). The growing popularity of this form of toxic masculinity among some Asian American men has led them to believe they are owed sex, particularly by Asian American women, who are otherwise labelled as "race-traitors". Disappointingly, Lin himself seems to hold and promote some of these views. During a postgame press conference in 2017, Lin fielded a question about "the stereotype of Asian guys not being attractive" (Diaz, 2017). Lin's response bears some tell-tale signs of misogylinity:

I feel like a lot of the time we had a lot of Asian girls going for non-Asian guys. ... You just see a lot of the opposite. You don't see a lot of non-Asian girls going for Asian guys. That's just like when they say "yellow fever" growing up, it wasn't like all these white girls are going for Asian guys. (Diaz, 2017) 
Here, Lin laments “Asian girls going for non-Asian guys", not-so-subtly accusing them of betraying Asian American men and juxtaposing their sexual agency_particularly with respect to interracial intimacy — with the supposed denial of Asian men's sexual options.

Thus, under the logic of misogylinity, Asian American women are seen as privileged thanks to their heightened ability to access sex; the same feminization that emasculates Asian American men turns Asian American women into hyperfeminine objects of desire (Espiritu, 1997). One of the few pieces that mentions Asian American women at all makes this argument, quoting Asian American professor Ruth Chiung who argues that "[i]f you look at it historically, the dominant group has always favored the female of a minority, seeing them as assets, commodities or possessions" (Chi, 2012). Strangely, while the first part of this quote advances the idea that Asian American women are favoured, the latter points to the extreme racialized and gendered violence Asian American women are subject to. Unfortunately, this is all too often missed in the sampled texts. One quotes author Helen Zia, who explains that "Asians were first viewed in America as 'coolies,' laboring on railroads, laundry or in restaurants” (Washington, 2012). Of course, making this generalization about "Asians" elides the fact that for decades, only Asian men even had the opportunity to live and work in the United States. Asian women were considered morally suspect and likely prostitutes, to the extent that Chinese women were completely and explicitly barred from immigration by the 1875 Page Law (Espiritu, 1997). While Asian American men do at times decry the history of these sexist immigration policies, it is often as an example of (heterosexual) Asian American men being denied sexual agency, rather than Asian American women being denied the right to exist based on sexual stereotypes. Indeed, only one sampled text alluded to the fact that sexual stereotypes can be damaging to Asian American women as well as men, referring to the reduction of Asian American women's 
representation in popular culture to "exotic sex object character" (Concepcion, 2015). Overall, then, Asian American women are largely absent in coverage of Lin's Asian American identity except as sexual objects validating his reclaimed masculinity. I therefore argue that uncritically gloating over Lin's sexual potency is therefore a severely limiting and non-intersectional way to engage in antiracist politics.

Despite the general sense of celebration that Lin was turning the tide against Asian American emasculation, plenty of media coverage found ways to subordinate his masculinity, or recounted emasculating incidents. Jason Whitlock's demeaning comments about Lin's genitalia immediately come to mind, but I will not dwell on them much here, as I have already addressed them elsewhere (see "Disallowance of anti-Asian sentiment" in "Themes of Asianness" section). Suffice to say, Whitlock's comments blatantly trafficked in emasculating Asian stereotypes. Other instances of emasculation were subtler. One writer chooses to describe Lin as "a thinframed NBA point guard" (Serby, 2012, p. 92). This is a curious choice, since Lin's official weight is listed as 200 pounds, a very normal and perhaps even above-average figure for a 6foot-3-inch tall point guard. Derrick Rose, who was the reigning Most Valuable Player at the time of Lin's emergence, is approximately the same height as Lin, but 5 pounds lighter. Yet Rose is consistently commended on his strength for his position. In a similar vein, Lin often bristled at the fact that he was sometimes described as "deceptively quick" despite matching John Wall, considered one of the fastest players in the league, in draft combine speed tests. One interviewer, however, pointed out to Lin how the insult cuts both ways, "[b]ecause to call someone freakishly blank or amazingly, naturally blank is to say that they don't have to work at it, and to call you deceptively [sic] means that there's not an innate talent” (Dubner, 2018). Thus Lin, while 
framing himself as the victim of a double standard, still benefits from being spared anti-Black notions of innate athleticism and natural talent.

Post-Linsanity coverage of Lin seems to recount an increasing number of situations that challenge Lin's masculinity, which aligns with the thematic analysis finding that Lin's standing as an NBA player had begun to falter. Lin's encounters with one-time teammate Kobe Bryant are especially evocative, with Bryant caught on video berating Lin and other teammates for being “soft like Charmin in this motherfucker!" (Torre, 2015). Pablo Torre (2015) detailed yet another incident in which a visibly frustrated Bryant "[threw] a left hook into the emasculated air" after he felt Lin made a mistake at the end of a game. In these situations, Lin is clearly made subordinate to Bryant's “alpha-male” comportment.

As the Bryant incidents attest to, Lin was sometimes emasculated through the depiction of an oppositional Black hypermasculinity. One text details efforts by a few dedicated Lin fans to draw attention to hard fouls perpetrated against him (Keh, 2016a). They felt that the physical contact in each play was excessive enough to warrant greater punishment than what the referees decided to hand out. Moreover, they felt that Lin was the victim of this sort of injustice an unusually high number of times, leading to speculation that Lin's unique race was a factor. The violent victimization of Lin at the hands of his mostly Black opponents created, perhaps unintentionally, the image of Lin as the physically dominated Asian American man, beaten and bloodied by a mob of brutish Black men.

\section{Asian Americans as invisible.}

It is no accident that several of the quotes from the previous section equate Asian American emasculation to a lack of visibility in popular culture. Chon-Smith (2014) contends that "Asians are classified as having the largest brains and smallest genitalia", and thus " $[\mathrm{t}] \mathrm{o}$ speak of the 
physicality of Asian American men is to speak of their invisibility, distinguishing the mind from (body) matter in a negative dialectic of absence" (p. 300). In the "Asian Americans as invisible" frame, Asian Americans are understood as largely absent from popular culture, and overlooked in many other aspects.

The sampled texts frequently alluded to this "dearth of Asian representation in media and popular culture" (Keh, 2016b). One writer expressed that "Asian-Americans face an uphill battle to escape the periphery in cultural discussions in this country" (Lee, 2017). This comment implies that not only are Asian Americans not seen, their concerns and interests are rarely heard either. One Asian American writer argued that before Lin, "there were no viable Asian-American men in sports or pop culture that the general population would've been able to pick out of a police lineup" (Chi, 2012). In a concrete example of just this sentiment, Steve Tisch, a film producer, was asked about the possibility of Lin's story being adapted to film. Tisch replied, seemingly without any irony, “[c]an Will Smith or Tom Cruise play him?” (Armstrong, 2012, p. 50). Tisch's comment highlights the normal and expected nature of Asian American invisibility, to the extent that he did not think twice about naming a Black actor and white actor as the two most logical candidates to play the role of an Asian American basketball star. Even if Tisch's comment was sarcastic, it still serves as a reminder of the lack of Asian American representation in the film industry, particularly for leading men.

Given the invisibility of Asian Americans in popular culture, Lin's ascent to becomingif only briefly — the biggest story in sport was seen as an important moment for Asian Americans. Many Asian Americans expressed the positive impact his visibility had on their personal lives, and the community as a whole. One Chinese student admitted that it was simply comforting to know that " $[\mathrm{t}]$ here is some guy's face, who looks like us, and he is playing in the 
NBA" (Frazier, 2014), while an Asian American writer discussed the power of "finally having someone [they could] relate to enter the public consciousness" (Luo, 2012, p. SP11). Lin's relatability in these cases helps affirm the supraethnic viability of Asianness, by allowing Asian Americans to see themselves reflected in areas of public life they have traditionally been excluded from. In the post-Linsanity era, Lin himself has reacted positively to the recent rise of Asian American media representation, praising Hollywood romantic comedy Crazy Rich Asians and actor Sandra Oh’s Golden Globe Award win as "breakthroughs” (Chow, 2019).

Having the sort of representation provided by high profile Asian Americans like Lin was seen as important to one writer because it has the power to "make us see the overlooked and often covert racism less-famous people of his ethnicity have forever faced in sports and beyond" (Wise, 2012, p. D03). In other words, Lin offers a window into the day-to-day realities of the Asian American experience, making their interests more likely to be recognized. Furthermore, Asian Americans United board member Helen Gym noted that Lin has also "galvanized a vocal and sharply politicized Asian America which is going directly to bat on anti-Asian slurs, stereotyping and racist frameworks that have marginalized our community" (Zirin, 2012). The characterization of this group as "vocal" and "sharply politicized" seems to mark a departure from the quiet, uncomplaining model minority stereotype. Model minority discourse itself seems incompatible with a desire to increase visibility. While model minorities are supposed to quietly blend in, Asian Americans must stand out if they are to combat their perceived invisibility.

However, there is good reason to be cautious in uncritically adopting the stance that more visibility is inherently better. As Mark Tseng-Putterman (2016) notes, this can result in a "fail[ure] to recognize the violence inherent to the Black hypervisibility so many Asian Americans seem to covet". Tseng-Putterman (2018) calls this blind spot "the myth of Black 
privilege", which holds that the hypervisibility of Blackness in popular culture pushes other racial groups to the margins in discourse on race and racism. This way of thinking pits Black people against other races in competition for supposedly limited space in racial discourse.

Several instances of this myth appear to be at work in coverage of Lin. A common refrain was that "[e]ven the most vigilant parts of our society do not treat all racism the same way" (Kang, 2012). Here, Kang's phrasing is vague. How do responses to different forms of racism differ? Are some races treated worse than others? Lin is similarly opaque when he asserts that "[t]here's this whole thing where it's OK to make fun of certain guys more than it is other guys" (Torre, 2015). Just who these "certain guys" and "other guys" are is not made explicit, but an examination of other coverage points to an implied Afro-Asian binary with respect to visibility.

The notion of Black privilege was made explicit in Trevor Medeiros's (2012) article regarding the lack of disciplinary measures taken against Jason Whitlock. He wondered what would happen "if it was a white columnist, say, Skip Bayless, and not the African-American Whitlock, tweeting about the size of Lin's package?" Here Medeiros seems to be suggesting that Black people are held to different standards, allowing them to get away with more racist comments than their white colleagues. He went on to conclude that "you can expect to be punished when you bash African-Americans ... and Muslims ..., but it's OK to take to social media and talk in not-so-complimentary terms about an Asian-American point guard and his genitalia" (Medeiros, 2012). Again, Medeiros proposes that Black people are granted special privileges, not only as perpetrators of racial discrimination, but as victims too.

Another case that invokes the myth of Black privilege was Lin's response to a bit performed by host Chris Rock at the 2016 Academy Awards. The bit traded in humour derived from stereotypes of Asians as good at math and sources of child labour. In response, Lin (2016) 
tweeted "[s]eriously though, when is this going to change?!? Tired of it being "cool" and "ok" to bash Asians smh \#Oscars". While this sentiment on its own does not invoke the myth of Black privilege, an Associated Press report on the controversy quoted the executive director of Asian Americans Advancing Justice as decrying the Black-white binary for narrowing conversations about race and consequently "devalue[ing] the experiences of minority groups" (Reed, 2016). While this seems like a noble cause, calls to move beyond the Black-white binary in fact "set[] up blackness ... and by extension, those people socially defined as "black," as an impediment to the laudable goals of a multiracial coalition and complex understanding of race relations in North America" (Deliovsky \& Kitossa, 2013, p. 160). Thus, the desire to abolish the Black-white binary reflects a belief that it privileges the awareness of certain kinds of racism (i.e., anti-Black) while pushing others (i.e., anti-Asian) to the margins. The implication of Lin's tweet, then, is that while it is okay to "bash Asians", it is not seen as okay to bash other races, Black people in particular. Lin's comments about the Oscars were also made against the backdrop of the \#OscarsSoWhite movement, which was created in an effort to draw attention to the lack of recognition being given to people of colour in the film industry. A Black comedian peddling jokes based on Asian stereotypes likely added to the racial tensions already at work with the creation of the alternative hashtag \#OscarsSoBlackAndWhite. This competing hashtag was created to criticize Rock and other Black people for failing to bring equal attention to the underrepresentation of non-Black people of colour in Hollywood, despite plenty of evidence to the contrary (Tseng-Putterman, 2018).

Another way in which the myth of Black privilege is inscribed is through what TsengPutterman (2016) calls “anti-Blackness as metaphor". This is the tendency of Asian Americans to repurpose Black thought and anti-Black language as a way to make Asian American struggles 
more legible. However, as Tseng-Putterman (2016) notes, "[t]he shortcut works so well not because average Americans inherently pay more attention to Black issues than Asian American ones, but because of the work of generations of Black thinkers and activists who have pushed Black history and struggle at least marginally into the American mainstream”. This has the effect of reducing Black struggle to a rhetorical device for advancing Asian American issues, while at the same time limiting the level of nuance available for analyzing Asian American issues.

In media coverage of Lin, anti-Blackness as metaphor is commonly expressed by comparing instances of anti-Asian racism to hypothetical anti-Black racist scenarios. Speaking on a television image that depicted Lin in a fortune cookie, Guy Aoki, head of the Media Action Network for Asian Americans, remarked that "[w]e're more sensitive to black history in this society" before illustrating his point by asking us to "[i]magine if 80 percent of the league were Asian American. And a black player's face was put in the middle of fried chicken and watermelon. How would that go over?" (Wise, 2012, p. D03). The analogy to racist stereotypes about Black people adds shock value to Aoki's statement, while his comment about society's sensitivity to Black history fails to locate the source of that awareness in centuries of Black activism and struggle. Commenting on the ESPN headline that used an anti-Asian racial slur, Congresswoman Judy Chu claimed that " $\mathrm{t}] \mathrm{he}$ 'c' word is for Asian Americans like the ' $\mathrm{n}$ ' word is for African Americans" (Gold, 2012). This crude comparison again deploys anti-Black language as a metaphor to advance the cause of getting people to take "the 'c' word" more seriously.

One final example of anti-Blackness as metaphor worth considering is the recurrent comparison of Lin's impact on Asian Americans to Jackie Robinson's breaking of baseball's colour barrier for Black athletes. This comparison completely erases the fact that Black baseball 
players were not simply "overlooked"; they were actively excluded and segregated by deeply rooted structural barriers used to maintain white supremacy. Chon-Smith's (2014) comments on now-retired baseball star Ichiro Suzuki apply equally to Lin, in which Lin's "racial transcendence seemingly answers Robinson's call for racial equality within the construct of a global multiculturalism that privileges racelessness rather than race consciousness, all the while making the once political—black radicalism in popular sport—actively long forgotten" (p. 305).

In summary, Lin's fame counters notions of Asian American silence and cultural invisibility, which a great deal of media coverage recognized as a positive development for combating anti-Asian sentiment. However, efforts to take advantage of Lin's visibility as a springboard for Asian American political action often relied on attacks on Black hypervisibility and the accompanying myth of Black privilege.

\section{Asian Americans as forever foreigners.}

While the previous section analyzes the idea that Asian Americans are often erased from popular culture, some writers noted that there was sometimes an exception. As one Asian American put it, they "rarely saw someone who looked like [them] represented in media, and in the rare instances that someone showed up in a movie, they were often portrayed as mute, bumbling and perpetually foreign" (Lee, 2017). Indeed, the invisibility of Asian Americans in popular culture likely stems in part from the idea that all Asians, American or not, are outsiders to American culture. This illustrates the fourth stereotypical media frame, that Asian Americans are forever foreigners. Within this frame, their place of birth and English skills often become the subject of scrutiny, and their allegiances assumed to be with their ancestral homeland. No matter how many generations of their family have lived in the United States, they are always perceived as being on the outside looking in. 
A small number of sampled media reinforced this stereotype by persistently linking Lin to his Chinese or Taiwanese heritage. Journalist Pedro Velazco (2012) insisted on his right to do so in the name of "fun", and decried the "PC [politically correct] situation" that occurs when this right is limited. He makes his case by arguing that his own nickname for Lin, "Chairman Wow" successfully and harmlessly manages to reference Lin's Chinese heritage and the excitement generated by his rise to fame. While Velazco seems confident that his nickname celebrates Lin and his heritage, it suffers from a staggeringly ahistorical conflation of China and Taiwan, who have been bitter rivals for decades. Nicknaming the son of Taiwanese immigrants-whose families likely fled there from China to escape its communist regime—after Mao Zedong, the former Chinese Communist Party leader, completely erases that violent and contentious history. This blunder clearly illustrates the importance of historical and geographical specificity when writing about an Asian American's heritage.

Velazco's piece notwithstanding, most of the texts sampled in the present study were careful to emphasize Lin's Americanness, with many also bringing awareness to the forever foreigner stereotype. The AAJA recommendations specifically warned that "Jeremy Lin is Asian American, not Asian" and that "to characterize him as a foreigner is both inaccurate and insulting" (Tanner, 2012). Timothy Yu wrote that "in contemporary America, Asians ... are generally depicted as comical foreigners with 'ching-chong' accents" but that "[e]very time [Lin] talks to the media, he dispels the idea that all Asian-Americans are like foreigners speaking broken English" (Yu, 2012). Lin's articulateness and experience as a native English speaker are thus offered as proof that Asian Americans are just as American as anyone else. Some pointed to his fame as validating in itself, with one Asian American voice commenting that his success "represents a step for the Asian-American community as it becomes part of American culture 
more broadly" (Beck, 2012a, p. A1). However, this comment also subtly reinforces the notion that Asian Americans are outsiders who are still in the process of becoming more American, a testament to the forever foreigner myth's persistence and ability to be internalized.

Lin's style of play and aesthetic choices also seemingly mark him as American. In a previous section on the supraethnic viability of Asianness, I address how Lin's "normal” size made him a more suitable proxy than the gargantuan Yao Ming for aspiring Asian American basketball players. However, Yao's nationality was also frequently mentioned as a barrier to identification. As one fan put it, Yao is "7 feet and from China" while "Jeremy is [the fan's] size and from America", making it easier to "identify with him" (Zilgitt, 2012, p. 1A). Unlike Yao and other foreign, mainly white European players, Lin's brand of basketball is deemed recognizably Black and American. While foreign players are frequently stereotyped as "soft", Lin allegedly "moves on the court with a confidence and cool more in common with the AfricanAmerican basketball aesthetic" (Zirin, 2012). One former coach of Lin's noted that "he had some funk to his game", drawing on Black American musical traditions as a metaphor for how Lin was able to "[break] people down with ease" (Armstrong, 2012). Lin's influence also opened at least one coach's eyes to the fact that other "Asian guys are playing — and they're ballers" (Samuel, 2017, p. 98). Andrew Ti (2012) takes things a step further, reporting that some Black people have taken to calling Lin "that Chinese ['n'-word]" based on his Americanness, "the fact that he's not white" and the fact that "he plays like anyone else who can ball" (Ti, 2012). The phrase implies that Lin has succeeded in not just imitating Blackness, but in actually becoming Black through his basketball skill and style. For Lin and other Asian American men, their abilities on the court are thus tied to their ability to perform the aesthetics of American Black masculinity. 
Lin's off-court persona has also been mined for traces of Black American aesthetics. An old social media account name of Lin's, "ChiNkBaLLa88”, is described by Asian American journalist Jay Kaspian Kang (2012) as a "strange, thoroughly American word contraption, [in which] a racial slur is fused ... with a highly racialized, identifiably black swagger". Kang saw this as representative of a broader Asian American experience, typified by his own childhood growing up "somewhere between white and black" and "fill[ing] the vacant parts of [his] identity with basketball and hip-hop" (Kang, 2012). A substantial part of Lin's Americanness, it seems, is thus derived from identifying with Blackness.

Lin's decision to get dreadlocks in 2017 seems to be a clear manifestation of this Asian American identification with Black aesthetics. Lin had already been using his hair for some time as a mode of self expression. The link between American identity, self expression, and hair was summed up by one writer who claimed that Lin "was one of the first [famous Asian Americans] to be seen as full American. He was allowed to have his flaws, his crazy haircuts" (Lee, 2017). Ironically then, Lin's desire to stand out is what makes him quintessentially American. However, the cultural and religious significance of dreadlocks to Black people challenged the idea that Lin had the right to wear them. While he professed to wanting his hair to bring people together and start conversations, I have already detailed how it instead brewed animosity and anti-Black racism against his main detractor, Kenyon Martin (see "Disallowance of hostility toward Asian Americans" in "Themes of Asianness" section). At the risk of reading too much into small details, the fact that Lin got his hair done at a salon called "All Hair Matters" perhaps also hints at an attitude of colourblind racism. The name is a play on the anti-Black slogan used to delegitimize the Black Lives Matter movement. The fact that his earlier hair experimentations were done "under the supervision of teammate Spencer Hawes" (Janes, 2016) is also suspect, 
since Hawes is an infamously vocal conservative and Donald Trump supporter (Powell, 2016). Despite Lin's claims of taking an informed approach to getting dreadlocks, one therefore has to wonder about the underlying political attitudes shaping his desire for Blackness in the first place.

While Lin's identity with Blackness serves as a way into Americanness, his defeat of Blackness can have a similar effect. In a previous section on the theme of the necessary defeat of Blackness, I mentioned that Asian American blogger Phil Yu "cherishe[d] seeing a picture of two white fans wearing Lin's No. 17 Knicks jersey" (Washington, 2012), which was compared to the thrill of seeing Lin defeat and dunk on his Black opponents. Just before this comparison, Yu also states that "[s]eeing Jeremy Lin accepted and celebrated in this American sport, it makes us more American, and it makes other people see us as more American" (Washington, 2012). In this one short sequence, national belonging for Asian Americans is bound to the simultaneous performance and defeat of Blackness as a means of acceptance by white America.

\section{Asian and Black Americans as enemies.}

The array of ways in which Asian Americans are racialized in opposition to Black people can be summarized in the belief that Asian and Black Americans are natural enemies. The model minority myth has played a significant role in creating this perception, attempting to use Asian American successes to undermine Black struggle and drive a wedge of distrust and resentment between the communities. Heavily publicized events like the 1992 Los Angeles riots and BlackKorean conflict in New York City only served to cement this narrative in the popular imagination.

Nonetheless, some media coverage of Lin promotes the belief that his successful integration into the NBA promises to subvert expectations of Asian and Black Americans as antagonists. One piece quoted journalist William Wong, who suggested that "Lin has a chance to 
be a model for positive social relationships between blacks and Asians", while acknowledging that " $[\mathrm{t}]$ hese relationships range from loving, copacetic, friendly and respectful to alienated, hostile, suspicious and hateful" (Zirin, 2012). Ironically, some of the previously described antiBlack themes of Asianness appear in this frame as antidotes to Black-Asian antagonism. Wong declared that "Lin is playing smoothly with a lot of black ballers and doing it in a way that is inclusive and collaborative" (Zirin, 2012). Lin's ability to successfully coexist with Black peers thus simultaneously supports the supraethnic viability of Asianness and supposedly refutes the idea that Asian and Black Americans are sworn enemies. Wong then asserted that Lin was also "winning the respect of many black players" (Zirin, 2012), which mobilizes the helpful Black cohort theme to demonstrate Lin's acceptance by his Black colleagues.

Lin himself seems to express a desire to bridge racial gaps. In his Players’ Tribune piece defending his dreadlocks, he argued that "[w]ith all the division, political turmoil and senseless violence in our society right now, we need to talk to each other more than ever" (Lin, 2017). He further went on to list things "like racial discrimination, police brutality or the day-to-day difficulties of being a minority" (Lin, 2017) as necessary topics of discussion. This is consistent with Lin's oft-repeated notion that he is "able to relate to minorities or people who are in certain situations" (Janes, 2016), situations, presumably, like the police violence he casually invokes. The issue, of course, is that different "minorities" have very different experiences with police violence, not to mention other "day-to-day difficulties". Lin might suffer the inconvenience of getting stopped by arena security who fail to recognize him, but it is doubtful he will ever be assaulted by police like his Black colleagues Sterling Brown and Thabo Sefolosha. In other words, Lin's attempts at forging interracial coopertion rely on a flattening of the racialized 
experiences of differently racialized groups. In a telling interview, Lin elaborated on how he perceives his own positionality:

I'm not black, obviously, but I can relate with a minority. And then I can also relate and understand how important it is to have a functional police and justice system in place to protect us and protect our country. I see like what's going on on both ends, and it's like, I'd be scared to be a cop, I'd be scared to be a civilian, I'd be scared to be anybody right now and that's just not the way that this country is supposed to be. The whole responding-to-violence-with-violence is one of the worst things that I can think of 'cause it's just like it just gets crazier and crazier. (Serby, 2016)

Here, Lin seems to employ an “All Lives Matter”-esque analysis to the matter of police violence. According to Lin, all violence is equally bad, and all people have equal reason to feel fear. Lin also claims to relate to Blackness through his own marginalized position, but then constructs Blackness as oppositional to the police, who he supports. In other words, Lin can relate to Blackness up until the point where it involves distrust and hostility toward police. This recalls Greg Tate's (2003) phrase “everything but the burden”, a reflection of how white people feel free to take all the aspects of Black culture they covet, while leaving the rest behind. Lin's comments, when taken with the benefits that he has received from his basketball career and hair choices, demonstrate that white people are not the only ones guilty of this practice. Thus, there is reason to be skeptical about embracing Lin's ability to act as a harbinger of Afro-Asian peace and mutual support. 


\section{Conclusion}

As I neared the completion of this project, footage surfaced of a visibly distraught Jeremy Lin voicing his anxiety about remaining unsigned to a new team (ESPN, 2019). Just weeks after the euphoria of winning an NBA championship, Lin's future NBA prospects were looking grim. Not long after, it was confirmed that Lin had given up waiting on NBA teams, electing instead to sign a contract to play in the Chinese Basketball Association for the Beijing Ducks (Sportsnet Staff, 2019). With the possibility that this is the last we see of Lin in the NBA, my thesis takes on renewed significance as a retrospective on Lin's career as arguably the most influential nonBlack Asian American athlete of all time.

When Lin stepped onto the court on February 4, 2012, few could have predicted that it was the beginning of public referendum on the position of Asian Americans within the racial hierarchy of the United States. Lin showed the world that Asian American men could subvert their emasculated, foreign, and even absent image to become "ballers", yet had difficulty escaping the model minority discourse that attempted to render his "Lincredible" success legible as a story of humble striving under U.S. meritocracy. While some Asian Americans were frustrated by the persistence of this frame, it nonetheless allowed Lin to access and profit from Blackness while being lionized precisely for his non-Blackness. Lin's flexible position was maintained through emphasizing his supraethnic viability, celebrating his victories over Black adversaries, protecting him from Black racial hostility, and rewarding only those Black voices that offered him support - all tenets of cultural appropriation.

Moreover, if we accept that Asianness and Blackness are located on opposite ends of a racial spectrum, with whiteness filling the normative middle ground, Lin's success as an Asian American in Black domains implies white success in those same Black domains. Put glibly, 
anything "Black" that Asian Americans can do, whites should be able to do even better. When Jeremy Lin is lauded for his ability to play basketball and wear dreadlocks, it is because of his ability to act as a proxy for whiteness. Therefore, the favourable coverage of Lin demonstrates that non-whites can be strategically celebrated for crossing racial boundaries when it serves the purposes of whiteness. Asian Americans can thus serve whiteness not only as the recipients of white violence, but as tools of white violence against other people of colour, namely Black people. This creates an atmosphere of distrust and resentment among different communities of colour. Rather than create new possibilities for Afro-Asian solidarity, the media discourse surrounding Lin instead "pitted Asian Americans against Blacks fighting for position under mainstream America's rim” (McElroy, 2014, p. 446). For Lin, and by extension other Asian American men, Black hypervisibility and overrepresentation in sport was constructed as a double standard that formed a barrier to their full participation in U.S. cultural life. Yet sports represent one of the few "means of masculine self-expression within an otherwise limited structure of opportunity" (Majors, 1990, p. 109) for Black men. This makes it clear that the myth of Black privilege ignores the depth and breadth of Black marginalization, while conveniently sidestepping the many ways in which Asian Americans are privileged.

Likewise, the idea that Asian American men are uniquely mistreated in comparison to Asian American women derives from the heterosexist discourse of misogylinity. Celebrating Lin as a symbol of Asian American masculine virility conflates racial justice with the sexual conquest of women. This marginalizes Asian American women and other Asian Americans who are not cishet men from antiracist efforts by erasing the long history of racialized, gendered violence that Asian American women continue to experience. 
When Lin's career took off in 2012, it was one of the first times that Asian American issues of cultural belonging, visibility, masculinity, and racial positioning had entered popular cultural discourse. Seven years later, the popularity of recent Asian American and Asian Canadian-starring films (e.g., Crazy Rich Asians, Always be My Maybe, The Farewell), television series (e.g., Kim's Convenience, Killing Eve), celebrity chefs (e.g., Eddie Huang, David Chang) and more have offered opportunities to continue these conversations. So too have the rising prominence of athletes like tennis star Naomi Osaka and recent NBA draft pick Rui Hachimura, both of whose mixed Black and Asian ancestries promise to complicate and enrich the discourse on Asian representation. This noticeable rise in the visibility of Asian Americans calls for critical interrogations of Asian American representation in popular media, and how these representations dovetail with or diverge from Asian American political interests. My thesis research represents just one small contribution to that project.

In a short but influential essay, Mari Matsuda (1996) defiantly proclaims "we will not be used". On the one hand, this is a call to the powers-that-be to stop circulating discourse on Asian Americans that positions them as a wedge between communities of colour and hinders interracial coalition-building. This is well-travelled ground when it comes to academic literature on Lin, which is often critical of the model minority discourses endemic to media coverage of him (Leung, 2013; Kim, 2014; McElroy, 2014). However, Asian Americans themselves can be complicit in endorsing these ideologies. Asian American men in particular are susceptible to acting as wedges not just along racial lines, but gendered ones as well. Therefore, it is crucial to understand Lin not merely as a hollow puppet manipulated by the media, but as an active agent in shaping his own narrative. 
These are not uniquely American issues either; the cross-pollination between Asian Americans and Asian Canadians mean that Asian Canadian men like myself have a role to play. During his recent stint with the Toronto Raptors, Lin developed a friendship with Chinese Canadian actor Simu Liu (Lou, 2019). Liu was recently involved in an online dispute in which many of his supporters targeted Asian women (and some men) who had made comments perceived as attacking Liu's masculinity (Lau, 2019a). While Liu himself was not directly involved in these attacks, one of the victims stressed that misogynist Asian men "seem to love [Liu], and when you're loved by those kinds of people, it's absolutely your responsibility to do something about it" (Lau, 2019b). It is my firm belief that this sentiment applies equally to Liu, Lin, and all Asian men.

Lin may be out of the spotlight now, but Liu is set to star as the main superhero in an upcoming Marvel movie (Nathoo, 2019). Huang, the outspoken and aggressively macho Taiwanese American chef (see "Misogylinity" in "Theoretical Perspectives" section) is developing a film about a fictional Asian American basketball player's struggle against adversity (McNary, 2019) — sound familiar? With this next generation of Asian American/Canadian men at the helm of Asian representation, one can hope that they learn to wield their power responsibly, and if not, that their fellow Asians in the United States, Canada, and elsewhere, will not hesitate to hold them accountable. Yes, representation matters, but what are we willing to sacrifice as a community in order to achieve that visibility? Keeping this question in mind, I argue that celebrating Lin for subverting certain Asian American stereotypes through performative Blackness must only be done with a critical awareness of its limits as an emancipatory political strategy. Asian Americans and their allies should take care to form multiracial coalitions that are 
built on mutual aid and a serious consideration of the specific needs of women, queer folks, and other racialized communities, rather than competition and exploitation. 


\section{References}

Abdel-Shehid, G. (2005). Who da man?: Black masculinities and sporting cultures. Toronto, ON: Canadian Scholar's Press, Inc. [CSPI]. Retrieved from http://ezproxy.lib.ryerson.ca/login?url=http://search.ebscohost.com/login.aspx?direct=tru $\underline{\mathrm{e} \& \mathrm{db}=\text { nlebk\&AN}=129028 \& \text { site }=\text { ehost-live }}$

Armstrong, K. (2012, February 12). Welcome to Lin city: The true Hollywood story of the Knick sensation who has taken over New York. Daily News, p. 50. Retrieved from LexisNexis Academic database.

Arnaldo, C. (2016). In S. Davé, L. Nishime, \& T. G. Oren (Eds.), Global Asian American popular cultures (pp. 27-45). New York. NY: New York University Press.

Asian American Journalists Association (2014). Media advisory on Jeremy Lin news coverage. Retrieved from https://www.aaja.org/media_advisory_on_jeremy_lin_coverage Banerjee, M. (2006). The Rush Hour of Black/Asian coalitions? Jackie Chan and Blackface minstrelsy. In H. Raphael-Hernandez \& S. Steen (Eds.), AfroAsian encounters: Culture, history, politics (pp. 204-222). New York, NY: New York University Press.

Bonesteel, M. (2017, October 6). Jeremy Lin responds to dread criticism with grace, kindness. The East Bay Times. Retrieved from LexisNexis Academic database.

Beck, H. (2012a, February 8). From ivy halls to the garden, surprise star jolts the N.B.A.. The New York Times, p. A1. Retrieved from LexisNexis Academic database.

Beck, H. (2012b, July 17). For fans of Knicks, conflict over Lin. The New York Times, p. B9. Retrieved from LexisNexis Academic database. 
Brown, D. \& Pavlovic, A. (2012, February 12). Jeremy Lin: Star's rise resonates in Palo Alto, where it first started. San Jose Mercury News. Retrieved from LexisNexis Academic database.

Bryman, A. (2001). Social research methods. Oxford, UK: Oxford University Press.

Campbell, K., \& Wiggins, E. L. (2015). Walking a tightrope. Journalism Practice, 9(2), 184199. https://doi.org/10.1080/17512786.2014.916486

Carr, D. (2012, February 20). Media hype for Lin stumbles on race. The New York Times, p. B1. Retrieved from LexisNexis Academic database.

Cashmore, E. (1997). The Black culture industry. London, UK: Routledge. Retrieved from http://ebookcentral.proquest.com/lib/ryerson/detail.action?docID=165651

Cepeda, E. (2012, March 4). Esther Cepeda: What we can learn from Jeremy Lin. Lowell Sun. Retrieved from LexisNexis Academic database.

Cepeda, E. (2017, November 19). Racism toward country's fastest-growing minority oddly OK. Lowell Sun, p. E4. Retrieved from LexisNexis Academic database.

Chang, S. (2014). Racial Upside: Deconstructing the merits of Jeremy Lin's NBA contract. Virginia Sports and Entertainment Law Journal, 14, 1-12.

Chevannes, B. (1994). Rastafari: roots and ideology. Syracuse, N.Y.: Syracuse University Press. Chi, V. (2012). Jeremy Lin: His impact on changing the perception of the Asian American male. Retrieved June 25, 2019, from http://www.thepostgame.com/commentary/201202/jeremy-lin-asian-american-malesports-pop-culture-nba-hollywood-bruce-lee 
Chiang, Y., \& Chen, T. (2015). Adopting the diasporic son: Jeremy Lin and Taiwan sport nationalism. International Review for the Sociology of Sport, 50(6), 705-721. https://doi.org/10.1177/1012690213491263

Chon-Smith, C. (2014). Yellow bodies, black sweat: Yao Ming, Ichiro Suzuki, and global sport. Journal for Cultural Research, 18(4), 291-314. https://doi.org/10.1080/14797585.2014.941161

Chong, D., \& Druckman, J. N. (2007). Framing theory. Annual Review of Political Science, 10(1), 103-126. https://doi.org/10.1146/annurev.polisci.10.072805.103054

Chow, C. (2019, February 22). Jeremy Lin: 'There's definitely some bittersweetness to my career.' Retrieved June 26, 2019, from https://theundefeated.com/features/jeremy-lin-onbeing-the-only-asian-american-in-the-nba-at-times-it-kind-of-sucks/

Colón, A. (2003, October 14). Black, black, or African American? Retrieved from https://www.poynter.org/reporting-editing/2003/black-black-or-african-american/

Combs, M. T., \& Wasserstrom, J. N. (2013). The guard's three bodies: Linsanity, celebrity and national identity. The International Journal of the History of Sport, 30(11), 1259-1270. https://doi.org/10.1080/09523367.2013.806910

Concepcion, J. (2013, November 15). Getting angry about Jeremy Lin all over again. Retrieved June 28, 2019, from Grantland website: https://grantland.com/the-triangle/getting-angryabout-jeremy-lin-all-over-again/

Crenshaw, Kimberlé. (1991). Mapping the margins: Intersectionality, identity politics, and violence against women of color. Stanford Law Review, 43(6), 1241-1299. https://doi.org/10.2307/1229039 
Cunningham, P. (2009). “Please don’t fine me again!!!!!” Journal of Sport \& Social Issues, 33(1), 39-58. https://doi.org/10.1177/0193723508328630

Da, X. S. (2007). Education and labor relations: Asian Americans and Blacks as pawns in the furtherance of white hegemony note. Michigan Journal of Race \& Law, 13, 309-336.

Dash, P. (2006). Black hair culture, politics and change. International Journal of Inclusive Education, 10(1), 27-37. https://doi.org/10.1080/13603110500173183

Deggans, E. (2012, February 20). TV's true colors. Tampa Bay Times, p. 2B. Retrieved from LexisNexis Academic database.

Deliovsky, K., \& Kitossa, T. (2013). Beyond Black and White: When going beyond may take us out of bounds. Journal of Black Studies, 44(2), 158-181. https://doi.org/10.1177/0021934712471533

Diaz, R. (2017, April 26). Jeremy Lin talks Asian American masculinity. Retrieved from https://charactermedia.com/jeremy-lin-talks-asian-american-masculinity/

Dickerson, N. (2015). Constructing the digitalized sporting body: Black and White masculinity in NBA/NHL internet memes. Communication \& Sport, 4(3), 303-330.

Ding, K. (2012, February 11). Orange County Register, p. C. Retrieved from LexisNexis Academic database.

Dolnick, S. (2012, February 11). At SoHo bar, a new star's fans share his heritage. The New York Times, p. D1. Retrieved from LexisNexis Academic database.

Donnellon, S. (2012, February 15). Sam Donnellon: 'Lin-credible' that race is being raised in NBA again. The Philadelphia Daily News, p. 60. Retrieved from LexisNexis Academic database. 
Doucet, A. and Mauthner N. (2006). Feminist methodologies and epistemologies in C. D. Bryant and D. L. Peck (Eds.), Handbook of 21st Century Sociology (pp. 26-32). Thousand Oaks, CA: Sage.

Douglas, D.D. (2012). Venus, Serena, and the inconspicuous consumption of blackness: A commentary on surveillance, race talk, and new racism(s). Journal of Black Studies, 43(2), 127-145.

Dubner, S. J. (2018). Extra: Jeremy Lin full interview. Retrieved June 26, 2019, from Freakonomics website: http://freakonomics.com/podcast/jeremy-lin/

Eng, D. L. (2001). Racial castration: Managing masculinity in Asian America. Durham, NC: Duke University Press.

Entman, R. M. (1993). Framing: Toward clarification of a fractured paradigm. Journal of Communication, 43(4), 51-58. https://doi.org/10.1111/j.1460-2466.1993.tb01304.x

Espiritu, Y. L. (1997). Asian American women and men: Labor, laws, and love. Thousand Oaks, CA: Sage Publications, Inc.

ESPN. (2019, July 28). Lin fears that NBA has "kind of given up on me". Retrieved from https://www.espn.com/nba/story/_/id/27276030/lin-fears-nba-kind-given-me

Fang, J. (2014, May 28). Masculinity vs. "misogylinity": What Asian Americans can learn from \#UCSB shooting |\#YesAllWomen. Retrieved April 27, 2019, from http://reappropriate.co/2014/05/masculinity-vs-misogylinity-what-asian-americans-canlearn-from-ucsb-shooting-yesallwomen/

Franks, J. S. (2016). Asian American basketball: A century of sport, community and culture. McFarland. 
Frazier, G. (2014, July 16). What's next for Lin as a Laker. Palo Alto Daily News. Retrieved from LexisNexis Academic database.

Gill, R. (2000). Discourse analysis. In M. W. Bauer, \& G. Gaskell (Eds.), Qualitative researching with text, image and sound (pp. 173-190). London, UK: Sage Publications Ltd. doi: 10.4135/9781849209731

Glassman, J. (2016). Emerging Asias: Transnational forces, developmental states, and “Asian Values". The Professional Geographer, 68(2), 322-329.

Gold, L. (2012, February 20). Local politicians say ESPN headline about Jeremy Lin was racist. Pasadena Star-News. Retrieved from LexisNexis Academic database.

Gramsci, A. (1971). Selections from the prison notebooks of Antonio Gramsci (Q. Hoare \& G. Nowell-Smith, Trans.). Q. Hoare \& G. Nowell-Smith (Eds.). New York, NY: International Publishers.

Grbich, C. (2012). Qualitative data analysis: An introduction. Sage.

Gu, R. Y. (2017, February 25). Jeremy Lin is still a symbol for whatever we want him to be. Retrieved June 8, 2018, from http://www.espn.com/nba/story/_id/18591999

Hall, S. (1997). Race, the floating signifier [PDF file]. Retrieved from https://www.mediaed.org/transcripts/Stuart-Hall-Race-the-Floating-SignifierTranscript.pdf

Hall, S. (2017). The fateful triangle: Race, ethnicity, nation. Retrieved from http://ebookcentral.proquest.com/lib/ryerson/detail.action?docID=4987643

Hall, S. (2003). Encoding/decoding. In S. Hall, D. Hobson, A. Lowe, \& P .Willis (Eds.), Culture, media, language: Working papers in cultural studies, 1972-79 (pp. 117-127). Retrieved from http://ebookcentral.proquest.com/lib/ryerson/detail.action?docID=179321 
Hamill, D. (2012, February 14). New Yorkers of all stripes feel Linsanity. The New York Times, p. 32. Retrieved from LexisNexis Academic database.

Hardin, M., Kuehn, K. M., Jones, H., Genovese, J., \& Balaji, M. (2009). 'Have you got game?' Hegemonic masculinity and neo-homophobia in U.S. newspaper sports columns. Communication, Culture and Critique, 2(2), 182-200. https://doi.org/10.1111/j.1753$\underline{9137.2009 .01034 . x}$

Hewitt, K. (2008). Martial arts is nothing if not cool: Speculations on the intersection between martial arts and African American expressive culture. In F. W. Ho \& B. Mullen (Eds.), Afro Asia: Revolutionary political and cultural connections between African Americans and Asian Americans (pp. 265-284). Durham, NC: Duke University Press.

Ho, F. (2006). Kickin' the white man's ass: Black Power, aesthetics, and the Asian martial arts. In H. Raphael-Hernandez \& S. Steen (Eds.), AfroAsian encounters: Culture, history, politics (pp. 295-312). New York: New York University Press.

Holland, F. (2012, March 12). Jeremy Lin a symbol of success, struggle for Asian Americans. $W G N-T V$, p. A. Retrieved from LexisNexis Academic database.

hooks, b. (1992). Black looks: Race and representation. Toronto, ON: Between the Lines.

Houck, D. W. (2000). Attacking the rim: The cultural politics of dunking. In T. Boyd \& K. L. Shropshire (Eds.), Basketball Jones: America above the Rim (pp. 151-169). New York, NY: New York University Press.

Hughey, M. W., \& Goss, D. R. (2015). A level playing field? Media constructions of athletics, genetics, and race. The ANNALS of the American Academy of Political and Social Science, 661(1), 182-211. https://doi.org/10.1177/0002716215588067

Hylton, K. (2009). “Race” and sport: Critical race theory. London, UK: Routledge. 
Janes, T. (2016). Charlotte Hornets' Jeremy Lin is a mystery to everyone but himself. Charlotte Observer. Retrieved June 26, 2019, from https://www.charlotteobserver.com/

Johnson, E. P. (2003). Appropriating Blackness: Performance and the politics of authenticity. Durham, NC: Duke University Press.

Kang, J. C. (2012, March 20). A Question of Identity. Retrieved April 6, 2019, from http://grantland.com/features/the-headline-tweet-unfair-significance-jeremy-lin/

Kang, J. C. (2019, August 28). Where does affirmative action leave Asian-Americans? The New York Times. Retrieved from https://www.nytimes.com/

Kawakami, T. (2012, February 15). Tim Kawakami: The beauty of Jeremy Lin isn't his race; it's that he looks as if he belongs. San Jose Mercury News. Retrieved from LexisNexis Academic database.

Keh, A. (2016a, April 16). A fan asks if Jeremy Lin's race leads to referee bias; N.B.A. International York Times, p. 1. Retrieved from LexisNexis Academic database.

Keh, A. (2016b, October 26). I was never Jackie Chan, and I'm not Jeremy Lin. The New York Times. Retrieved from LexisNexis Academic database.

Kim, C. (2014). The Smell of communities to come: Jeremy Lin and post-racial desire. Journal of Intercultural Studies, 35(3), 310-327. https://doi.org/10.1080/07256868.2014.899954

Kim, C. J. (1999). The racial triangulation of Asian Americans. Politics \& Society, 27(1), 105138. https://doi.org/10.1177/0032329299027001005

Kim, C. J., \& Lee, T. (2001). Interracial politics: Asian Americans and other communities of color. Political Science \& Politics, 34(3), 631-637. 
Kim, J. Y. (1999). Are Asians Black?: The Asian-American civil rights agenda and the contemporary significance of the Black/White paradigm. The Yale Law Journal, 108(8), 2385-2412. https://doi.org/10.2307/797390

Kim, K. Y. (2005, January 31). Jin tha MC; Mainstream America's first Asian-American solo rapper battles myths, markets and the tightrope line between exposure and exploitation. Colorlines; Oakland, 7(4), 47.

Klaus, E. \& Lünenborg, M. (2012). Cultural citizenship. Participation by and through media. In E. Zobl \& R. Drüke (Eds.), Feminist media: Participatory spaces, networks and cultural citizenship (pp. 197-212). Bielefeld, Germany: transcript.

Kleisath, C. M. (2014). The costume of Shangri-La: Thoughts on white privilege, cultural appropriation, and anti-Asian racism. Journal of Lesbian Studies, 18(2), 142-157. https://doi.org/10.1080/10894160.2014.849164

Korhonen, P. (1997). Monopolizing Asia: The politics of a metaphor. The Pacific Review, 10(3), $347-365$.

Kurylo, A. (2012). Linsanity: The construction of (Asian) identity in an online New York Knicks basketball forum. China Media Research, 8(4), 15-28.

Lapchick, R. (2018). The 2018 racial \& gender report card: National Basketball Association. (2018). Retrieved July 16, 2019, from https://www.tidesport.org/nba

Lau, S. [NoTotally]. (2019a, August 21). I have stans in my mentions, pray for me [Tweet]. Retrieved from https://twitter.com/NoTotally/status/1164297758762655744

Lau, S. [NoTotally]. (2019b, August 21). Does any of this mean Simu Liu reads a virulent MRAzn subreddit? He'd have to answer that, and I'm not implying that here. But they seem to love him, and when you're loved by those kinds of people, it's absolutely your 
responsibility to do something about it [Tweet]. Retrieved from https://twitter.com/NoTotally/status/1164304331715125248

Lee, E. (2012). Jeremy Lin and the limitations of the "hard-working Asian American" narrative. Retrieved June 25, 2019, from https://www.politico.com/states/newyork/albany/story/2012/02/jeremy-lin-and-the-limitations-of-the-hard-working-asian$\underline{\text { american-narrative-069733 }}$

Lee, H. (2007). Diverging identities: Ethnic and religious identities among second-generation Korean Americans. In M. Zhou \& J. V. Gatewood (Eds.), Contemporary Asian America: A multidisciplinary reader (2nd ed, pp. 360-375). New York: New York University Press.

Lee, J. (2017). Jeremy Lin remains an American icon, even five years after Linsanity. Retrieved June 28, 2019, from https://bleacherreport.com/articles/2692897-jeremy-lin-remains-anamerican-icon-even-five-years-after-linsanity

Lee, R. G. (1999). Orientals: Asian Americans in popular culture. Philadelphia, PA: Temple University Press.

Leonard, D. (2016). Lin, Te'o, and Asian American masculinities. In S. I. Thangaraj, C. R. Arnaldo, Jr., \& C. B. Chin (Eds), Asian American sporting cultures (pp. 221-246). New York, NY: New York University Press.

Leong, N. (2013). Racial capitalism. Harvard Law Review, 126(8), 2151-2226.

Leung, C. (2012, February 14). Why I am both thrilled and worried by the rise of Jeremy Lin. Retrieved June 25, 2019, from https://slate.com/culture/2012/02/jeremy-lin-inspireslinsanity-why-this-is-both-thrilling-and-worrisome.html 
Leung, M. (2013, Summer). Jeremy Lin's Model Minority Problem. Contexts: Understanding People in Their Social Worlds; Berkeley, 12(3), 52-56.

Lewis, B. (2017, October 5). Former Nets star blasts Jeremy Lin's new look. The New York Post. Retrieved from https://nypost.com/

Lin, J. (2012). So ... about my hair. Retrieved May 15, 2018, from https://www.theplayerstribune.com/en-us/articles/jeremy-lin-brooklyn-nets-about-my$\underline{\text { hair }}$

Lin, J. [JLin7]. (2016, February 29). Seriously though, when is this going to change?!? Tired of it being "cool" and "ok" to bash Asians smh \#Oscars [Tweet]. Retrieved July 17, 2019, from https://twitter.com/jlin7/status/704418688393416705?lang=en

Longman, J. (2013, April 22). From phenom to player. The New York Times, p. D1. Retrieved from LexisNexis Academic database.

Lopez, L. K. (2016). Asian American media activism: Fighting for cultural citizenship. New York, NY: New York University Press.

Lopresti, M. (2012, February 20). Lin-watching has fans partying. USA Today, p. 8C. Retrieved from LexisNexis Academic database.

Lott, E. (2013). Love and theft: Blackface minstrelsy and the American working class (20th anniversary ed.). Oxford, UK: Oxford University Press. Retrieved from http://ebookcentral.proquest.com/lib/ryerson/detail.action?docID=1318298

Lou, W. (2019, August 30). The end of Jeremy Lin: An ode to the great Asian-American sporting icon. Retrieved from https://ca.sports.yahoo.com/news/the-end-of-jeremy-lin-anode-to-the-great-asian-american-sporting-icon-141516710.html 
Luo, M. (2012, February 12). Lin's Appeal: Faith, Pride and Points. The New York Times, p. SP 11. Retrieved from LexisNexis Academic database.

Lupica, M. (2012a, February 13). Jeremy's tale all American: Seizes upon garden of opportunity. Daily News, p. 49. Retrieved from LexisNexis Academic database.

Lupica, M. (2012b, February 16). Garden party for everyone: Jeremy proves to be a Linspiration to all. Daily News, p. 63. Retrieved from LexisNexis Academic database.

Maeda, D. J. (2005). Black Panthers, Red Guards, and Chinamen: Constructing Asian American identity through performing Blackness, 1969-1972. American Quarterly, 57(4), 1079_ 1103.

Maese, R. (2012, February 17). A bona fide star no one saw coming. The Washington Post, p. D01. Retrieved from LexisNexis Academic database.

Magat, M. (2015). From rebounds to three-pointers: Linsanity, racial insults, and stereotypes in flux. Journal of American Folklore, 128(510), 438-448.

Majors, R. (1990). Cool pose: Black masculinity and sports. In M. Messner \& D. Sabo (Eds.), Sport, men, and the gender order: Critical feminist perspectives (pp. 109-114). Champaign, IL: Human Kinetics.

Majors, R. \& Billson, J. M. (1992). Cool pose: The dilemmas of Black manhood in America. New York, NY: Lexington Books.

Mano, D. (2017, October 5). Jeremy Lin wants to know what you think about his new dreadlocks. The Mercury News. Retrieved from LexisNexis Academic database.

Mautner, G. (2008). Analyzing newspapers, magazines, and other media. In R. Wodak \& M. Krzyżanowski (Eds.), Qualitative discourse analysis in the social sciences (pp. 30-53). London, UK: Macmillan International Higher Education. 
Matsuda, M. (1996). Where is your body?: And other essays on race, gender, and the law. Boston, MA: Beacon Press.

Mayeda, D. T. (1999). From model minority to economic threat: Media portrayals of major league baseball pitchers Hideo Nomo and Hideki Irabu. Journal of Sport and Social Issues, 23(2), 203-217. https://doi.org/10.1177/0193723599232007

Mayweather, F. [floydmayweather]. (2012, February 13). Jeremy Lin is a good player but all the hype is because he's Asian. Black players do what he does every night and don't get the same praise. [Tweet]. Retrieved May 1, 2018, from https://twitter.com/floydmayweather/status/169170084739289089?lang=en

McElroy, K. (2014). Basket case: Framing the intersection of "Linsanity" and Blackness. Howard Journal of Communications, 25(4), 431-451. https://doi.org/10.1080/10646175.2014.955928

McNary, D. (2019, August 26). "Fresh Off the Boat" author Eddie Huang directing coming-ofage story "Boogie”. Retrieved from https://variety.com/2019/film/news/fresh-off-theboat-author-eddie-huang-directing-coming-of-age-story-boogie-1203314726/

Medeiros, T. (2012). Jeremy Lin: Why are we letting Jason Whitlock off the hook for his tweet? Retrieved June 25, 2019, from https://bleacherreport.com/articles/1064840-jeremy-linwhy-are-we-letting-jason-whitlock-off-the-hook-for-his-tweet

Messner, M. A. (1992). Power at play: Sports and the problem of masculinity. Boston, MA: Beacon Press.

Metz, N. (2013, August 31). The trials of a Chicago director making Muhammad Ali doc. Chicago Tribune. Retrieved from https://www.chicagotribune.com/ 
Nakagawa, S. (2014, January 20). My debt to Dr. King. Retrieved July 17, 2019, from https://www.colorlines.com/articles/my-debt-dr-king

Nakayama, T. K., \& Krizek, R. L. (1995). Whiteness: A strategic rhetoric. Quarterly Journal of Speech, 81, 291-309.

Nathoo, Z. (2019, July 20). Canadian actor Simu Liu cast as Marvel's first Chinese superhero, Shang-Chi. Retrieved from https://www.cbc.ca/news/entertainment/simu-liu-shang-chi$\underline{\text { marvel-casting-1.5219238 }}$

Nopper, T. K. (2004). The hype about Asian rappers reveals low standards for Asian Americans in race politics. Retrieved February 7, 2019, from https://apimboston.org/hype-aboutasian-rappers-reveals-low-standards-asian-americans-race-politics

Nopper, T. K. (2012, August 30). Why couldn't Richard Aoki have been an informant? Retrieved from https://thenewinquiry.com/why-couldnt-richard-aoki-have-been-an$\underline{\text { informant/ }}$

Okihiro, G. Y. (2014). Margins and mainstreams: Asians in American history and culture. Retrieved from https://muse.jhu.edu/book/29082

Omatsu, G. (2007). "The four prisons" and the movements of liberation: Asian American activism from the 1960s to the 1990s. In M. Zhou \& J. V. Gatewood (Eds.), Contemporary Asian America: A multidisciplinary reader (2nd ed, pp. 56-88). New York, NY: New York University Press.

Omi, M., \& Winant, H. (1986). Racial formation in the United States: From the 1960s to the 1980s. New York, NY: Routledge \& Kegan Paul. 
Park, M. (2013). Asian American masculinity eclipsed: A legal and historical perspective of emasculation through U.S. immigration practices. The Modern American, 8(1). Retrieved from http://digitalcommons.wcl.american.edu/tma/vol8/iss 1/3

Park, M. K. (2015). Race, hegemonic masculinity, and the "Linpossible!": An analysis of media representations of Jeremy Lin. Communication \& Sport, 3(4), 367-389. https://doi.org/10.1177/2167479513516854

Perlman, M. (2015, June 23). Black and white: Why capitalization matters. Retrieved from https://www.cjr.org/analysis/language_corner_1.php

Pham, M.-H. T. (2017). Racial plagiarism and fashion. QED: A Journal in GLBTQ Worldmaking, 4(3), 67-80.

Phi, T.-b. T. (2008). Yellow Lines: Asian Americans and hip hop. In F. W. Ho \& B. Mullen (Eds.), Afro Asia: Revolutionary political and cultural connections between African Americans and Asian Americans (pp. 295-317). Durham, NC: Duke University Press.

Piquero, A. R., Piquero, N. L., Gertz, M., Baker, T., Batton, J., \& Barnes, J. C. (2011). Race, punishment, and the Michael Vick experience. Social Science Quarterly, 92(2), 535-551. https://doi.org/10.1111/j.1540-6237.2011.00781.x

Powell, S. (2016). Hornets' Spencer Hawes proud to use political voice. Retrieved July 17, 2019, from http://www.nba.com/article/2016/12/14/spencer-hawes-political-voice

Prashad, V. (2001). Everybody was kung fu fighting: Afro-Asian connections and the myth of cultural purity. Boston, MA: Beacon Press.

Prashad, V. (2006). Bandung is done: Passages in AfroAsian epistemology. In H. RaphaelHernandez \& S. Steen (Eds.), AfroAsian encounters: Culture, history, politics (pp. xixxiii). New York, NY: New York University Press. 
Prois, J. \& Workneh, L. (2017). Jeremy Lin's dreads and Kenyon Martin's Chinese tattoo are a false equivalency. Retrieved from https://www.huffingtonpost.ca/entry/jeremy-linkenyon-martin_n_59dce0d9e4b0208970d00545

Ramakrishnan, K. \& Wong, J. (2018, June 18). Survey roundup: Asian American attitudes on affirmative action. Retrieved from http://aapidata.com/blog/asianam-affirmative-actionsurveys/

Raphael-Hernandez, H. (2006). "It takes some time to learn the right words". In H. RaphaelHernandez \& S. Steen (Eds.), AfroAsian encounters: Culture, history, politics (pp. 103123). New York, NY: New York University Press.

Raphael-Hernandez, H., \& Steen, S. (2006). AfroAsian encounters: Culture, history, politics. In H. Raphael-Hernandez \& S. Steen (Eds.), AfroAsian encounters: Culture, history, politics (pp. 1-14). New York, NY: New York University Press.

Reed, S. (2016). NBA player Jeremy Lin addresses Asian stereotypes at Oscars. Retrieved June 26, 2019, from https://www.businessinsider.com/ap-nba-player-jeremy-lin-addresses$\underline{\text { asian-stereotypes-at-oscars-2016-3 }}$

Reid, J. (2012, February 16). . . And now for the rest of Lin's story. The Washington Post, p. D01. Retrieved from LexisNexis Academic database.

Robbins, L. (2016, July 21). Lin, returning for second act, still muses on days of Linsanity. The New York Times, p. A18. Retrieved from LexisNexis Academic database.

Roediger, D. R. (2007). The wages of whiteness: Race and the making of the American working class (revised ed.). London, UK: Verso.

Rohde, J. (2012, February 19). The Jeremy Lin profile. The Oklahoman, p. 4B. Retrieved from LexisNexis Academic database. 
Salaff, J. C. (2012, March 4). Lin-fatuated with new star. Orange County Register, p. A. Retrieved from LexisNexis Academic database.

Samuel, E. (2017, February 19). The daze of Linsanity: 5 years ago, Jeremy Lin took the Big Apple by storm, smashing stale stereotypes of Asians in the process. Daily News, p. 98. Retrieved from LexisNexis Academic database.

Serby, S. (2012a, February 16). Linfected city: Knicks' phenom taking over Manhattan. The New York Post, p. 66. Retrieved from LexisNexis Academic database.

Serby, S. (2012b, February 26). Linspiration: Knicks star breaks barriers for Asian youth. The New York Post, p. 92. Retrieved from LexisNexis Academic database.

Serby, S. (2016, July 23). Jeremy Lin opens up: On Knicks heartbreak, racism and Fitzpatrick. The New York Post. Retrieved June 26, 2019, from https://nypost.com/

Sportsnet Staff. (2019, August 27). Former Raptor Jeremy Lin signs with Beijing Shougang Ducks. Retrieved from https://www.sportsnet.ca/basketball/nba/report-former-raptorjeremy-lin-signs-beijing-shougang-ducks/

Stelloh, T \& Rosenberg, N. (2012, February 13). From the pulpit and in the pew, the Knicks' Lin is a welcome inspiration. The New York Times, p. D2. Retrieved from LexisNexis Academic database.

Stokes, J. C. (2013). How to do media and cultural studies (2nd ed.). London; Thousand Oaks, Calif: SAGE.

Su, C. (2014). From perpetual foreigner to national hero: A narrative analysis of US and Taiwanese news coverage of Linsanity. Asian Journal of Communication, 24(5), 474 489. https://doi.org/10.1080/01292986.2014.913640 
Sultana, F. Reflexivity, Positionality and participatory ethics: Negotiating fieldwork dilemmas in international research. ACME: An International Journal for Critical Geographies, 6(3), 374-385. Retrieved from https://www.acme-journal.org/index.php/acme/article/view/786

Sung, W. (2016). David Choe's "Koreans gone bad": the LA riots, comparative racialization, and branding a politics of deviance. In S. Davé, L. Nishime, \& T. G. Oren (Eds.), Global Asian American popular cultures (pp. 89-103). New York, NY: New York University Press.

Tanner, J. (2012, February 24). Jeremy Lin Journalism Guide Released By AAJA. WPIX-TV. Retrieved from LexisNexis Academic database.

Tate, G. (2003). Everything but the burden: What White people are taking from Black culture. New York, NY: Broadway Books.

Thangaraj, S. (2013). Competing masculinities: South Asian American identity formation in Asian American basketball leagues. South Asian Popular Culture, 11(3), 243-255. https://doi.org/10.1080/14746689.2013.820482

Tharps, L. L. (2014). The case for Black with a capital B. The New York Times. Retrieved from: https://www.nytimes.com/

Ti, A. (2012). What We Talk About When We Talk About “This Jeremy Lin Ni**a.” Retrieved June 25, 2019, from https://deadspin.com/what-we-talk-about-when-we-talk-about-thisjeremy-lin-5884747

Torre, P. S. (2015, March 27). Why it's not easy being Jeremy Lin. Retrieved April 6, 2019, from http://www.espn.com/espn/feature/story/_id/12561636/inside-jeremy-lin-life$\underline{\text { linsanity-new-york-knicks }}$ 
Tseng-Putterman, M. (2015, May 7). When Asian emasculation meets misogyny: On Eddie Huang's Black feminist problem. Retrieved January 26, 2019, from https://www.racefiles.com/2015/05/07/when-asian-emasculation-meets-misogyny-oneddie-huangs-black-feminist-problem/

Tseng-Putterman, M. (2016, December 19). Against antiblackness as metaphor. Retrieved July 5, 2019, from http://reappropriate.co/2016/12/against-antiblackness-as-metaphor/

Tseng-Putterman, M. (2017a, January 16). When silence is betrayal: On Asian American debt to the radical King. Retrieved January 26, 2019, from https://medium.com/organizer$\underline{\text { sandbox/on-asian-american-debt-to-the-radical-king-ae5c44391a79 }}$

Tseng-Putterman, M. [tsengputterman]. (2017b, October 8). Point is, Lin's dreads won't make him target of the aggressive black man trope being used to bash Martin's critique [Tweet]. Retrieved from https://twitter.com/tsengputterman/status/916330467196067840

Tseng-Putterman, M. (2018). \#OscarsSoBlackandWhite and the myth of Black privilege. Retrieved July 6, 2019, from https://www.theroot.com/oscarssoblackandwhite-and-themyth-of-black-privilege-1822420636

Umemoto, K. (2007). “On strike!”: San Francisco State College strike , 1968-1969: The role of Asian American students. In M. Zhou \& J. V. Gatewood (Eds.), Contemporary Asian America: A multidisciplinary reader (2nd ed, pp. 25-55). New York, NY: New York University Press.

Vargas, N., \& Stainback, K. (2016). Documenting contested racial identities among selfidentified Latina/os, Asians, Blacks, and Whites. American Behavioral Scientist, 60(4), $442-464$. 
Velazco, P. (2012, February 23). Lin joyride is great, but hoopla around him triggers prickly PC situation. Kokomo Tribune. Retrieved from LexisNexis Academic database.

Wallace, A. A. (2017). Communication games: Dating coaches, masculinity, and working at play in seduction communities. NORMA, 12(3-4), 286-301. https://doi.org/10.1080/18902138.2017.1312952

Wang, C. (2004). Capitalizing the big man: Yao Ming, Asian America, and the China Global. Inter-Asia Cultural Studies, 5(2), 263-278. https://doi.org/10.1080/1464937042000236748

Wang, O. (2006). These are the breaks: Hip-hop and AfroAsian cultural (dis)connections. In H. Raphael-Hernandez \& S. Steen (Eds.), AfroAsian encounters: Culture, history, politics (pp. 146-164). New York, NY: New York University Press.

Washington, J. (2012). Jeremy Lin Slam Dunks Asian Stereotypes. Retrieved June 25, 2019, from http://www.nbcnewyork.com/news/sports/Jeremy-Lin-Knicks-Asian-Stereotypes$\underline{139539998 . h t m l}$

Wenner, L. (2002). MediaSport. London, UK: Routledge. Retrieved from http://ebookcentral.proquest.com/lib/ryerson/detail.action?docID=165047

Whaley, D. E. (2006). Black bodies/yellow masks: the Orientalist aesthetic in hip-hop and black visual culture. In H. Raphael-Hernandez \& S. Steen (Eds.), AfroAsian encounters: Culture, history, politics (pp. 188-203). New York: New York University Press.

Wheeler, R. (2008). Is kung fu racist? In F. W. Ho \& B. Mullen (Eds.), Afro Asia: Revolutionary political and cultural connections between African Americans and Asian Americans (pp. 291-294). Durham: Duke University Press. 
White, white (2016). In The Diversity Style Guide. Retrieved from https://www.diversitystyleguide.com/glossary/white-white/

Wise, M. (2012, February 19). Lin challenges defenses - and stereotypes. The Washington Post, p. D03. Retrieved from LexisNexis Academic database.

Wodak, R. \& Krzyżanowski, M. (Eds.). (2008). Qualitative discourse analysis in the social sciences. London, UK: Macmillan International Higher Education.

Yam, K. (2019, February 20). Why 'Linsanity' was a major turning point for Jeremy Lin's AsianAmerican identity. Retrieved from https://www.huffingtonpost.ca/entry/jeremy-lin-iembrace-my-asian-american-side-feel-a-deeper-understanding-of-myroots_n_5c6d8546e4b0e37a1ed3f22b

Yep, K. S. (2012). Peddling sport: Liberal multiculturalism and the racial triangulation of blackness, Chineseness and Native American-ness in professional basketball. Ethnic and Racial Studies, 35(6), 971-987. https://doi.org/10.1080/01419870.2012.661867

Yin, K. (2017, February 22). Capitalizing for equality. Retrieved from https://consciousstyleguide.com/capitalizing-for-equality/

Youn, A. (2012, February 24). What Lin means to Asian Americans. USA Today, p. 13A. Retrieved from LexisNexis Academic database.

Yu, T. (2012, February 21). Will Jeremy Lin's success end stereotypes? Retrieved June 25, 2019, from https://www.cnn.com/2012/02/20/opinion/yu-jeremy-lin/index.html

Zhou, M., \& Gatewood, J. V. (2007). Transforming Asian America: Globalization and contemporary immigration to the United States. In M. Zhou \& J. V. Gatewood (Eds.), Contemporary Asian America: A multidisciplinary reader (2nd ed, pp. 115-138). New York, NY: New York University Press. 
Zillgitt, J. (2012, February 17). Leap of faith launched new star; how did everyone miss that Lin would be a hit? USA Today, p. 1A. Retrieved from LexisNexis Academic database.

Zirin, D. (2012, February 29). Jeremy Lin Inspires a Nation. Retrieved from https://www.thenation.com/article/jeremy-lin-inspires-nation/ 